Keila Cardoso Barbosa

\title{
Estudo de polimorfismos dos genes EGF e EGFR em astrocitomas difusamente infiltrativos
}

Dissertação apresentada à Faculdade de Medicina da Universidade de São Paulo para obtenção do título de Mestre em Ciências

Área de concentração: Neurologia

Orientadora: Profa. Dra. Suely Kazue Nagahashi Marie

\section{São Paulo} 2008 


\section{Dados Internacionais de Catalogação na Publicação (CIP)}

Preparada pela Biblioteca da

Faculdade de Medicina da Universidade de São Paulo

Creprodução autorizada pelo autor

\section{Barbosa, Keila Cardoso}

Estudo de polimorfismo dos genes EGF e EGFR em astrocitomas difusamente infiltrativos / Keila Cardoso Barbosa. -- São Paulo, 2008.

Dissertação(mestrado)--Faculdade de Medicina da Universidade de São Paulo. Departamento de Neurologia.

Área de concentração: Neurologia.

Orientadora: Suely Kazue Nagahashi Marie.

Descritores: 1.Polimorfismo genético 2.Polimorfismo de um único nucleotídeo 3.Genes erb B-1 4.Fator de crescimento epidérmico 5.Astrocitoma 6.Estudos de casos e controles

USP/FM/SBD-010/08 
Aos meus pais, Tadeu e Mariusa, pelo apoio e dedicação, fazendo de suas vidas a minha vida para meu sucesso. Aos meus irmãos, Ximene, Heuder e Eliene, pela paciência e apoio nas várias madrugadas em que passamos juntos fazendo esse trabalho. 
Ao meu querido noivo André, meu companheiro e amigo, pela compreensão, paciência, auxílio, e sobretudo pelo amor que demonstra por mim. Você me ensinou e ajudou muito, e sem você tenho certeza que esse caminho seria muito árduo. Amo te. 


\section{Agradecimentos}

Gostaria de agradecer as pessoas que de alguma forma contribuíram para a realização desse trabalho e que pra sempre estarão guardadas em minha memória e em meu coração. Obrigada a todos, amigos e família, por terem compartilhado comigo momentos decisivos de minha vida acadêmica, me apoiando, incentivando e lutando comigo em busca de meu ideal que agora se realiza na forma desse trabalho.

À minha orientadora $\operatorname{Prof}^{a} \operatorname{Dr}^{a}$ Suely Kazue Nagahashi Marie, que esteve ao meu lado, auxiliando nas minhas dúvidas. A senhora desde o começo me incentivou e me trouxe pelas mãos até o final dessa trajetória. Minha sincera gratidão e o meu muito obrigada por todos esses anos.

À $\operatorname{Dr}^{\mathrm{a}}$ Sueli Mieko Oba Shinjo, pessoa a quem eu tenho um imenso carinho por tudo que me ensinou desde que iniciei minha vida na pesquisa laboratorial. A você devo minha eterna gratidão pela amizade e pelo profissionalismo que me conduziu em todos esses anos. Obrigada por sua imprescindível ajuda nesse trabalho e saiba que, com muito carinho, te guardo em meu coração e me espelho em você para um dia ser tão competente.

Aos professores Carlos Gilberto Carlott Júnior e Suzana M. Fleury Malheiros, pela ajuda na captação das amostras e encaminhamento dos casos que fizeram parte dessa casuística.

Ao Prof. Paulo Lotufo pelo apoio a ajuda nos cálculos estatístico epidemiológicos. 
A grande amiga e irmã Eliene Dutra Campos, que com sua generosidade me permitiu a honra de sua amizade. Você me ajudou muito na composição desse trabalho trazendo alegria e maturidade para minha vida. Hoje você é parte de minha família e muito obrigada por ter aparecido no meu caminho.

Os meus queridos amigos Mônica Rusticci e Marcelo D. Campos pelo apoio, alegria, ajuda e pelas conversas que me trouxeram a realidade. Vocês são muito especiais.

À minha inesquecível amiga Miyuki Uno, por sua ajuda nos cálculos estatísticos e acima de tudo por sua amizade e lealdade. Nunca encontrei uma pessoa como você. Obrigada pelo apoio e pelo incentivo.

Aos meus amigos de laboratório - LIM 15: Célia Miyagui, Priscila Carvalho, Renata Correia, Mussya Cisotto, Thais Freire, Patrícia Takahashi, Juliana Kitahara, Márcia H. Matsunaga, Érica M. Matsunaga, Mariana Brandão, Thatiana Bastos, Mariah Munhoz, D. Alice Yamada, Márcia de Azevedo, Maria Eunice da Silva, Rose Bedim, Dra Mary S. de Carvalho, Dr Pedro A. Santana, Dra Valéria M.F. Muoio e Darcy T. Borges pelos momentos alegres e sobretudo pela amizade.

Aos amigos de laboratório - UNINOVE: Cristiane Cardelino, Fernanda Bróglio, Felipe M. Messias, Cristina S.S. Viana, Sandra T. R. Nora, Carlos C. Herman, Juliano M. do Prado, Regina M.M. Barreiro, Marta S. Pugas, Débora Ranzoni, Alicia Tartar, Ricardo Bucci e Fabiano Gontijo pela paciência e pela 
descontração. Vocês me fazem muito bem. Agradeço a Deus por ter me dado a benção de conhecer vocês.

À CAPES (Coodernação de Aperfeiçoamento de Pessoal de Nível Superior) pelo suporte financeiro.

Aos pacientes e familiares que participaram desse trabalho por depositarem em nós, médicos e pesquisadores a confiança e por contribuírem hoje para uma melhor condição de vida futura.

Aos meus familiares Herbst: Marilda, Luciana, Alexandre Matias, Ana Paula, Patric Chaad, Luiz Henrique, Mara R.O.P., Clodoaldo, Bruna, Arnaldo, Áurea, Blenda e Amanda. Vocês são peças fundamentais da minha vida e sem vocês tenho certeza que não teria conseguido. Obrigada pelos momentos de alegria e valeu pela compreensão nesse ano que fui tão ausente. Amo vocês.

Aos meu familiares Fonseca: Elza, Mariene, Juliana, Márcio, Gerson, Cilene, Leonardo, Estela. Obrigada pelo apoio, carinho e por entenderem minha ausência. Obrigada pelos momentos felizes que juntos desfrutamos.

À Deus por ter me dado forças para seguir esse caminho e por ter me abençoado com pessoas especiais que marcaram minha vida. 
Mestre não é quem sempre ensina, mas quem de repente aprende. João Guimarães Rosa/ Grande Sertão: Veredas 


\section{Sumário}

Lista de Abreviaturas

Lista de Tabelas

Lista de Figuras

Resumo

Summary

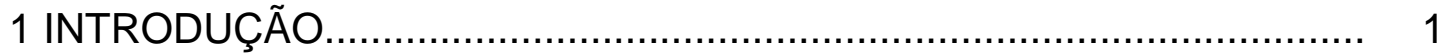

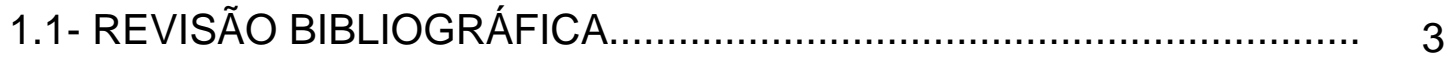

1.1.1 - Astrocitomas Difusamente Infiltrativos.................................... 3

1.1.2 - Astrocitoma de Baixo grau ou Astrocitoma Grau II..................... 5

1.1.3 - Astrocitoma Anaplásico ou Astrocitoma Grau III........................ 8

1.1.4 - Glioblastoma ou Astrocitoma Grau IV ........................................ 10

1.1.5 - Progressão Tumoral em Astrocitomas........................................ 13

1.2 - Desenvolvimento do Câncer.................................................... 15

1.3 - Single Nucleotide Polimorfismo......................................... 16

1.3.1 - Receptor de Fator de Crescimento Epidérmico (EGFR).............. 18

1.3.2 - SNP x Hiperexpressão do EGFR .................................... 23

1.3.2.1 - SNPs da Região Não Codificadora do Exon 1 do EGFR............ 25

1.3.2.2 - SNP do Exon 16 do EGFR .............................................. 27

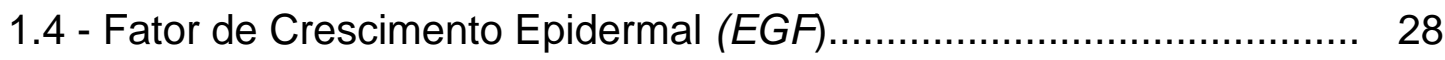

1.4.1 - SNP da Região Não Codificadora do Exon 1 do EGF................... 30

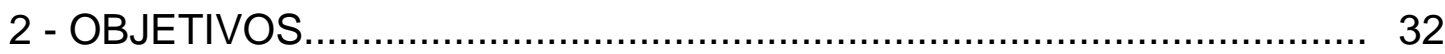

3 - CASUÍSTICA E MÉTODOS ..................................................... 33 
3.1 - Casuística.

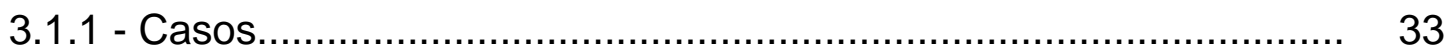

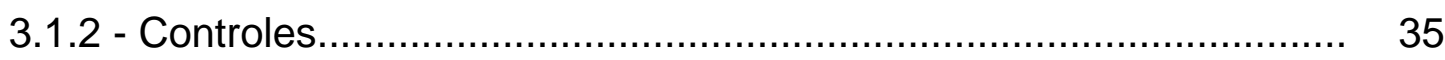

3.1.3 - Equipe de Capitação do Material Biológico.................................. 37

3.1.4 - Aspectos Éticos.................................................................... 39

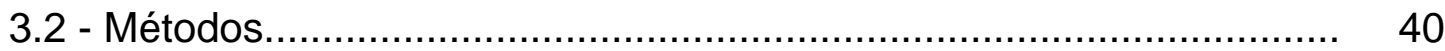

Extração de DNA de Sangue Periférico............................................ 40

Extração de RNA ................................................................... 42

3.2.1- Seqüência, Localização dos Primers EGFR e EGF...................... 44

Exon 1 - Região Não Codificadora do EGFR -

Polimorfismos c.-191C>A e c.-216G>T ............................. 44

Exon 16 - Polimorfismo c.2073A>T (EGFR)................................ 45

Exon 1 - Região não Codificadorado EGF- Polimorfismo c.61 A>G.... 46

3.2.2 - Reação em Cadeia de Polimerase (PCR)................................. 47

3.2.3 - Sítos de Restrição das Endonucleases........................................ $\quad 50$

Enzima BseRI e Sacll - Polimorfismo c.-191C>A e c.-216G>T 51 (EGFR).

Enzima Bsrl - Polimorfismo c.2073A>T (EGFR)........................... 51

Enzima Alul - Polimorfismo da Região Não Codificadora 52 c. $61 \mathrm{~A}>\mathrm{G}(\mathrm{EGF})$.

3.2.4 - Reação de Digestão Enzimática................................................... 53

3.2.5 - Síntese da Primeira Fita de DNA Complementar (CDNA).............. 57

3.2.6 - Reação de PCR em Tempo Real (Real Time PCR)....................... 58

3.2.7 - Curva de Dissociação ("Melting Curve")...................................... 60

3.2.8 - Quantificação Relativa de Expressão de EGFR ……………….... 62 
3.3 - Análise Estatística

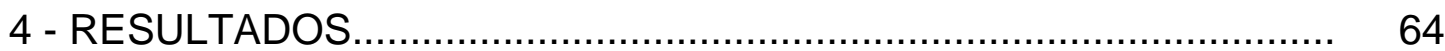

4.1 - Distribuição Demográfica dos Casos e Controles........................ 64

4.2 - Determinação dos Genótipos dos Polimorfismos de EGFR e EGF... 65

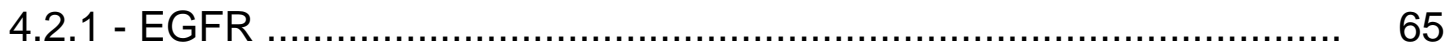

Polimorfismo c. 2073 A $>$ T.................................................. 65

Polimorfismo c.-191C>A ................................................. 66

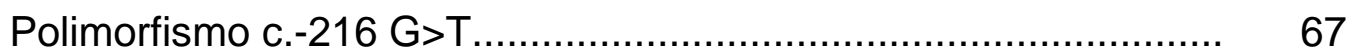

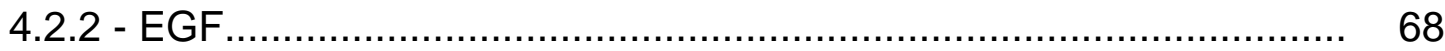

Polimorfismo c. 61 A >G....................................................... 68

4.3 - Freqüências Alélicas................................................................ 69

4.4 - Análise da Expressão Gênica do EGFR ................................ 72

4.4.1 - Análise da Expressão Relativa de EGFR em Relação aos Genótipos do Polimorfismo c. -191 C>A do EGFR.

4.4.2 - Análise de expressão relativa de EGFR em relação aos genótipos no polimorfismo c.-216 G>T de EGFR.

4.4.3 - Análise do Aumento de Expressão Relativa de EGFR em Relação aos Genótipos do Polimorfismo c.2073 A>T do EGFR.................. 79

4.5 - Análise da Sobrevida em Relação ao Genótipo................................ 82

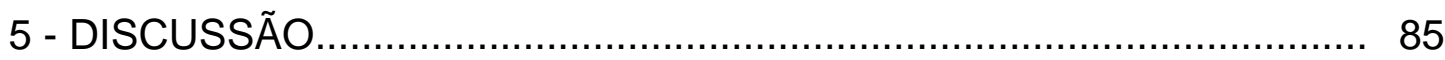

5.1 - Polimorfismos da Região Não Traduzida de EGFR ..................... 86

5.2 - Polimorfismo do Exon 16 de EGFR ....................................... 89

5.3 - Polimorfismo da Região Não Tarduzida de EGF........................... 91

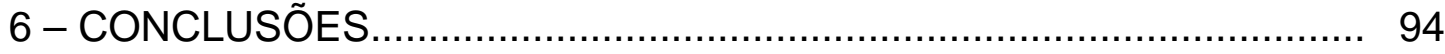




\section{Lista de Abreviaturas}

AS1 - Hospital São Paulo Da Universidade Federal de São Paulo

AS2 - Hospital das Clínicas da Universidade de Ribeirão Preto

AS3 - Hospital das Clínicas da Universidade de São Paulo

BRAF - Proto-oncogene responsável por uma proteína da familia das tirosina quinase

c-erbB1 - epidermal growth factor receptor

cDNA - DNA complementar

Ct - Threshold

DCC - "deleted in colorectal carcinoma"

DNA - Ácido Desoxirribonucléico

Dnase - Deoxyribonuclease

dNTP - Desoxirribonucleotídeos Fosfatados

DTT - Dithiothreitol

EDTA - Ethylenediamine Tetraacetic Acid

EGF - Epidermal Growth Factor

EGFR - Epidermal Growth Factor Receptor

GBM - Glioblastoma

Grau I - Astrocitoma Pilocítico

Grau II - Astrocitoma de Baixo Grau

Grau III - Astrocitoma Anaplásico

H\&E - Hemtatoxilina e Eosina

HPRT - Hipoxantina Riboxil Transferase

kDA - KiloDalton

$\mathrm{KHCO}_{3}$ - Carbonato de Potássio

LOH - Loss of Heterozygosity

MDM-2 - gene regulador negativo de p53

Min. - Minutos

$\mathrm{mM}$ - Milimolar 
$\mathrm{NaCl}$ - Cloreto de Sódio

$\mathrm{ng} / \mu \mathrm{L}$ - nanograma/microlitro

$\mathrm{NH}_{4} \mathrm{Cl}$ - Cloreto de Amônia

OMS - Organização Mundial da Saúde

OR - odds ratio

$\mathrm{pb}$ - pares de base

PCR - Polymerase Chain reaction

pmol - picomol

p53 - Gene supressor de tumor

PDGF-A - Platelet-derived growth factor, alfa polypeptide

PDGFR- $\alpha$ - "platelet-derived growth factor receptor, alfa peptide

PTEN - "phosphatase and tensin homolog" - gene associado a migração e adesão celular.

RAS - Oncogene responsável pela produção da proteina Ras.

RB - gene supressor de tumor associado ao retinoblastoma

RLT - Tampão de lise do Kit quiagen

RNA - Ácido Ribonucléico

RNAm - RNA mensageiro

RNase - Ribonuclease

RPE - Tampão de Lavagem 2 do Kit Qiagen

rpm - rotações por minuto

RW1 - Tampão de Lavagem 1 do Kit Qiagen

Seg. - Segundos

SDS - Dodecil Sulfato de Sódio

SNC - Sistema Nervoso Central

SNP - Single Nucleotide Polymorphism

TCLE - Termo de Consentimento Livre e Esclarecido

TE - Tris-EDTA

TGF- $\alpha$ - Fator de Crescimento Transformador Alfa

TK - Tirosina Quinase 
Tris-Hcl - TrisHydrochloride

$\mathrm{U}$ - unidade

UTR - Untranslated

$\mu \mathrm{L}$ - Microlitro

$\chi^{2}-$ qui-quadrado 


\section{Lista de Tabelas}

Tabela 1- Distribuição dos casos quanto a gênero, idade, grau de astrocitoma (OMS) e centro de origem dos casos

Tabela 2 - Distribuição dos controles quanto a gênero, idade e centro de origem controles.

Tabela 3 - Seqüência de primers, tamanhos dos produtos de PCR utilizados para cada reação de PCR

Tabela 4 - Tamanho dos fragmentos após digestão com endonucleases para os polimorfismos do gene EGFR:

c.2073 A>T, c.-216 G>T, c.-191 C>A, e para o gene EGF: c. $61 \mathrm{~A}>\mathrm{G}$

Tabela 5 - Seqüência de primers para análise de expressão de EGFR e HPRT por PCR em tempo real.

Tabela 6 - Distribuição por idade, gênero, em casos com astrocitomas difusamente infiltrativos e controles

Tabela 7 - Freqüências alélicas dos polimorfismos dos genes EGFR e EGF.

Tabela 8 - Razão de odds (OR) e 95\% de intervalo de confiança (95\% IC) entre casos de astrocitomas difusamente infiltrativos e controles de acordo com a idade, sexo, genótipo dos polimorfismos de EGFR e EGF. 


\section{Lista de Figuras}

Figura 1- Fotomicroscopia ótica em H\&E de astrocitoma de baixo grau 7

Figura 2- Fotomicroscopia ótica em H\&E de astrocitoma anaplásico... $\quad 9$

Figura 3- Fotomicroscopia ótica de glioblastoma multiforme............... 12

Figura 4- Vias de alterações genéticas envolvidas na progressão de astrocitomas difusamente infiltrativos................................. 14

Figura 5- Sinalização de ativação do EGFR e progressão celular........ 18

Figura 6- Sinalização da cascata do EGFR para sua ativação............. 19

Figura 7- Cromossomo 7 e seqüência do gene EGFR ....................... 20

Figura 8- EGFR e seus domínios................................................ 21

Figura 9- Alteração polimórfica c. -191 C>A......................................... 26

Figura 10- Alteração polimórfica c. -216 G>T ...................................... 26

Figura 11- Alteração polimórfica c.2073 A>T .................................... 27

Figura 12- Cromossomo 4 e sequência do gene EGF...................... 29

Figura 13- Alteração polimórfica c. 61 A>G.................................... 31

Figura 14- Seqüência da região não codificadora do EGFR .............. 44

Figura 15- Seqüência do exon 16 do EGFR .................................... 45

Figura 16- Seqüência do exon 1 do EGF......................................... 46

Figura 17- Eletroforese em gel de agarose dos produtos de PCR....... 49

Figura 18- Sítios das enzimas de restrição BseR I e Sac II. ................ 51

Figura 19- Sítio da enzima de restrição Bsr I................................. 51

Figura 20- Sítio das enzimas de restrição Alul................................. 52

Figura 21- Eletroforese em gel de agarose e poliacrilamida dos fragmentos dos polimorfismos de EGFR e EGF.

Figura 22- Curvas de dissociação de dos produtos de PCR do gene EGFR.

Figura 23- Distribuição dos genótipos do polimorfismo c. 2073 A>T do gene EGFR em casos e controles.

Figura 24- Distribuição dos genótipos do polimorfismo c.191C>A do gene EGFR em casos e controles. 
Figura 25- Distribuição dos genótipos do polimorfismo c.-216G/T do gene EGFR em casos e controles.

Figura 26- Distribuição dos genótipos do polimorfismo c.61 $A>G$ do gene EGF em casos e controles..

Figura 27- Expressão relativa do gene EGFR em astrocitomas.

Figura 28- Expressão relativa de EGFR nos genótipos do polimorfismo c.-191 C>A de EGFR em astrocitomas de diferentes graus de malignidade

Figura 29- Expressão relativa de EGFR nos genótipos do polimorfismo c.-216G>T de EGFR em astrocitomas de diferentes graus de malignidade.

Figura 30- Expressão relativa de EGFR nos genótipos do polimorfismo c.2073 A>T de EGFR em astrocitomas de diferentes graus de malignidade.

Figura 31- Kaplan-Meier dos casos de GBM no polimorfismo c.-191 C $>A$ do EGFR

Figura 32- Kaplan-Meier dos casos de GMB no polimorfismo c.-216 $\mathrm{G}>\mathrm{T}$ do EGFR.

Figura 33- Kaplan-Meier dos casos de GBM no polimorfismo c.2073A>T do EGFR.

Figura 34- Kaplan-Meier dos casos de GBM no polimorfismo c.61 $A>G$ do EGF. 


\section{Resumo}

INTRODUÇÃO: Os astrocitomas difusamente infiltrativos são os tumores mais freqüentes de Sistema Nervoso Central (SNC) com uma taxa de 5-7 novos casos por 100.000 pessoas ano. São tumores altamente invasivos e estão associados com alterações de alguns genes como EGF (fator de crescimento epidérmico) e o EGFR (receptor do fator de crescimento epidérmico), que podem criar um aumento da atividade mitogênica, acarretando aumento de proliferação e maturação celular, apoptose, angiogênese e metástase. O nível de expressão destes genes pode ser influenciado por alterações genéticas, como a presença de polimorfismos. Uma mudança única de base (SNP) pode alterar a expressão gênica e, sendo assim, estar associada ao aumento do risco de desenvolver astrocitomas. Nesse trabalho, foram analisados 2 SNPs na região não traduzida (c.-191C>A e c.-216G>T) e um SNP no exon 16 (c.2073A>T) do gene EGFR, e um outro SNP na região não traduzida no gene $E G F(c .61 \mathrm{~A}>\mathrm{G})$. Os SNPs foram associados a expressão gênica do EGFR e a sobrevida dos pacientes. MĖTODOS: Foi realizado um estudo caso-controle com 193 casos de astrocitomas difusamente infiltrativos e 200 controles por amplificação por PCR seguido de digestão enzimática. Os produtos digeridos das amostras foram analisados por eletroforese em gel de agarose e poliacrilamida e corados com brometo de etídeo. A expressão gênica foi realizada após extração de RNA do tecido tumoral seguida de transcrição reversa e PCR em tempo real. Testes de qui-quadrado, odds ratio (OR), intervalo de confiança 95\% (IC95\%), t de Student e curvas de Kaplan-Meier foram realizados para análises estatística. RESULTADOS: A análise das freqüências dos genótipos dos polimorfismos mostrou uma diferença na distribuição entre casos e controles para o polimorfismo c.2073A>T. Pacientes com o genótipo TT apresentou um menor risco para astrocitoma quando comparados com o genótipo AA (OR=0,51, IC95\%=0,29-0,99). Nenhuma correlação foi encontrada para os outros polimorfismos analisados. Também 
não foi encontrada correlação entre os genótipos dos polimorfismos e os níveis de expressão de EGFR e a sobrevida dos pacientes. CONCLUSÃO: Nosso trabalho mostrou haver um possível fator de proteção quando o paciente é portador do genótipo TT, o que pode levar a uma diminuição do risco de desenvolver o tumor. Pacientes com genótipo TT do polimorfismo c.2073A>T do gene EGFR apresentam um menor risco para astrocitomas difusamente infiltrativos do que os com o genótipo AA. 


\section{Summary}

INTRODUCTION: Diffusely infiltrative astrocytomas are the most frequent tumors of the Central Nervous System (CNS) with a rate of 5-7 new cases in 100,000 individuals per year. They are highly invasive, and they are associated to alterations in some genes as EGF (epidermal growth factor) and EGFR (epidermal growth factor receptor), which may increase mitogenic activity, leading to increase of proliferation, cellular maturation, apoptosis, angiogenesis, and metastasis. Genetic alterations, as presence of polymorphisms of single nucleotide change (SNP) could influence their expression level, and thus could be associated to increased risk in developing astrocytomas. In the present study, two SNP of non-coding region (c.-191C>A and c.-216G>T) and one SNP in exon 16 (c.2073A>T) of EGFR, and another SNP of non-coding region of EGF (c.61A>G) were analyzed. The SNPs were associated to EGFR expression level and to survival time. METHOD: a case-control study of 193 of diffusely infiltrative astrocytomas and 200 controls was carried out, with PCR amplification and enzymatic digestion, which products were analyzed in agarose gel or polyacrylamide gel electrophoresis stained by ethidium bromide. EGFR expression level was studied by real time PCR after RNA extraction followed by reverse transcription of tumor tissues compared to epileptic non-neoplastic brain tissues. Stastistical analysis were performed by $\chi$-square, odds ratio (OR), $95 \%$ confidence interval $(95 \% \mathrm{Cl})$, Student-t test and Kaplan Meier. RESULTS: The polymorphic genotype frequency was different between case and controls for the polymorphism c.2073A>T. Patients with TT genotype presented lower risk to develop astrocytoma when compared to genotype AA (OR=0.51, CI95\%=0.290.99). No other correlation was observed for the remaining studied polymorphisms. There was neither correlation between the polymorphic genotypes and the EGFR expression levels nor with survival time. CONCLUSION: The present study showed a possible protection factor in 
developing astrocytomas for the patients harboring the genotype TT of c.2073A $>$ T polymorphism of EFGR, thus the patients presenting TT genotype have lower risk to develop diffusely infiltrative astrocytoma than patients presenting the genotype AA. 


\section{1 - Introdução}

O ministério da saúde relata que os tumores de Sistema Nervoso Central (SNC) são a oitava causa de morte entre todas as neoplasias, com aproximadamente 5500 casos no ano de 2002, o último ano com informações disponíveis (http://www.datasus.gov.br), acesso em 05 de janeiro de 2003). Estes representam, em todas as faixas etárias apenas $4 \%$ das mortes por todas as neoplasias, porém até os vinte anos de idade, uma em cinco mortes por câncer é decorrente de tumores do SNC.

Os gliomas são os tumores mais freqüentes de SNC e são definidos patologicamente como os tumores que evidenciam a diferenciação glial na histologia, imunohistoquímica e ultraestrutura. Entre os tumores gliais, os astrocitomas são mais freqüentes. Segundo a Organização Mundial de Saúde (OMS), os astrocitomas são classificados baseados na presença de indicadores como atipia nuclear, mitoses (com configuração normal e anormal), hiperproliferação endotelial, na qual a luz do vaso é cercada por células endoteliais empilhadas ao invés de uma única camada e necrose. A gradação tumoral é determinada pelo número de critérios, sendo que o astrocitoma grau I não apresenta critério de malignidade; a grau II, apresenta 1 critério que geralmente é atipia nuclear; o grau III, apresenta 2 critérios, sendo geralmente atipia celular e mitoses; e o grau IV apresenta 3 ou 4 critérios, que são atipia nuclear, mitoses, proliferação endotelial e/ou necrose. Dessa forma, os 
astrocitomas são classificados de acordo com a sua diferenciação e malignidade nos estágios de I a IV (Cavanee et al.,2000 ; Louis et al., 2007).

As alterações polimórficas envolvendo a troca de apenas 1 nucleotídeo (SNP) em genes específicos podem estar envolvidas em processos neoplásicos, ativando a proliferação celular como o caso dos genes EGF (fator de crescimento epidérmico) e EGFR (receptor do fator de crescimento epidérmico). Esses genes foram descritos como sendo possíveis marcadores genéticos de tumorigênese, inclusive nos gliomas. Por esse motivo o presente estudo analisou a presença de 3 polimorfismos do EGFR e 1 polimorfismo do EGF e a correlação destes com o grau de malignidade em astrocitomas difusamente infiltrativos. 


\section{1 - Revisão Bibliográfica}

\subsection{1 - Astrocitomas Difusamente Infiltrativos}

Os tumores que se originam no tecido cerebral são denominados tumores primários do SNC e são classificados pelo tipo de célula do qual se originam. Os astrocitomas são tumores originados de células gliais astrocíticas. Os astrocitomas de grau II a IV, são conhecidos como astrocitomas difusamente infiltrativos, apresentam grande poder de invasão celular de tecido cerebral normal adjacente e as seguintes características:

- podem ocorrer em todas as partes do SNC, preferencialmente nos hemisférios cerebrais

- ocorrem em adultos, em sua maioria

- apresentam heterogeneidade histopatológica.

- apresentam uma progressão da malignidade tumoral.

Incidência:

Os astrocitomas são tumores mais freqüentes intracranianos e ocorrem em mais de $60 \%$ entre todos os tumores primários de SNC. A incidência difere 
entre as regiões geográficas, mas normalmente a taxa é de 5-7 novos casos por 100.000 pessoas por ano (Kleihues e Cavanee, 2000). 


\subsection{2 - Astrocitoma de baixo grau ou Astrocitoma grau II}

O astrocitoma de baixo grau (grau II) é caracterizado pelo alto grau de diferenciação celular e crescimento lento (Kleihues e Cavanee, 2000). Pode estar localizado em qualquer região do SNC, mas aparece preferencialmente na região supratentorial do cérebro .

Ocorrem, em sua grande maioria, em adultos jovens com faixa etária entre 30 e 40 anos, sendo predominante no sexo masculino.

Os astrocitomas de baixo grau representam de 10 a $15 \%$ de todos os tumores astrocíticos, com uma incidência de 1,4 casos novos por cada 1 milhão de pessoas ao ano e podem se localizar em qualquer região do SNC, mas preferencialmente nos hemisférios cerebrais. Apresenta uma média de sobrevida de cerca de 6 a 8 anos após intervenção cirúrgica, embora haja uma variação individual, com alguns casos permanecendo latentes por vários anos e outros progredindo para astrocitomas de maior grau de malignidade (DaumasDuport et al., 1988).

Quando os pacientes com astrocitoma grau II desenvolvem uma recidiva tumoral, a segunda amostra cirúrgica freqüentemente mostra evidências de aumento de atipia nuclear, hipercromasia, atividade mitótica característica de astrocitoma anaplásico e, eventualmente, proliferação microvascular e/ou necrose característica de GBM. A progressão para anaplasia é imprevisível, bem como o tempo que estas mudanças levam para ocorrer (Kleihues e Cavanee, 2000). 
Com relação a fatores prognósticos, a menor idade e a ressecção total são consideradas preditivas para recorrência e progressão mais lenta do tumor (Shafqat et al., 1999).

Os caminhos moleculares e citogenéticos para a formação tumoral ainda não foram elucidados, sendo muito complexos e envolvem o acúmulo de alterações genéticas em genes que normalmente regulam a proliferação, diferenciação e morte celular. Dois exemplos são os genes EGF e EGFR que podem acelerar o crescimento tumoral partir da amplificação do gene ou a partir de mutações e/ou polimorfismos nestes genes (Kleihues e Cavanee, 2000).

As características histológicas dos astrocitomas de baixo grau estão ilustradas na Figura 1. 

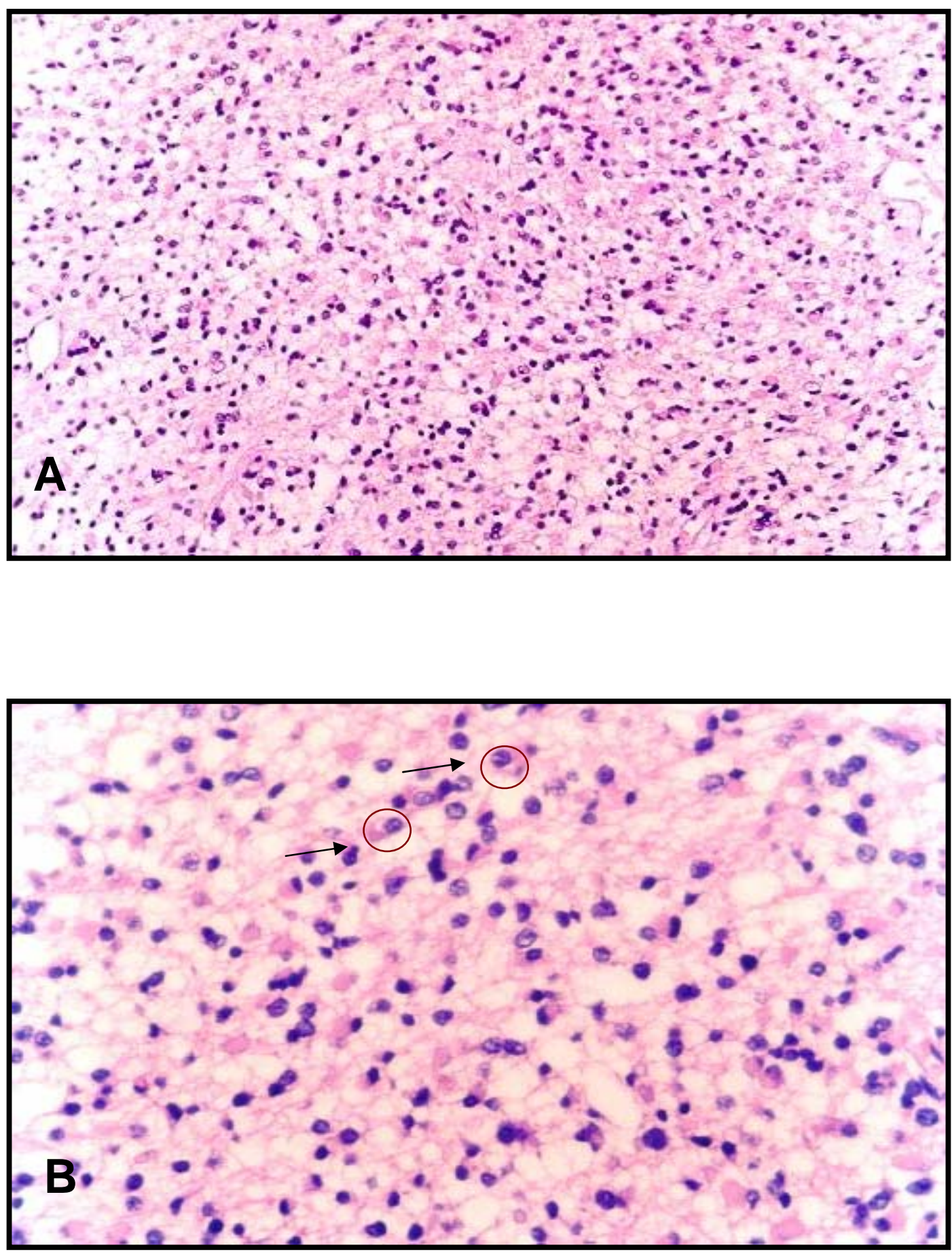

FIGURA 1: Fotomicroscopia ótica em H\&E de astrocitoma de baixo grau

A Figura mostra uma grande celularidade, atipia nuclear e com componente gemistocítico (seta). Aumento de 200X (A) e 400X (B). 


\subsection{3 - Astrocitoma Anaplásico ou Astrocitoma grau III}

O astrocitoma anaplásico é um tumor com anaplasia focal ou dispersa e com um grande potencial proliferativo.

Ocorrem preferencialmente em homens adultos com idade média de 41 anos e apresentam localização semelhante à dos astrocitomas de baixo grau, com preferência pelos hemisférios cerebrais (Kleihues e Cavanee, 2000).

Embora esses tumores possam se originar da progressão de um astrocitoma de baixo grau, possuem uma tendência intrínsica de progressão para GBMs, em um intervalo médio de aproximadamente 2 anos (Watanable et al., 1997). Entretanto, o período de latência e a rapidez com que progridem variam consideravelmente, indicando assim, a necessidade de marcadores prognósticos adicionais. Do ponto de vista clínico, morfológico e genético, o astrocitoma anaplásico constitui um estágio intermediário na rota de progressão para um GBM.

Assim como no astrocitoma grau II o EGFR e o EGF são importantes marcadores moleculares por induzirem a proliferação celular.

A Figura 2 representa algumas características histológicas dos astrocitomas anaplásicos. 

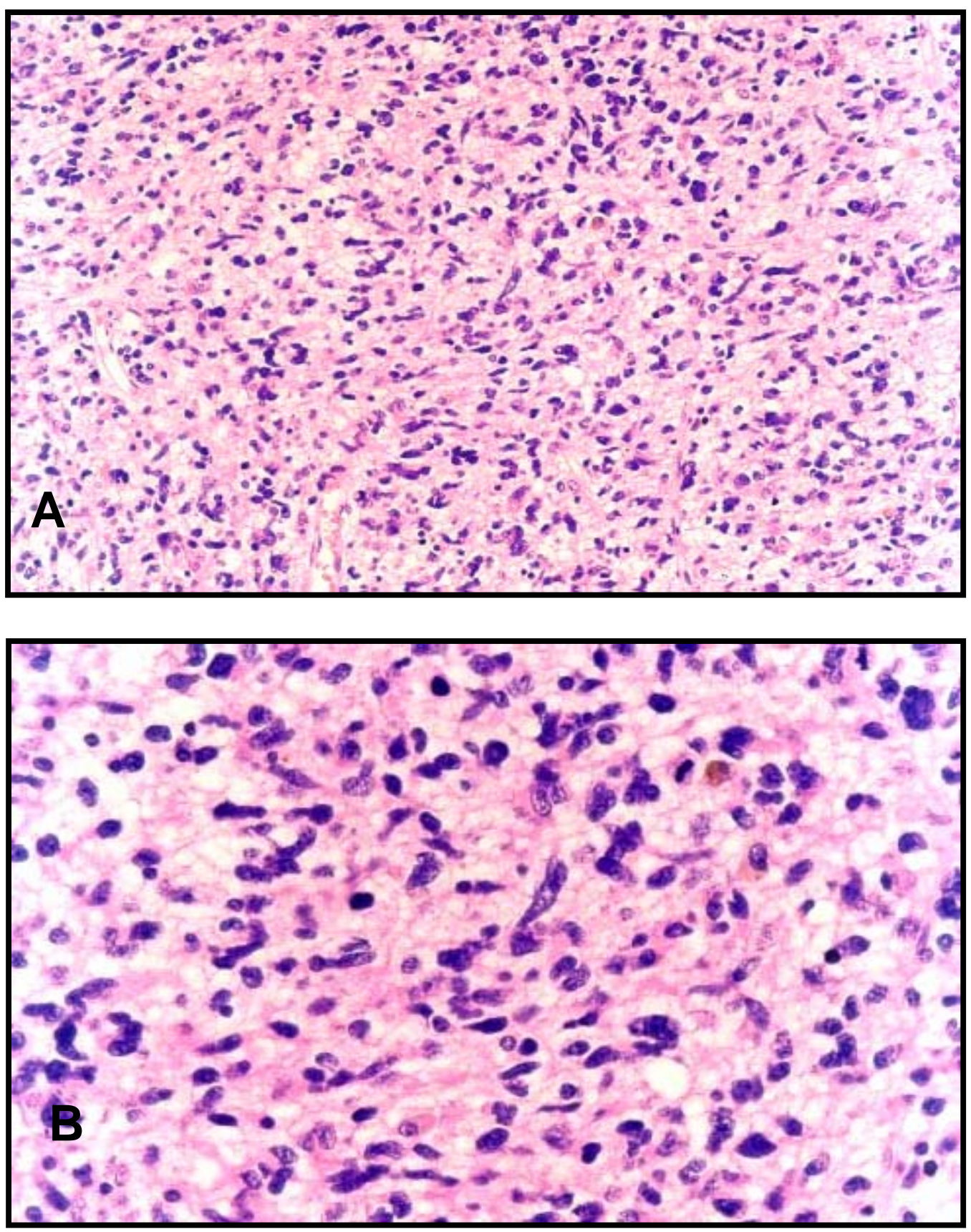

FIGURA 2: Fotomicroscopia ótica em H\&E de astrocitoma anaplásico As figuras mostram uma grande celularidade, atipia nuclear, atividade mitótica. Aumento de 200X (A) e 400X (B). 


\subsection{4 - Glioblastoma ou Astrocitoma grau IV}

O glioblastoma, também conhecido como glioblastoma multiforme (GBM), são os mais malignos dos tumores astrocíticos.

São também os mais freqüentes do SNC, perfazendo de 20 a 25\% do total das neoplasias intracranianas e cerca de 50\% dos tumores astrocíticos (Surawics et al., 1999). Os GBMs podem se manisfestar em qualquer idade, mas afetam preferencialmente adultos, mais freqüentemente homens, em aproximadamente $70 \%$ dos casos entre 45 e 70 anos de idade. Os GBMs ocorrem mais freqüentemente na substância branca dos hemisférios cerebrais.

Os GBMs são classificados como primários e secundários e acometem pacientes em faixas etárias diferentes com respostas a terapias adjuvantes distintas (Scherer, 1940; Kleihues e Ohgaki, 1999). Os GBMs primários são mais freqüentes em uma faixa etária maior (idade média de 55 anos). Após uma história clínica muito curta, normalmente menos de 3 meses, eles se manifestam de novo, ou seja, sem qualquer evidência clínica ou histopatológica da existência de uma lesão menos maligna anterior. Este tipo de GBM parece ser resistente à radioterapia e, deste modo, apresenta um prognóstico ruim (Nozaki et al.; 1999).

Os GBMs secundários se desenvolvem tipicamente em pacientes mais jovens, com idade média de 45 anos, através de uma progressão maligna de um astrocitoma de baixo grau ou de um astrocitoma anaplásico. O tempo de evolução varia consideravelmente, com intervalos entre 1 ano ou mais de 10 
anos (Ohgaki et al., 1999). Ocorrem em pacientes com história clínica e biópsias seqüênciais de astrocitomas de menor grau (Ohgaki et al., 1999).

Como nos tumores de menor malignidade, o EGFR e o EGF desempenham um papel na proliferação celular e desenvolvimento tumoral nos GBMs. Por ser um tumor altamente maligno apresentando características mais acentuadas de progressão tumoral, conseqüentemente, esses dois genes podem estar intimamente relacionados a esse tipo de alteração.

As características histológicas relevantes dos GBMs estão ilustradas na Figura 3. 

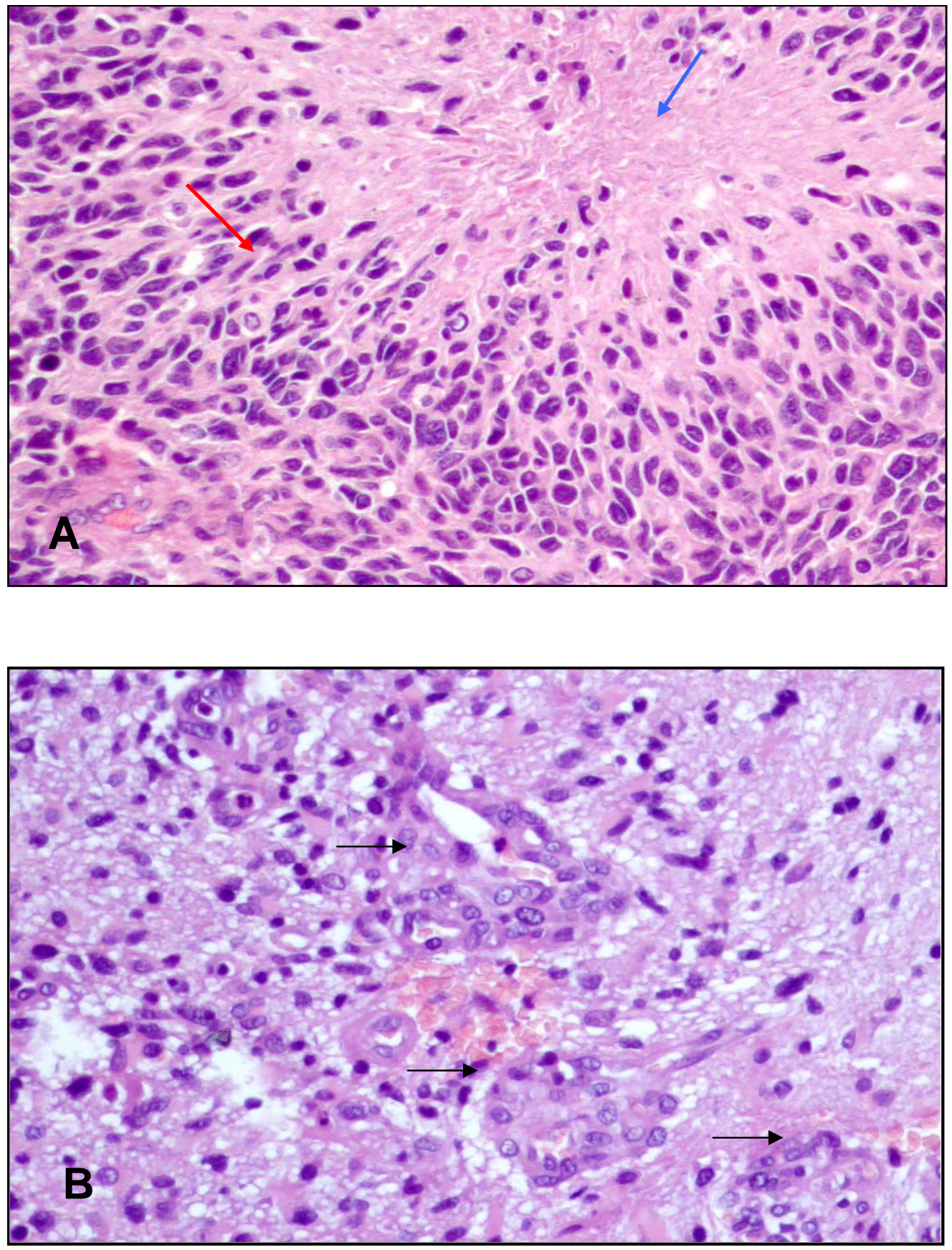

FIGURA 3: Fotomicroscopia ótica de GBM

As figuras mostram A-células em paliçada (seta vermelha), células multinucleadas, neoangiogênese (seta preta) e necrose (seta azul) B- neovascularização do tipo glomerulóide (seta preta) corados com H\&E. Aumento de 400X 


\subsection{5 - Progressão Tumoral em Astrocitomas}

Observam-se alterações distintas na progressão dos astrocitomas difusamente infiltrativos, havendo um número cada vez maior de evidências de que GBMs possam ser primários e secundários, pois evoluem passando por aquisições cumulativas de múltiplas e diferentes alterações genéticas (Collins e James, 1993; Furnari et al., 1996; Louis e Gusella, 1995; Von Deimling et al., 1995), com o envolvimento de um grande número de oncogenes. GBM secundário é aquele que evolui a partir de um astrocitoma menos maligno e o primário aquele que se apresenta já na sua forma mais maligna. A hiperexpressão de vários genes acelera o crescimento celular, incluindo a hiperexpressão do receptor do fator de crescimento epidérmico (EGFR). Esta hiperexpressão pode decorrer da amplificação gênica, de mutações ou da perda de heterozigozidade de várias porções dos cromossomos, incluindo 9p, 10q, 11p e 19q, o que leva a perda de lócus com possíveis genes supressores de tumor (Von Deimling et al., 1995). A Figura 4 mostra as duas maneiras possíveis de desenvolvimento dos GBMs (primário ou secundário) a partir das alterações genéticas anteriormente descritas. 


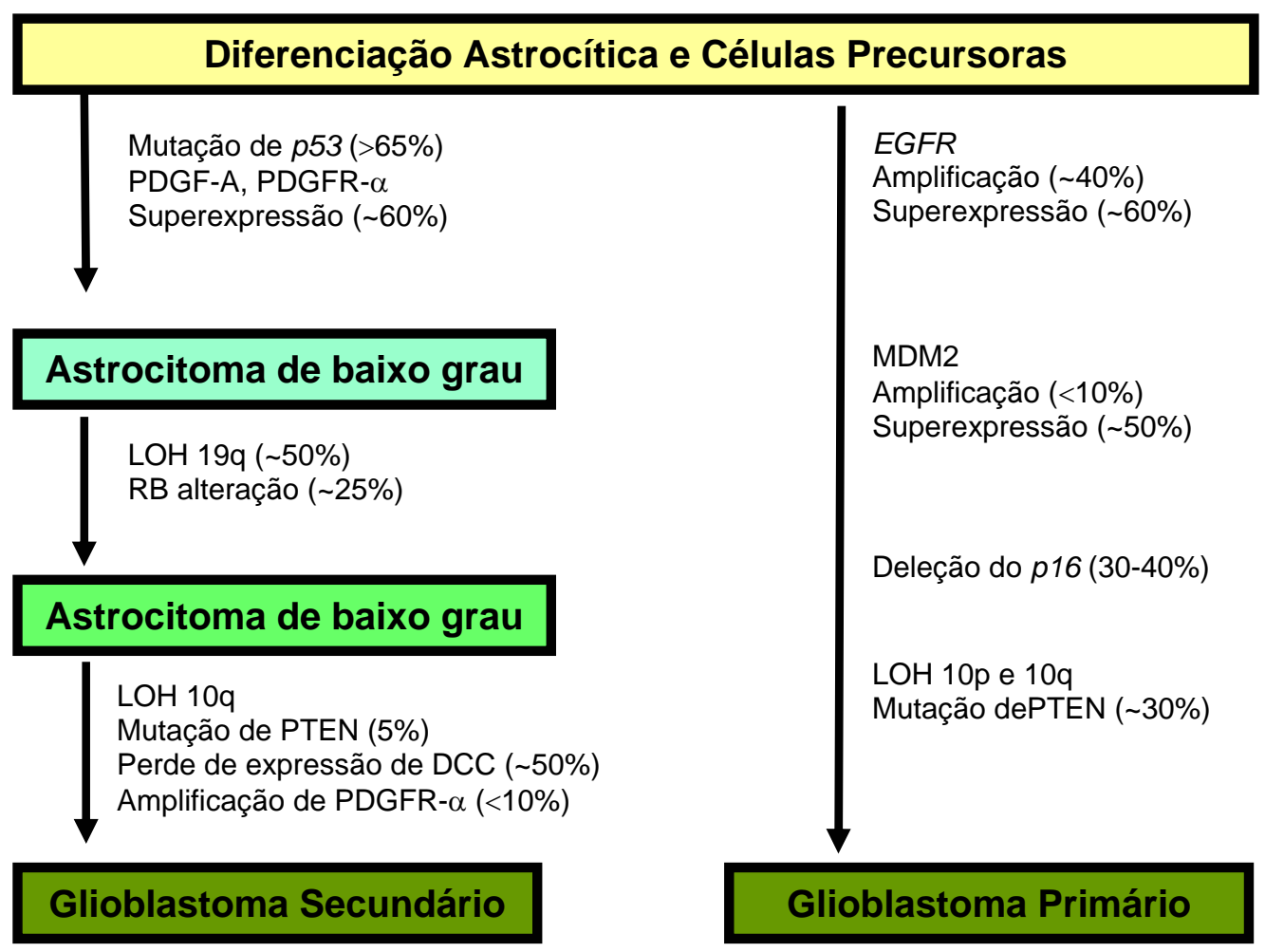

Figura 4: Vias de alterações genéticas envolvidas na progressão de astrocitomas difusamente infiltrativos.

O esquema mostra os dois tipos possíveis de desenvolvimento do GBM. O GBM secundário se desenvolve a partir de um astrocitoma de baixo grau ou de um astrocitoma anaplásico, e GBM primário se manifesta de novo, sem qualquer evidência clínica ou histopatólogica da existência de uma lesão menos maligna anterior. 


\section{2- Desenvolvimento do câncer}

Recentemente houve um grande avanço em relação às informações entre a variação genética natural do genoma humano e suas implicações clínicas e funcionais. Isso foi possível devido à silenciosa revolução na tecnologia de genotipagem e do desenvolvimento da bioinformática, possibilitando a análise do genótipo de grande quantidade de indivíduos, com fácil acesso às informações e análise do complexo banco de dados.

As doenças multi-fatoriais como o câncer podem ocorrer devido à interação entre fatores genéticos e ambientais. Apenas na vigência da combinação destes múltiplos fatores há predisposição à doença na presença de alterações genéticas.

Estas variações genéticas do genoma humano são numerosas e sabe-se hoje que excede o estimado. A variação mais comum é a substituição de uma única base, ou seja, polimorfismo de uma única base (SNP - "single nucleotide polimorphisms"). 


\section{3 - Single Nucleotide Polymorphism (SNP)}

Dentre os genes relacionados com o desenvolvimento de câncer, incluindo os gliomas, muitos são polimórficos, apresentando SNPs ou variações do número de pequenas seqüências repetidas de DNA. O SNP pode ser definido como uma alteração de uma única base de nucleotídeo que apresenta uma freqüência menor que $1 \%$ na população, sendo a maior determinante de variações possíveis em desenvolver uma doença, resposta a medicação, e resposta a toxicidade (Risch, 2000).

Estas variações do genoma humano podem, ainda, influenciar na taxa de transcrição gênica, na estabilidade do RNA mensageiro (RNAm), ou na quantidade e atividade das proteínas. Desse modo, uma doença pode ser agravada devido à influência de alelos específicos de genes polimórficos.

Observações iniciadas em 1950, sugerem que as pessoas exibem diferentes respostas aos medicamentos e que essas variações poderiam estar relacionadas com a hereditariedade (Evans and Johnson, 2001). Análises da seqüência do genoma humano têm mostrado um elevado número de variações no genoma humano (inserção, deleção, substituição), bem maior do que o estimado (Sachidanandam et al., 2001), sendo o SNP a mais comum. O valor estimado de SNPs é de 30.000 a 1.000 .000 e o valor encontrado por Sachidanandam foi de 1.420 .000 alterações. 
Numerosos SNPs têm sido identificados em genes que podem estar relacionados com o desenvolvimento e progressão do câncer e também com resposta ao tratamento, onde se incluem genes relacionados à resposta inflamatória, regulação do ciclo celular, metabolismo, angiogênese, migração celular e reparo do DNA.

Entre os genes com polimorfismos funcionalmente importantes, inclui-se o fator de crescimento epidérmico (EGF) e o seu receptor (EGFR), que apresentam um importante papel no crescimento, desenvolvimento, diferenciação e motilidade das células normais e cancerígenas (Hsieh et al., 2005). 


\subsection{1 - Receptor de fator de crescimento epidérmico (EGFR)}

A maior parte dos eventos envolvendo amplificação do gene em astrocitomas de alto grau envolve o gene EGFR. EGFR é um receptor de tirosina quinase (TK) de superfície celular, cujos ligantes extracelulares, entre eles o EGF e o fator de crescimento transformador alfa (TGF- $\alpha)$, levam à sua ativação inicializando processos diversos como crescimento, proliferação, apoptose, adesão, migração e diferenciação, além de ser um bom marcador de superfície celular de tumores sólidos (Anderson et al., 2004; Roskoski, 2004; Artega, 2002; Ciardello \& Tortora, 2003, Venook, 2005, Rocha-Lima et al., 2007). A Figura 5 ilustra o processo de ativação do EGFR a partir de seus ligantes.

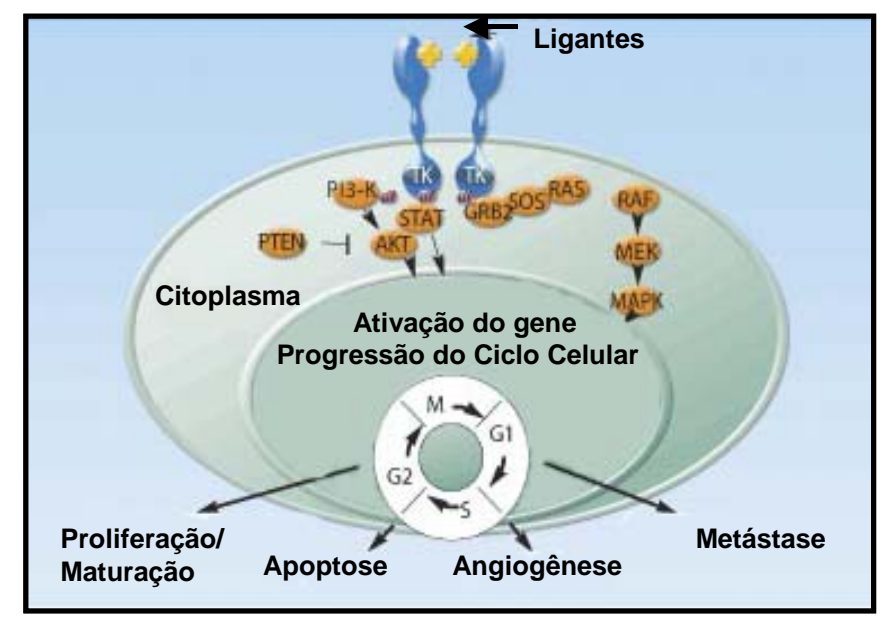

Figura 5: Sinalização para ativação do EGFR e progressão celular

A figura mostra a ativação do ciclo celular (proliferação, apoptose, angiogêne, metástase) decorrente da ligação do EGFR com um de seus ligantes. Figura retirada e adaptada do site www.merck.de/servlet/PB/menu/1381570/index.html) 
O EGFR é expresso em epitélio normal, estroma, células gliais e células da musculatura lisa, o que media o crescimento, desenvolvimento e diferenciação (Venook et al., 2005). Ativado por seus ligantes, o EGFR ativa mediadores de tirosina quinase para sinalização de caminhos envolvendo Ras/mitogênese ativador de tirosina quinase, phosphoinositol-3-quinase/ATK, e janus quinase/ sinal de transdução e ativação de fatores de transcrição, ativando fatores transcritos nos núcleos celulares (Talapatra e Thompson, 2001; Woodburn, 1999), conforme ilustra a Figura 6.

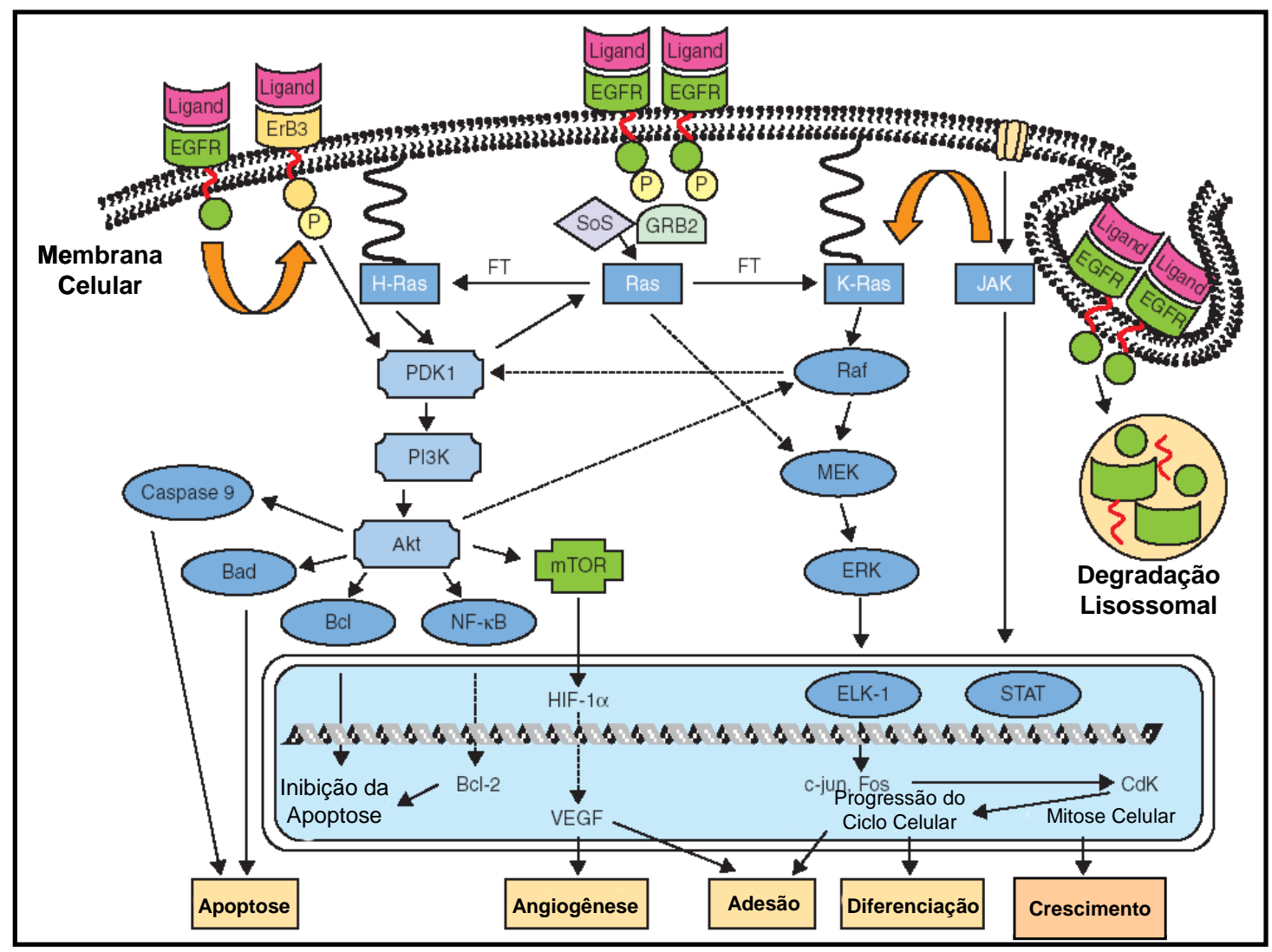

Figura 6: Sinalização da cascata do EGFR para sua ativação.

Diagrama esquemático do EGFR e do caminho de sinalização da cascata do EGFR. Esquema modificado de Venook, 2005. 
EGFR é uma proteína que na sua forma selvagem possui peso molecular de $170 \mathrm{kDa}$, e é codificada pelo proto-oncogene c-erbB1 localizado no cromossomo 7p12.1-12.3, constituído por 28 exons. A Figura 7 mostra a localização do gene EGFR no cromossomo 7 e ainda todos os 28 exons e introns com seus respectivos tamanhos em pares de base (pb).

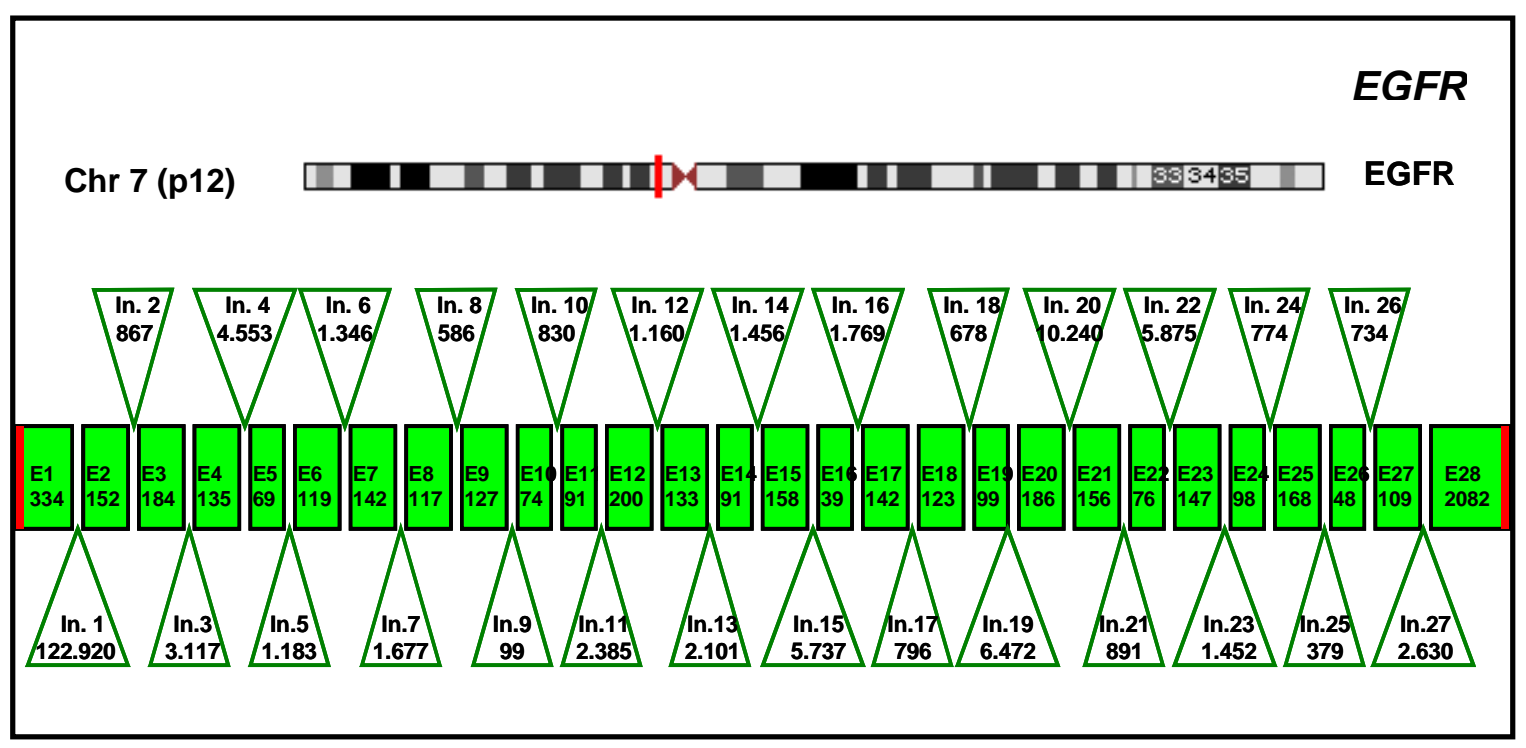

Figura 7: Cromossomo 7 e seqüência do gene EGFR

Representação esquemática do cromossomo 7 e da estrutura do gene EGFR. O gene EGFR possui 28 exons (E1 a E28), introns de diferentes tamanhos (In.1 a In.27).

A proteína é composta por três domínios ou regiões principais (Kleihues \& Cavanee et al., 2000; Anderson et al., 2004; Roskoski, 2004; Artega, 2002; Ciardello \& Tortora, 2003; Holbro \& Hynes, 2004). 
a) Domínio extracelular, que possui a região na qual se acopla ao ligante;

b) Domínio transmembrânico;

c) Domínio intracelular, com o sítio catalítico da tirosina quinase

Kleihues \& Cavanee (2000) e Pedersen (2001) consideram um quarto domínio na região C-terminal, responsável pela endocitose, que finaliza o processo de ativação do EGFR.

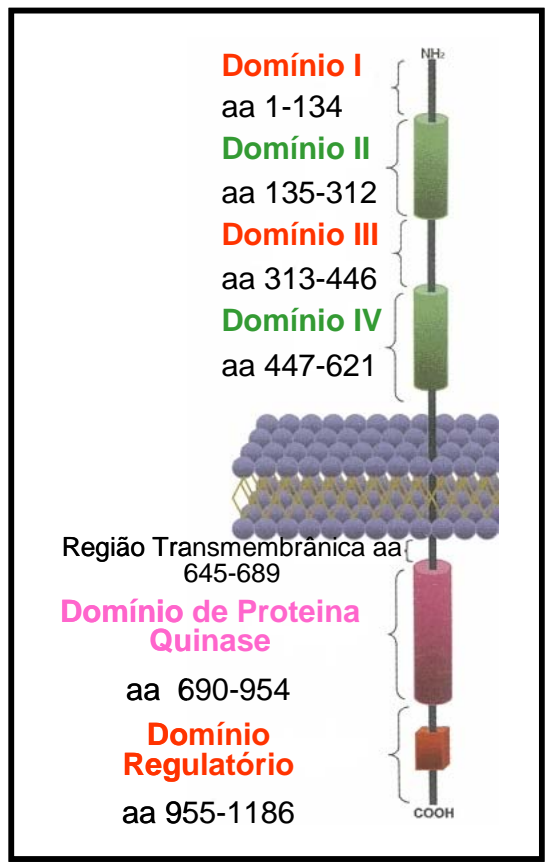

Figura 8: EGFR e seus domínios

Mostrando a estrutura conformacional do gene EGFR e um diagrama caracterizando seus domínios. Figura retirada e adaptada de Pedersen et al., 2001 
O EGFR desempenha um papel essencial na sinalização da transdução para a proliferação, diferenciação e sobrevida celular (Liu et al., 2005). O domínio extracelular é rico em cisteína, e o domínio intracelular contem um sítio de TK e múltiplos sítios de autofosforilação agrupados na porção C-terminal. A porção extracelular é dividida em quatro domínios. Os domínios I e III são pobres em cisteína e contém conformacionalmente o sítio em que o ligante (EGF) ou fator de transformação de crescimento alfa (TGF $\alpha$ ) se acoplam. Os domínios ricos em cisteína, II e IV, contêm sítios de N-glicosilação e pontes dissulfeto, sítios e pontes, que determinam a conformação terciária do domínio externo do receptor (Kuan et al.,2001). A Figura 8 ilustra os domínios com exatidão.

Em muitas linhagens de células humanas, a expressão de TGF $\alpha$ possui uma forte correlação com a hiperexpressão de EGFR. Assim, o TGF $\alpha$ parece agir de maneira autócrina, estimulando a produção via ativação de EGFR. A junção do ligante ao domínio extracelular do EGFR resulta em dimerização do receptor e início da transdução de sinal intracelular, cujo primeiro passo é a ativação da TK. A conseqüência primária desta ativação é a fosforilação dos próprios resíduos de tirosina (autofosforilação), seguida de ativação de transdutores de sinal que levam à mitogênese (Kuan et al.,2001). 


\subsection{2 - SNP e Hiperexpressão do EGFR}

O aumento de expressão do EGFR é encontrada em aproximadamente $30 \%$ dos tumores primários humanos e tem sido associado com o estágio da doença, prognóstico, sobrevida, e resposta à quimioterapia. Entre os mecanismos do aumento de expressão do EGFR estão a ativação da transcrição e a amplificação do gene. Esse aumento de expressão foi detectado em uma variedade de tumores epiteliais, como câncer de mama, pulmão, bexiga, ovário, próstata e cabeça e pescoço (Grandis \& Sok, 2004). Causas epigenéticas, como ativação transcricional, são os principais responsáveis pela elevação dos níveis de EGFR detectada na maioria dos cânceres (Grandis \& Sok, 2004), com exceção dos gliomas nos quais a amplificação do gene é relativamente comum.

A superexpressão do EGFR e/ou mutações na seqüência do gene têm sido encontradas em GBMs, tumores de esôfago, próstata, cólon, mama, ovário, pâncreas, cabeça e pescoço, entre outros. Sugere-se que a formação do tumor resulte da ativação constitutiva do receptor, ou a ativação e degradação do receptor inapropriadamente prolongada, o que bloquearia a endocitose do receptor (Ware et al., 2003; Kitange et al., 2003; Maher et al., 2001.).

Muitos GBMs (astrocitoma grau IV) com amplificação de EGFR apresentam também mutações (Ekstrand et al., 1992). O receptor mutante resulta de rearranjos do gene com deleções internas (Sugawa et al.,1990). A 
maioria das deleções são específicas de exons que codificam a porção do domínio extracelular da molécula de EGFR, podendo então levar a uma ativação constitutiva da cascata de sinalização sem a necessidade do ligante (Pederson et al., 2001; Kuan et al. 2001).

Um terceiro mecanismo que pode levar a um aumento de expressão de EGFR é a presença de polimorfismos. Para facilitar e homogeneizar a correta descrição dos polimorfismos, nosso trabalho se baseou na descrição do banco de dados do Human Genome Variation Society [(HGVS) www.hgvs.org/mutnomen.html] que determina regras para utilização da nomenclatura. Os trabalhos publicados há cerca de 10 anos mostram que o sistema de nomenclatura tinha sido determinado pela descrição da alteração (mutações e polimorfismos) na cadeia de DNA ou na seqüência da proteína (Antonarakis et al., 1998). Essas recomendações de nomenclatura têm sido amplamente aceitas e estimularam a uniformização e a correta descrição das mudanças nas seqüências. 


\subsubsection{1 - SNPs da Região Não Codificadora (UTR) do Exon 1 do EGFR}

O EGFR é um possível fator genético de risco de câncer (Liu et al., 2005). Dois polimorfismos importantes são os c.-191C>A e o c.-216G>T resultante de uma substituição de uma citosina por uma adenina, e de uma guanina por uma timina respectivamente, na região promotora do gene do EGFR. Eles estão localizados em uma região crítica para a atividade do promotor; onde estão localizados os sítios de início transcricionais e de afinidade com múltiplas proteínas nucleares (Liu et. al, 2005). Estudos de transfecção transitória em células primárias de câncer humano (células linfoblastóides) mostraram uma diferença significativa da atividade do promotor entre os dois haplótipos mais comuns (-216G-191C e -216T-191C). A substituição de guanina por timina na posição -216 aumenta a atividade do promotor em 30\%. A expressão do RNA mensageiro (RNAm) com o haplótipo T-C foi significantemente maior quando comparada ao haplótipo $\mathrm{G}-\mathrm{C}(p<0,02)$ (Li et al.,2005). As Figuras 9 e 10 ilustram a localização desses polimorfismos no DNA genômico. 


\section{$>\quad$ Polimorfismo c. $-191 \mathrm{C}>\mathrm{A}$}

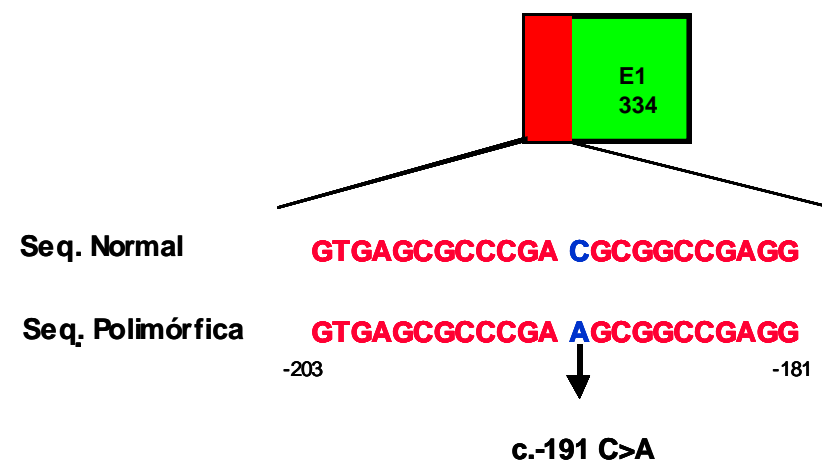

Figura 9: Alteração polimórfica c. -191C>A

Esquema ilustrando a localização do polimorfismo c.-191C>A na região promotora (vermelha) do exon 1 (verde) do gene EGFR. A seqüência normal e polimórfica estão apresentadas em vermelho caracterizando região não codificadora e em azul mostrando a troca de nucleotídeo (SNP).

Polimorfismo c. $-216 \mathrm{G}>\mathrm{T}$

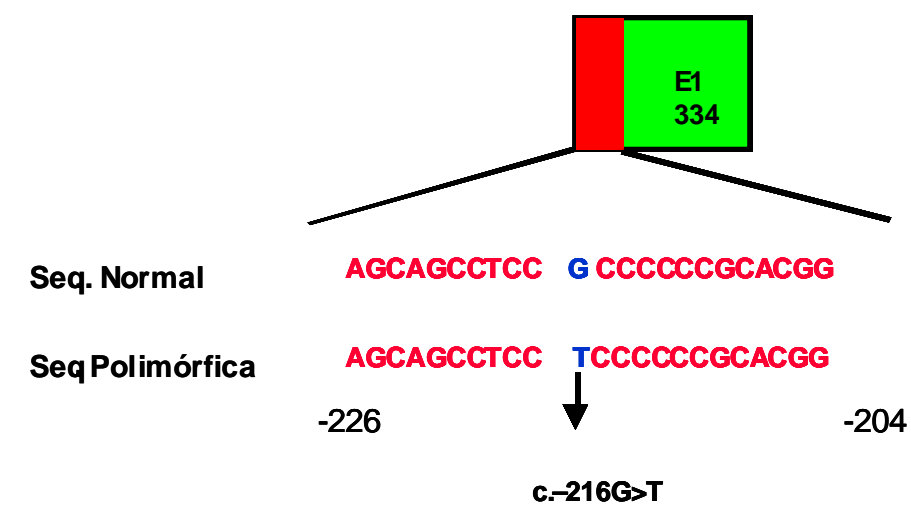

Figura 10: Alteração polimórfica c. -216G>T

Esquema ilustrando a localização do polimorfismo c.-216G $>T$ na região não traduzida (vermelha) do exon 1 (verde) gene EGFR. A seqüência normal e polimórfica estão apresentadas em vermelho caracterizando região não codificadora e em azul mostrando a troca de nucleotídeo (SNP) 


\subsubsection{2 - SNP do Exon 16 do EGFR}

Outro polimorfismo funcionalmente importante é o c.2073A>T com substituição de uma adenina por uma timina no exon 16 . O ponto de mutação 2073 ACT $\rightarrow$ ACA altera o códon de parada na produção da cisteína (Shintani et al., 1999). Sugere-se que o EGFR truncado possa interferir na conformação tridimencional da estrutura transmembrânica, assim como na expressão do EGF, causando uma disfunção do receptor. A Figura 11 mostra a localização do polimorfismo c.2073A>T no exon 16.

Polimorfismo c. 2073 A $>$ T

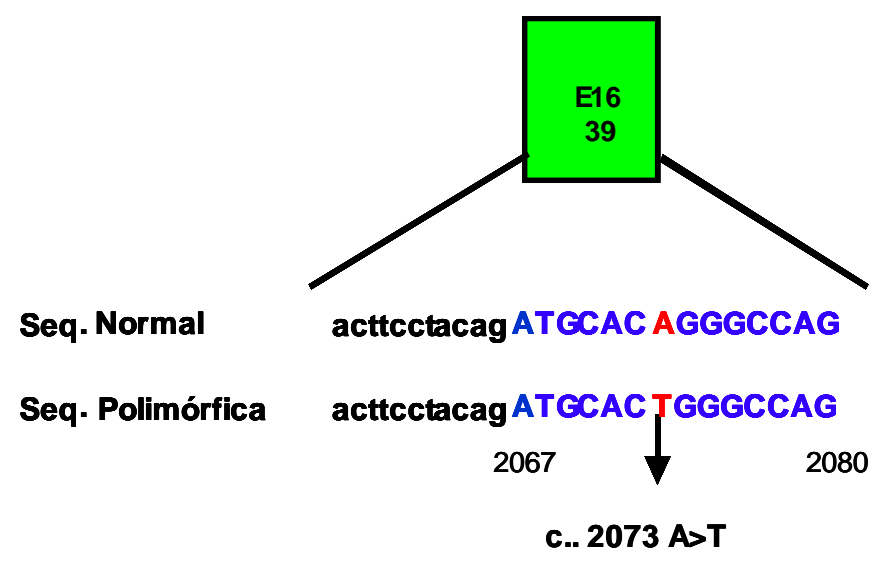

Figura 11: Alteração polimórfica c. 2073A>T

Esquema ilustrando a localização do polimorfismo c.2073A>T na região do exon 16 (verde) do gene EGFR. A seqüência normal e polimórfica estão apresentadas em azul caracterizando exon 16, preto intron 15 e em vermelho mostrando a troca de nucleotídeo (SNP). 


\section{4 - Fator de Crescimento Epidérmico (EGF)}

Uma das características dos tumores é a desregulação do crescimento celular. Essa desregulação pode se dar, entre outras causas, através de alteração genética adquirida, ou ainda por alterações epigenéticas em genes que influenciam sinal de transdução.

Em tumores primários de SNC, receptores de TK, que são necessários para uma proliferação normal e diferenciação celular, são importantes marcadores de gliomagênese (Kleihues and Cavenee, 2000; Smith et. al, 2001 e Kapoor and O'Rourke, 2003). Alterações no EGF e no EGFR acontecem em mais da metade de todos os pacientes com GBM (Libermann et. al, 1985; Wong et. al, 1992; Nishikawa et. al, 1994; Frederick et. al, 2000).

O gene de EGF está localizado no cromossomo 4q25-27 com 24 exons e codifica uma proteína que ativa a síntese de DNA, proliferação celular e estimula a mitose nas células epidérmicas (Araújo et al., 2007; Laurence and Gusterson, 1990; Carpenter and Cohen, 1990).

A Figura 12 mostra com detalhes a localização cromossômica desse gene e detalha o tamanho de cada intron e cada exon desse gene.

Recentemente, Shahbazi (2002) estudou o gene EGF em melanoma e encontrou uma menor produção de EGF em indivíduos com genótipo AA, comparativamente aos indivíduos com GG e AG. Entretanto, esses achados não foram confirmados pelo grupo russo (McCarron et al.,2003). 


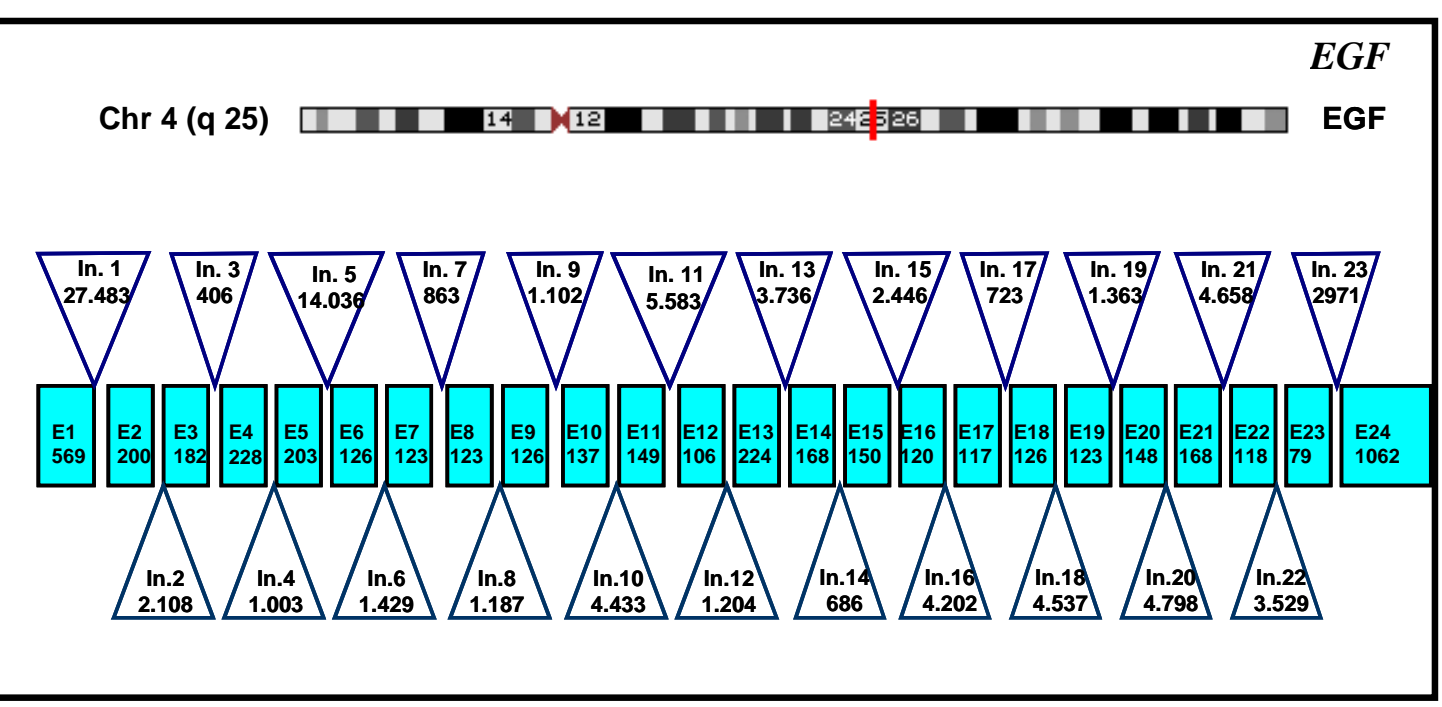

Figura 12: Cromossomo 4 e seqüência do gene EGF

Representação esquemática do cromossomo 4 e da estrutura do gene $E G F$. O gene EGF possui 24 exons (E1 a E24), introns de diferentes tamanhos (In.1 a In.23).

Os receptores do EGF são ativados por ligantes da família dos fatores de crescimento do EGF que são produzidos pelas mesmas células que expressam receptores ErbB (secreção autócrina), ou por células vizinhas (secreção parácrina). As proteínas que pertencem a essa família são caracterizadas pela presença de um domínio EGF-like que são constituídos por três grupos: grupo intramolecular dissulfeto (confere ligação específica), uma estrutura adicional que é um domínio de imunoglobulina e um sítio de glicosilação.

É bem descrita a relação de interação entre EGF e EGFR podendo ser um fator de susceptibilidade e prognóstico em variados tumores como melanoma, GBM, ou câncer gástrico (Araújo, et al. 2007; Moulder, et al. 2001) 


\subsection{1 - SNP da Região Não Codificadora do Exon 1 (UTR)}

Shahbazi et. al (2002) identificou um SNP na região 5' não traduzida (UTR) do gene EGF que parece ter uma seqüência funcional. O polimorfismo c.61 A>G apresenta a substituição de uma guanina (G) por uma adenina (A) e aumenta a produção de EGF em cultura de células de sangue periférico. Pacientes com melanoma com genótipo GG apresentam um aumento de risco relativo de desenvolver o tumor comparado com a população normal.

Pouco se conhece a respeito da atuação do EGF como fator mediador no desenvolvimento do câncer, mas hipoteticamente ele está fortemente associado à tumorigênese (Shahbazi, 2002). O que dá subsídios para essa teoria são as análises mutacionais e funcionais, que demonstram EGF operando pelas vias RAS e BRAF em tumores melanocíticos (Mattei et al., 1994 ; Okamoto et al., 2006). A Figura 13 mostra a localização do polimorfismo c.61A>G na região não codificadora do exon 1 do gene EGF. 


\section{$>$ Polimorfismo c.61A $>\mathrm{G}$}

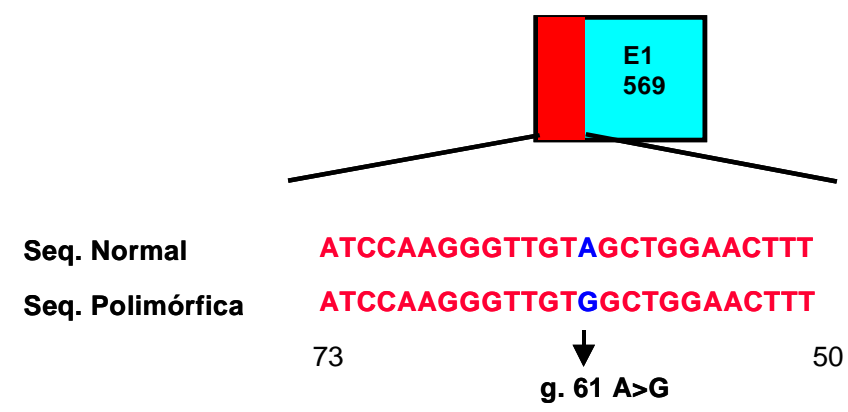

Figura 13: Alteração polimórfica c.61A>G

Esquema ilustrando a localização do polimorfismo c.61A>G na região não traduzida (vermelho) do exon 1 (azul) do gene EGF. A seqüência normal e polimórfica estão apresentadas em vermelho caracterizando UTR do exon 1 e em azul mostrando a troca de nucleotídeo (SNP). 


\section{2 - Objetivos}

Os objetivos deste estudo são:

1- Analisar os polimorfismos dos genes EGFR e do gene EGF em um estudo caso-controle.

1.1 - Polimorfismo do gene EGFR:

a) c. $-191 \mathrm{C}>\mathrm{A}$

b) c. $-216 G>T$

c) $c .2073 \mathrm{~A}>\mathrm{T}$

1.2 - Polimorfismo do gene EGF:

a) $\mathrm{c.61A}>\mathrm{G}$

2- Correlacionar os polimorfismos com a sobrevida dos pacientes e os níveis de expressão do gene EGFR. 


\section{3 - Casuística e Métodos}

\section{1 - Casuística:}

As amostras foram coletadas no período de abril de 2002 a fevereiro de 2006. Foram selecionados para este estudo dois grupos: A) pacientes submetidos à cirurgia de SNC e diagnosticado histopatologicamente pelo serviço de anatomia patológica como astrocitoma grau II, grau III e grau IV; e B) grupo controle, ou seja, sem neoplasia.

\subsection{1 - Casos}

O grupo de casos (A) foi composto por 128 pacientes provenientes do Hospital das Clínicas da Universidade de São Paulo (AS3); 33 pacientes do Hospital São Paulo (AS1); 31 pacientes do Hospital das Clínicas da Universidade de Ribeirão Preto da Universidade de São Paulo (AS2), totalizando 193 pacientes subdivididos em: 34 astrocitomas grau II, 30 astrocitomas grau III, e 129 astrocitomas grau IV (Tabela 1). A tabela completa detalhada dos casos está apresentada no Anexo I. 
Tabela 1: Distribuição dos casos quanto a gênero, idade, grau de astrocitoma (OMS) e centro de origem dos casos.

\begin{tabular}{|c|c|c|c|c|c|c|c|}
\hline & & \multirow[b]{2}{*}{$\mathbf{N}^{\circ}$} & \multicolumn{2}{|c|}{ Sexo } & \multicolumn{3}{|c|}{ Idades (anos) } \\
\hline & & & Feminino & Masculino & Mínima & Máxima & Média \\
\hline \multirow{4}{*}{ 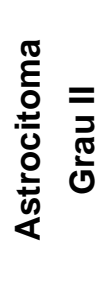 } & AS - 1 & 7 & 0 & 7 & 29 & 65 & 42.9 \\
\hline & AS - 2 & 4 & 2 & 2 & 28 & 44 & 38.5 \\
\hline & AS - 3 & 23 & 11 & 12 & 23 & 56 & 35.0 \\
\hline & Total & 34 & 13 & 21 & & & \\
\hline \multirow{4}{*}{ 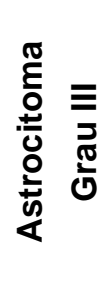 } & AS - 1 & 7 & 1 & 6 & 25 & 61 & 42.1 \\
\hline & AS - 2 & 4 & 0 & 4 & 32 & 42 & 37.6 \\
\hline & AS - 3 & 19 & 7 & 12 & 15 & 58 & 33.8 \\
\hline & Total & 30 & 8 & 22 & & & \\
\hline \multirow{4}{*}{ 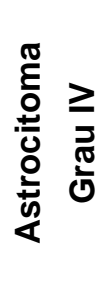 } & AS - 1 & 19 & 7 & 12 & 20 & 76 & 52.3 \\
\hline & AS - 2 & 24 & 10 & 14 & 18 & 78 & 55.6 \\
\hline & AS - 3 & 86 & 32 & 54 & 11 & 78 & 53.3 \\
\hline & Total & 129 & 49 & 80 & & & \\
\hline
\end{tabular}




\subsection{2 - Controles}

O grupo controle consistiu de 200 indivíduos sem neoplasia para compor (pacientes hospitalizados nas respectivas instituições pareados aos casos por faixa etária e gênero). Trinta e quatro amostras foram provenientes do grupo AS1, 37 do grupo AS2, 129 amostras do grupo AS3. A tabela com as características dos controles está apresentada no Anexo II detalhada por instituição.

Esses pacientes foram incluídos a partir de um questionário seletivo e não podiam apresentar doenças relacionadas a fumo e álcool; doenças ocupacionais; doenças crônicas não-neoplásicas da cavidade oral, faringe e laringe; doenças crônicas não-neoplásicas do trato digestivo; condições crônicas; imunodeficiência; doenças mentais; doenças do SNC e capacidade grave ou incapacidade para compreender ou responder. Além disso, os critérios de inclusão/ exclusão incluíram o local de moradia, aceitando-se somente aqueles pacientes residentes na região metropolitana de São Paulo. A tabela completa de diagnósticos a serem excluídos como causa de hospitalização ou de atendimento ambulatorial para captação de controles e a lista de cidades incluídas como sendo da região metropolitana de São Paulo encontram-se nos Anexo III e IV respectivamente. 
Tabela 2: Distribuição dos controles quanto a gênero, idade e centro de origem dos controles.

\begin{tabular}{|c|c|c|c|c|c|c|}
\hline \multirow[b]{3}{*}{ AS - 1} & \multirow{3}{*}{$\frac{\mathbf{N}^{\mathbf{0}}}{34}$} & \multicolumn{2}{|c|}{ Sexo } & \multicolumn{3}{|c|}{ Idades / anos } \\
\hline & & Feminino & Masculino & Mínima & Máxima & Média \\
\hline & & 10 & 24 & 23 & 77 & 48.4 \\
\hline AS - 2 & 37 & 14 & 23 & 17 & 76 & 51.5 \\
\hline AS - 3 & 129 & 50 & 79 & 17 & 77 & 47.2 \\
\hline Total & 200 & 74 & 126 & & & \\
\hline
\end{tabular}




\subsection{3 - Equipe de Captação do Material Biológico}

A coleta das amostras casos e controles foi multicêntrica e multidisciplinar, com o envolvimento de profissionais de diversas áreas. Cada instituição colaboradora do projeto Genoma Clínico contou com uma equipe especialmente capacitada para garantir a integridade do material a ser analisado. Todos os pacientes foram entrevistados para obtenção de dados demográficos e epidemiológicos, com assinatura do termo de consentimento livre e esclarecido após explicação do objetivo do projeto. Todos os casos foram e/ou estão sendo acompanhados ambulatorialmemente, foram submetidos a tratamento complementar padronizado e realizaram exames de ressonância nuclear magnética periodicamente.

- Coleta da Amostra Tumoral - Para que os exames moleculares não sofressem alterações foi necessário o congelamento imediato da amostra tumoral em nitrogênio líquido após sua ressecção. Para tanto, cada uma das instituições contou com um profissional específico para tal procedimento.

- Coleta de Sangue - A coleta do sangue foi feita no momento da intervenção cirúrgica. 
- Análise Histopatológica - $O$ diagnóstico de astrocitoma foi relizado pelo neuropatologista de cada centro participante do projeto.

- Equipe Médica - Foi realizado acompanhamento clínico de todos os casos incluídos de modo regular segundo protocolo implantado. 


\subsection{4 - Aspectos éticos}

O presente estudo foi aprovado pela Comissão de Ética para análise de Projetos de Pesquisa da Diretoria Clínica do Hospital das Clínicas da Faculdade de Medicina da Universidade de São Paulo [(Protocolo de Pesquisa 209/05), Anexo V] e nos comitês de ética dos demais centros participantes. Todos os pacientes foram informados da natureza do projeto de pesquisa e assinaram um termo de consentimento livre e esclarecido (TCLE). Este termo foi preenchido por uma mesma pessoa envolvida no projeto e teve por meta esclarecer sobre os objetivos da pesquisa, sanar possíveis dúvidas sobre os procedimentos e ainda informar sobre a finalidade da coleta do material cirúrgico. O termo de consentimento utilizado em nosso projeto de pesquisa está apresentado no Anexo VI, sendo aplicado o mesmo termo nos demais centros.

Os tecidos não tumorais utilizados como controles normais não neoplásicos foram colhidos com o mesmo rigor das amostras tumorais de cirurgias de pacientes epilépticos que também assinaram o termo de consentimento livre e esclarecido (modelo no Anexo VII). 


\section{2- Métodos}

\section{- Extração de DNA de Sangue Periférico}

A extração do DNA genômico foi realizada de acordo com procedimento previamente descrito por MILLER et al. (1988) a partir de $10 \mathrm{~mL}$ de sangue periférico total coletado em tubos com EDTA $5 \%$ de todos os pacientes e controles do estudo. Ao sangue foram adicionados $50 \mathrm{~mL}$ de solução de lise $\left(\mathrm{NH}_{4} \mathrm{Cl} 150 \mathrm{mM}, \mathrm{KHCO}_{3}\right.$ 100nM, EDTA $10 \mathrm{mM}, \mathrm{pH}$ 7,4). A mistura foi mantida em banho de gelo por 30 min. e em seguida foi centrifugada por 15 min. a 1800 rpm. O sobrenadante foi descartado e o precipitado resuspenso em $10 \mathrm{~mL}$ de solução de lise e em seguida novamente centrifugado por 5 min. a $1800 \mathrm{rpm}$. O precipitado foi novamente resuspenso em $3 \mathrm{~mL}$ de solução de lise de núcleos (Tris- $\mathrm{HCl} 100 \mathrm{mM}, \mathrm{NaCl}$ 4M, EDTA $20 \mathrm{mM}, \mathrm{pH}$ 8,2), acrescido de $50 \mu \mathrm{L}$ de proteinase $\mathrm{K}(10 \mathrm{mg} / \mathrm{mL})$ e $300 \mu \mathrm{L}$ de SDS $10 \%$. A solução resultante foi incubada a $37^{\circ} \mathrm{C}$, por 18 horas. Adicionou-se $1 \mathrm{~mL}$ de $\mathrm{NaCl} 6 \mathrm{M}$, seguido de centrifugação por $20 \mathrm{~min}$. a $2600 \mathrm{rpm}$. O precipitado foi descartado e o sobrenadante centrifugado por $15 \mathrm{~min}$. a $2600 \mathrm{rpm}$. O sobrenadante foi separado e precipitado com 2 a 3 volumes de etanol absoluto gelado. O DNA precipitado foi removido com um capilar e armazenado em um microtubo onde foi diluído com tampão TE (Tris - HCl 10 mM, EDTA 0,1 mM pH 8.0). 
As concentrações das amostras de DNA foram determinadas através de leitura em espectrofotômetro GeneQuant Pro (GE Healthcare) em comprimento de onda de $260 \mathrm{~nm}$. As amostras selecionadas foram aliquotadas e diluídas para concentração de 50 a $100 \mathrm{ng} / \mu \mathrm{L}$ e armazenadas a $4^{\circ} \mathrm{C}$ até a utilização. 


\section{- Extração de RNA}

Para a extração de RNA de tecido (tumoral e não neoplásico) foram utilizados $30 \mathrm{mg}$ de tecido, processado com kit da Qiagen (RNeasy ${ }^{\circledR}$ Mini Kit). O tecido congelado foi estocado em nitrogênio líquido e permaneceu nessas condições até a primeira lise com $600 \mu \mathrm{L}$ tampão RLT (tampão rico em guanidina tiocianato) e homogeinização no aparelho polytron (PowerGen 125, Fisher Scientific). Em seguida o lisado foi centrifugado e o sobrenadante foi cuidadosamente transferido para um novo tubo e para cada 1 volume $(700 \mu \mathrm{L})$ de lisado foi utilizado a mesma quantidade de etanol $70 \%$. Essa mistura foi homogeneizada e transferida para um outro tubo contendo a coluna de purificação proveniente do kit a uma velocidade de $10.000 \mathrm{rpm}$ por $15 \mathrm{seg}$. $\mathrm{O}$ filtrado foi descartado e adicionou-se mais 1 volume de tampão RW1 [tampão rico em etanol e pouca quantidade de guanidina tiocianato $(700 \mu \mathrm{L})]$ na coluna. Novamente a coluna foi centrifugada a 10.000 rpm por 15 seg., e o filtrado foi descartado. Posteriormente a coluna foi transferida para novo tubo e foram adicionados mais $500 \mu \mathrm{L}$ de tampão RPE (solução tamponada com pH entre 7,5 - 8) e centrifugado a $10.000 \mathrm{rpm}$ por $2 \mathrm{~min}$. para secar a membrana de sílica-gel. Para a eluição do RNA a coluna foi transferida para um novo tubo e foram adicionados de 30-50 $\mu \mathrm{L}$ de água livre de RNase. Após repouso de 2 min., a coluna foi centrifugada a $10.000 \mathrm{rpm}$ por $1 \mathrm{~min}$. O RNA foi eluído em volume de aproximadamente $40 \mu \mathrm{L}$ e a leitura de sua concentração foi realizada 
no espectrofotômetro GeneQuant (GE Healthcare) sob comprimento de onda de $260 \mathrm{~nm}$. Amostras com valor abaixo de 1.7 não foram selecionadas para compor a casuística. As amostras quantificadas foram armazenadas em freezer a temperatura de $-80^{\circ} \mathrm{C}$. 
3.2.1 - Seqüência e Localização dos Primers para estudo dos polimorfismos de EGFR e EGF

As seqüências dos primers foi determinada a partir da análise da seqüência anteriormente publicada. Os primers foram desenhados com tamanho entre 17 a 21 nucleotídeos. A seqüência de cada primer está apresentada a seguir:

- $\quad$ Exon 1 - Região Não Codificadora do EGFR - Polimorfismo c.191C>A e c.-216G >T

As seqüências dos primers da região não traduzida do exon 1 do EGFR estão apresentadas na Figura 14 em verde. O tamanho do produto de PCR é de 489pb.

gggggecaccgctgtccacccogectccgggggccgctggccttgggtcccogctgctggttctcctccctcctcctcgcattctcctcct

Primer -191/-216 F

cctctgctcctcccgatccctcctccgecgectggtccetcctcctcccgccctgcctccccgcgcctcggcccgcgegagetagacgtc lggggageCCCCGGCGCAGCGCGGCCGCAGCAGCCTCCGCCCCCCGCACGGTGTGAGCGC CGACGCGGCCGAGGCGGCCGGAGTCCCGAGCTAGCCCCGGCGGCCGCCGCCGCCCAG ACCGGACGACAGGCCACCTCGTCGGCGTCCGCCCGAGTCCCCGCCTCGCCGCCAACGCC ACAACCACCGCGCACGGCCCCCTGACTCCGTCCAGTATTGATCGGGAGAGCCGGAGCGA GCTCTTCGGGGAGCAGCGATGCGACCCTCCGGGACGGCCGGGGCAGCGCTCCTGGCGCT GCTGGCTGCGCTCTGCCCGGCGAGTCGGGCTCTGGAGGAAAAGAAAGgtaagggcgtgtctcgcc

Primer -191/-216 R

Figura 14: Seqüência da região não codificadora do EGFR Localização dos primers sense e antisense (em verde) para amplificação do fragmento de PCR da região não codificadora (em vermelho) do exon 1 do gene EGFR (letras maiúsculas). 


\section{- $\quad$ Exon 16 - Polimorfismo c.2073A>T (EGFR)}

A seqüência dos primers do exon 16 do EGFR está apresentadas na Figura 15. O tamanho do produto de PCR é de $207 \mathrm{pb}$.

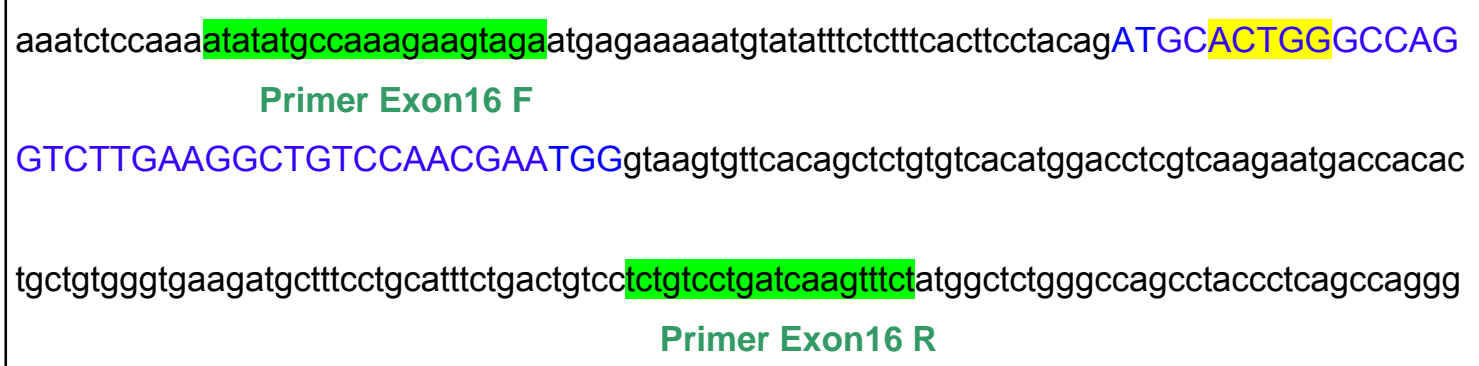

Figura 15: Seqüência do exon 16 do EGFR

Localização dos primers sense e antisense (em verde) para amplificação do fragmento de PCR do Exon 16 do gene EGFR (letras maiúsculas). A região em amarelo mostra o sitio de restrição da enzima Bsrl. 
- Exon 1 - Região Não Codificadora do EGF - Polimorfismo c. $61 \mathrm{~A}>\mathrm{G}$

Os primers da região não codificadora do exon 1 do gene EGF estão ilustrados na Figura 16. O tamanho do produto de PCR é de 242 pb.

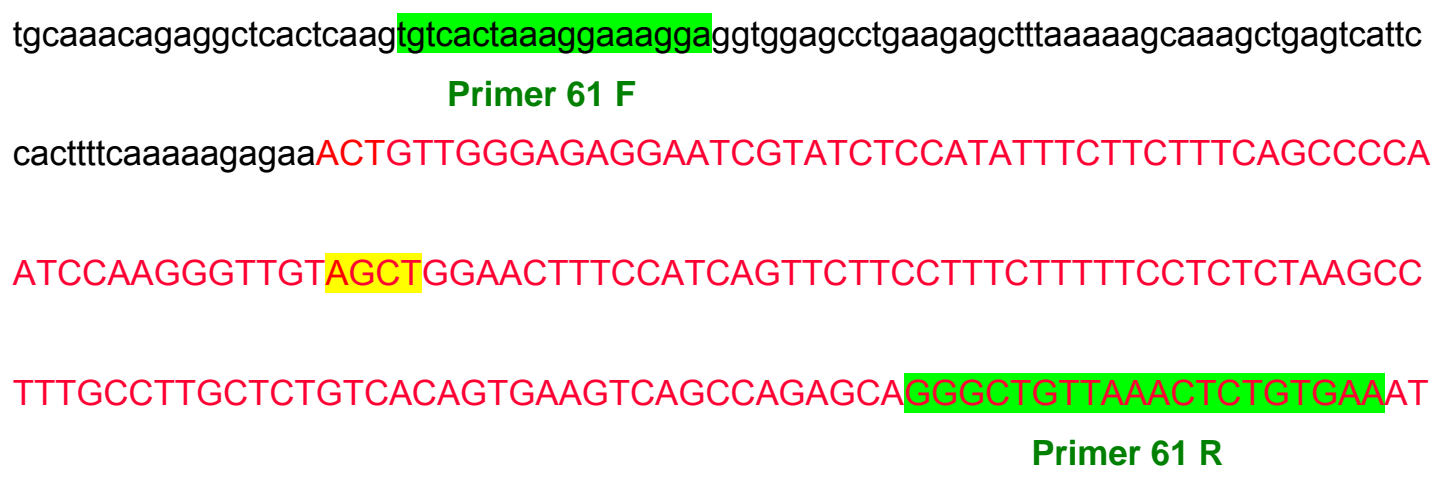

Figura 16: Seqüência do exon do EGF

Localização dos primers sense e antisense (em verde) para amplificação do fragmento de PCR da não codificadora do exon 1 do gene EGF (letras maiúsculas). A região em amarelo mostra o sitio de restrição da enzima . 


\subsection{2 - Reação em Cadeia de Polimerase (PCR)}

Foram utilizadas amostras de DNA extraídas de sangue periférico e aliquotadas em concentrações de 50 a $100 \mathrm{ng} / \mu \mathrm{L}$.

Os parâmetros de amplificação das regiões estudadas, as seqüências dos primers e o tamanho do produto de PCR estão descritos abaixo:

Tabela 3 : Seqüência de primers, tamanhos dos produtos de PCR utilizados para cada reação de PCR.

\begin{tabular}{|c|c|c|c|}
\hline Gene & Região & Sequência & Fragmento \\
\hline 안 & $\begin{array}{c}\text { Reg. Não Traduzida } \\
\text { c.-216 G>T } T^{A} \text { e c.-191 C>A }\end{array}$ & $\begin{array}{l}\text { F: CGCTGCTGGTTCTCCTCCCT } \\
\text { R: GCGAGACACGCCCTTACCTTT }\end{array}$ & $489 \mathrm{pb}$ \\
\hline & $\begin{array}{l}\text { Exon } 16 \\
\text { c. } 2073 \mathrm{~A}>\mathrm{T}^{\mathrm{B}}\end{array}$ & $\begin{array}{l}\text { F: ATATATGCCAAAGAAGTAGA } \\
\text { R: AGAAACTTGATCAGGACAGA }\end{array}$ & $207 \mathrm{pb}$ \\
\hline 崩 & $\begin{array}{l}\text { Região Não Traduzida } \\
\qquad \text { c. } 61 \mathrm{~A}>\mathrm{G}^{\mathrm{C}}\end{array}$ & $\begin{array}{l}\text { F: TGTCACTAAAGGAAAGGA } \\
\text { R: TTCACATTTAACAGCCC }\end{array}$ & $242 \mathrm{pb}$ \\
\hline
\end{tabular}

A: Liu, 2005

B: Hsieh, 2005

C: Bhowmick, 2004 
As reações de PCR para o exon 16 do gene EGFR e para o região não codificadora do exon 1 do EGF foram realizadas utilizando-se 100ng de DNA de sangue periférico em tampão Tris- $\mathrm{HCl} 10 \mathrm{mM}(\mathrm{pH} \mathrm{9,0),} \mathrm{KCl} 50 \mathrm{mM}$, contendo 1,5mM de $\mathrm{MgCl}_{2}, 0,25 \mathrm{mM}$ de cada dNTP, 20 pmols de cada primer e 0,5 unidade de enzima Tth DNA polymerase (Biotools) em um volume final de $25 \mu \mathrm{L}$. Para amplificação da região não codificadora do exon 1 do gene EGFR foram utilizados os mesmos reagentes nas mesmas concentrações, adicionando-se DMSO 10\%.

As reações de PCR foram realizadas no termociclador com sitema Peltier (PTC - 200, "MJ Research Peltier Termal Cycler, Watertown", EUA) e consistiram de uma denaturação inicial de $94^{\circ} \mathrm{C}$ durante 5 min., seguida por 35 ciclos de denaturação por $20 \mathrm{seg}$. a $94^{\circ} \mathrm{C}$, anelamento de $20 \mathrm{seg}$. a uma temperatura de $52^{\circ} \mathrm{C}$ e uma extensão por $20 \mathrm{seg}$. a $72^{\circ} \mathrm{C}$. Por fim, foi realizada uma extensão final por 10 min. a $72^{\circ} \mathrm{C}$. A reação foi mantida a $4^{\circ} \mathrm{C}$ até sua análise por eletroforese em gel de agarose.

Os produtos de PCR foram analisados quanto às eficiências das reações e aos tamanhos dos produtos esperados por eletroforese em gel de agarose 2\% em tampão TAE (tris-acetato EDTA) e visualizados após coloração com brometo de etídio, luz UV (ultra-violeta) e respectiva captação de imagem em Image Master® (Pharmcia Biotch). O padrão de tamanho molecular de 100 pb (Invitrogem) foi utilizado. A Figura 17 mostra a análise dos produtos de PCR. 


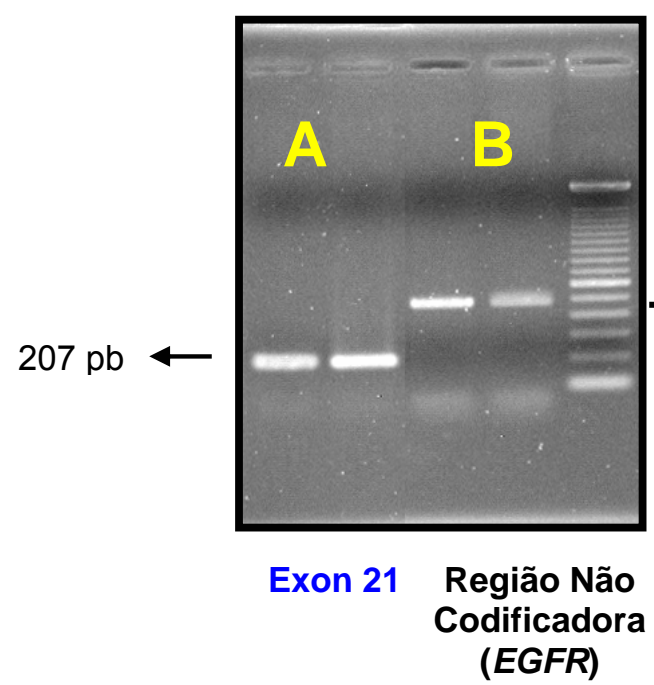

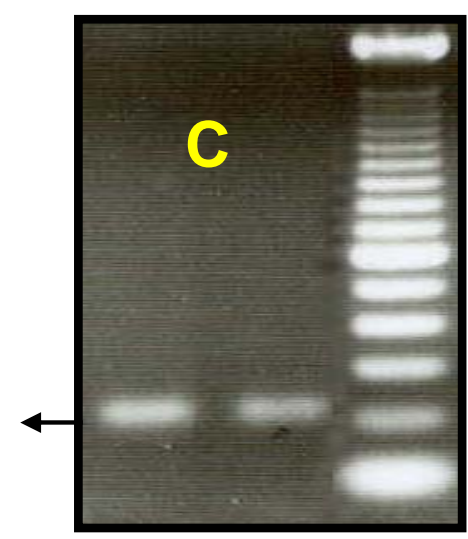

Região não
Codificadora
(EGF)

Figura 17: Eletroforese em gel de agarose dos produtos de PCR Produtos de amplificação do exon 16 do gene EGFR correspondente a um tamanho de fragmento de $207 \mathrm{pb}(\mathrm{A})$, região não codificadora do mesmo gene com um fragmento de $489 \mathrm{pb}$ (B) e produto amplificado da região não codificadora do exon 1 do gene EGF representando fragmento de $249 \mathrm{pb}$ (C). Foi utilizado marcador de tamanho molecular de $100 \mathrm{pb}$. 


\subsection{3 - Sítios de Restrição das Endonucleases.}

As enzimas de restrição auxiliaram na determinação dos genótipos dos polimorfismos.

Em nossa casuística foram utilizados 4 enzimas de restrição

- Alu I

- BseR I

- Bsr I

- Sac II.

A seguir estão apresentadas as características de cada enzima, com seus pontos de restrição e a localização/alteração provocada pelo polimorfismo. 
- Enzima BseR I e Sac II - Polimorfismo c.-191C>A e c.-216G>T (EGFR)

O polimorfismo c.-216 G>T é reconhecido pela enzima de restrição BseR I e o c.-191C>A pela enzima Sac II. O sítio de restrição dessas enzimas está apresentada abaixo na Figura 18.
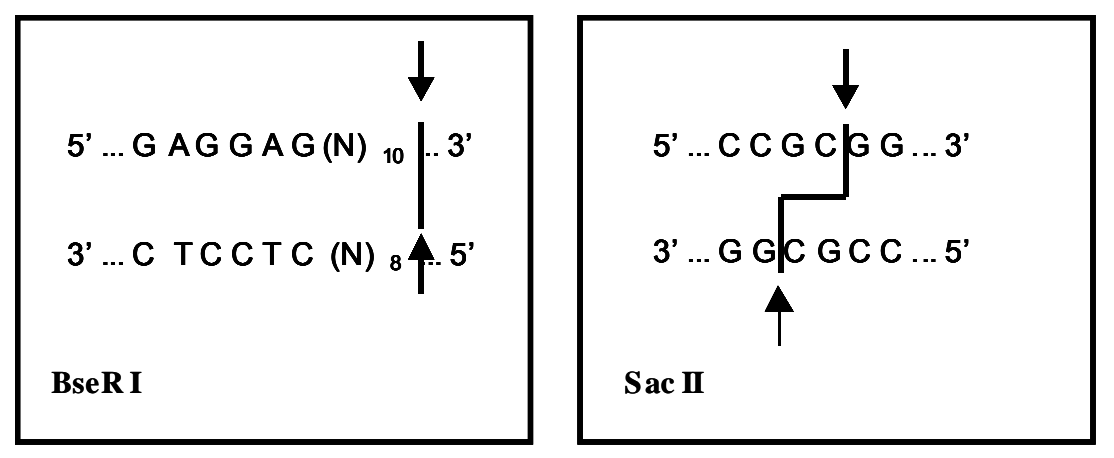

Figura 18: Sítios das enzimas de restrição BseR I e Sac II

- Enzima Bsr I - Polimorfismo c.2073A>T (EGFR)

O polimorfismo c.2073A>T é reconhecido pela enzima de restrição Bsr I. O sítio de restrição desta enzima está ilustrada abaixo na Figura 19:

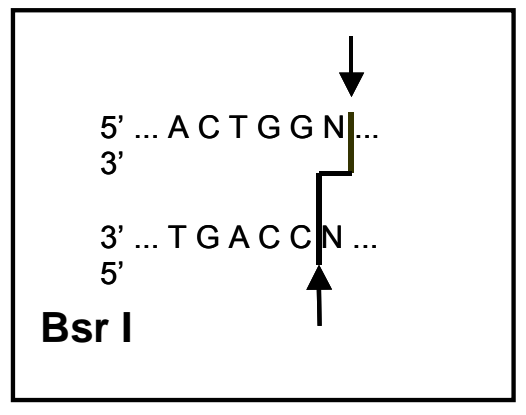

Figura 19: Sítio da enzima de restrição Bsr I 
- Enzima Alu I - Polimorfismo da Região Não Codificadora c.61A>G (EGF)

O polimorfismo c.61 A>G é reconhecido pela enzima de restrição (Alu I) que é um produto proveniente de um gene clonado de Arthrobacter luteus em E. coli. O sítio de restrição desta enzima está ilustrada abaixo na Figura 20:

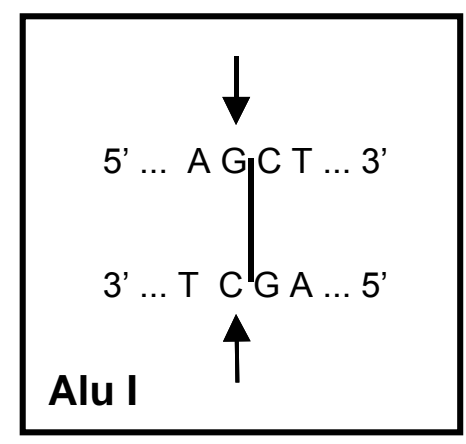

Figura 20: Sitio da enzima de restrição Alul 


\subsection{4 - Reação de Digestão Enzimática}

Foi utilizado $5 \mu \mathrm{L}$ de produto de PCR amplificado para a digestão do produto de amplificação para estudo do polimorfismo do exon 16 (A2073T) do gene EGFR com $1 \mathrm{U}$ de Bsrl e tampão 10x em volume final de $15 \mu \mathrm{L}$. Os fragmentos originados foram: 195 e $12 \mathrm{pb}$ para o homozigoto $\mathrm{AA}, 136,59$ e 12 pb para o homozigoto TT e 195,136, 59 e 12 pb para o heterozigoto AT (Tabela 4). Para a região promotora c.-216G >T, a enzima de restrição utilizada foi a Bserl e para região c.-191C>A utilizou-se a enzima Sacll, ambas em quantidade de $1 \mathrm{U}$ em volume de $15 \mu \mathrm{L}$. Os fragmentos originados a partir da digestão da região promotora -216 (c. -216 G>T) foram: 489 pb para o homozigoto GG, 326, 19, 13, 11, 10, 10, 9, 8 e 6 pb para o homozigoto TT e $489,326,19,13,11,10,10,9$, 8 e 6 pb para o heterozigoto TG (Tabela 4); e da mesma forma os fragmentos de digestão da região promotora -191 (c. -191 C>A) foram: 489 pb para o homozigoto AA, 294 e 195 pb para o homozigoto CC e 489, 294 e 195 para o heterozigoto CA. Para a digestão do produto de amplificação do polimorfismo do região não codificadora do exon 1 (c.61 A>G) do gene EGF realizada com $1 \mathrm{U}$ de enzima Alul os fragmentos originados foram: 193, 49 pb para homozigoto AA, 102, 91 e 49 pb para o homozigoto GG, e 193, 102, 91, 49 pb para o heterozigoto AG (Tabela 4). Os produtos de digestão foram analisados em eletroforese em gel de agarose $2 \%$ ou de poliacrilamida $10 \%$ corados com brometo de etídeo. 
Tabela 4: Tamanho dos fragmentos após digestão com endonucleases para os polimorfismos do gene EGFR: c.2073 A>T, c.-216 G>T, c.-191 C>A, e para o gene EGF: c.61A>G.

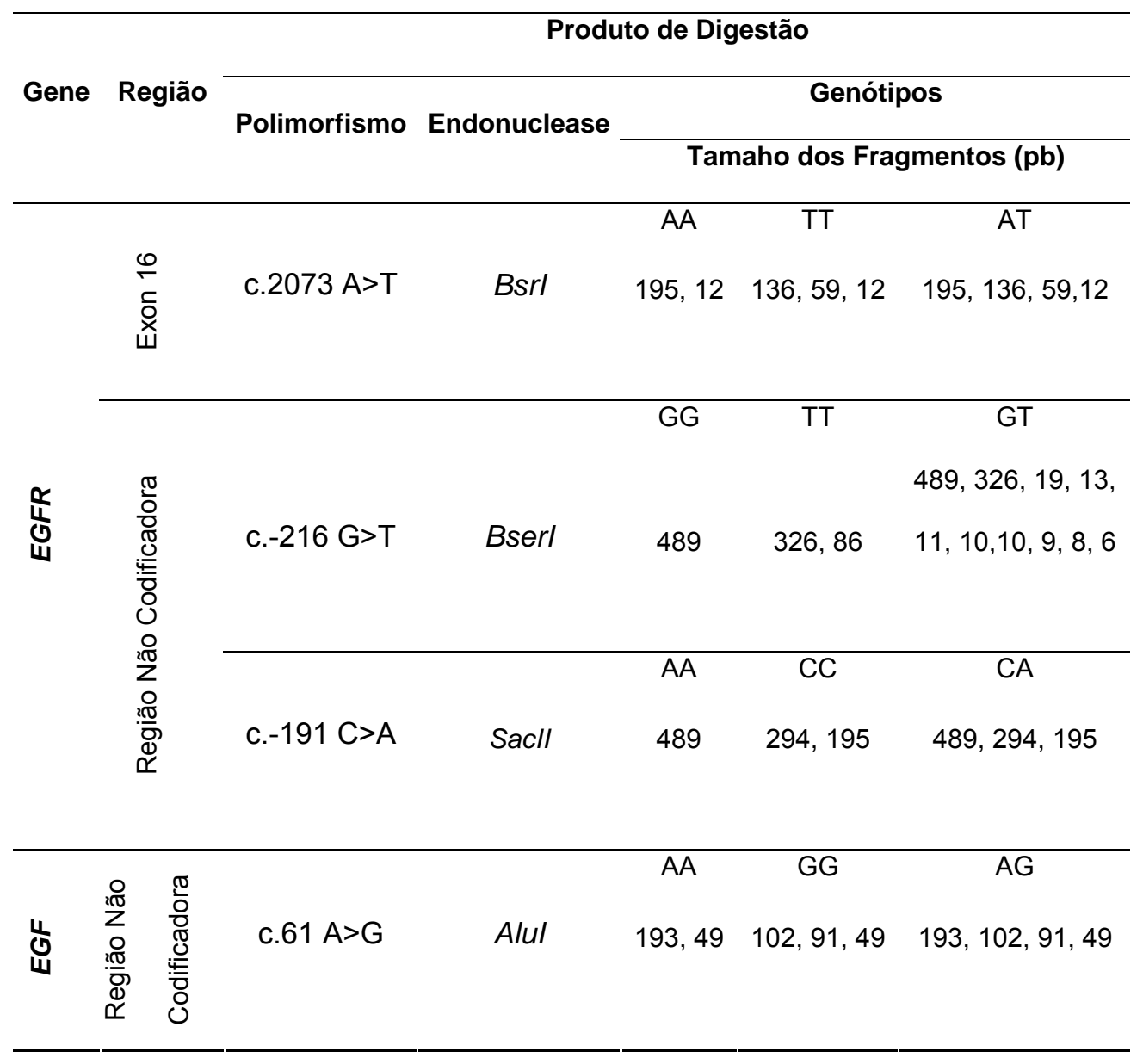


Com a confirmação do tamanho dos fragmentos amplificados foram analisados os tipos de genótipo para cada SNP. O gel de poliacrilamida foi, ainda, submetido à coloração por nitrato de prata. Essa técnica foi feita com a manutenção do gel em etanol $10 \%$ por 8 min., seguida de ácido nítrico $1 \%$ por 3 min. Após esse período o gel foi lavado em água Milli-Q e mantido em solução com nitrato de prata $0,1 \%$ e formaldeído $0,055 \%$ por 20 min. Após nova lavagem com $\mathrm{H}_{2} \mathrm{O}$ Milli-Q, procedeu-se à revelação com carbonato de sódio $3 \%$ contendo $0,111 \%$ de formaldeído seguida de uma nova solução de carbonato de sódio 3\% contendo $0,055 \%$ de formaldeído até a visualização das bandas e, por fim, a reação foi interrompida com ácido acético $10 \%$ durante 5 min. e, o gel foi lavado e mantido em água Milli-Q. Os géis demonstrando exemplos de análise dos produtos de digestão da região promotora estão apresentados na Figura 21. 


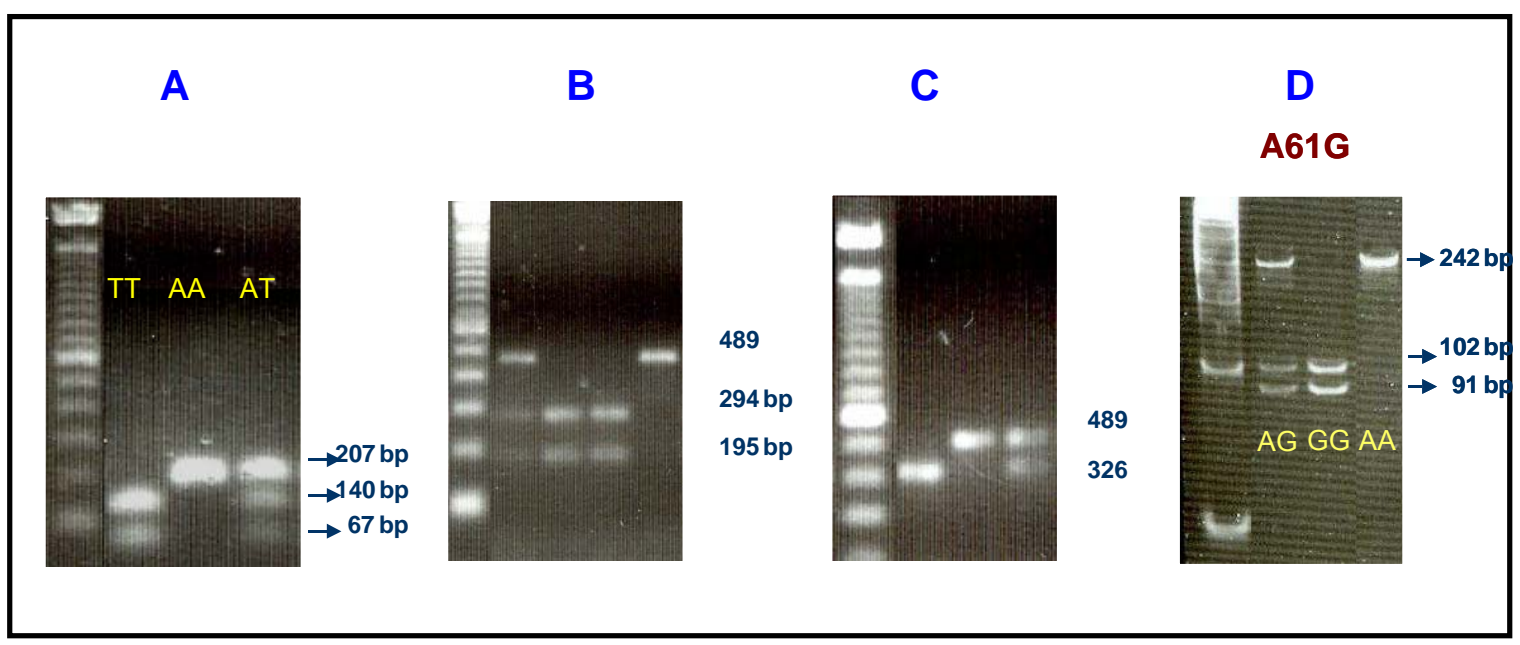

Figura 21: Eletroforese em gel de agarose e poliacrilamida dos produtos de PCR para análise dos polimorfismos de EGFR e EGF

A: genótipos do SNP c.2073 A>T de EGFR

B: genótipos do SNP C.-191 C>A de EGFR

C: genótipos do SNP c.-216 G>T de EGFR

D: genótipos do SNP c.61 A>G de EGF 


\subsection{5-Síntese da Primeira Fita de DNA Complementar (cDNA)}

Para cada 7,0 $\mu \mathrm{L}(1 \mu \mathrm{g})$ de RNA a ser reversamente transcrito, acrescentouse $0,5 \mu \mathrm{L}$ de DNase $(10 \mathrm{U} / \mu \mathrm{L}$ ), 2,0 $\mu \mathrm{L}$ do tampão de síntese $5 \mathrm{x}$ (First Strand Buffer, Invitrogen) e 0,5 $\mathrm{L}$ de inibidor de RNase (RNase-OUT, Invitrogen). Este produto foi incubado por $10 \mathrm{~min}$. a $37^{\circ} \mathrm{C}$ e por $5 \mathrm{~min}$. à temperatura de $75^{\circ} \mathrm{C}$ para o processo de denaturação.

A seguir, foi adicionado a cada amostra $0,1 \mu \mathrm{L}$ de Random Primers $(3 \mu \mathrm{g} / \mu \mathrm{L}$; Invitrogen), 1,0 $\mu \mathrm{L}$ de solução com mistura de dNTPs (deoxyNucleotide mix 10mM; Invitrogen) e $0,9 \mu \mathrm{L}$ de água MilliQ autoclavada. As amostras foram incubadas por mais $5 \mathrm{~min}$. a $65^{\circ} \mathrm{C}$.

Ao final deste processo, as amostras foram imediatamente resfriadas (em gelo) e foi acrescentado a cada amostra 2,0 $\mu \mathrm{L}$ do tampão de síntese 5x (First

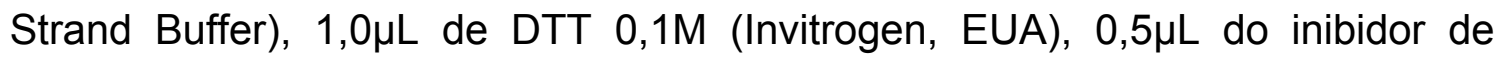
RNase, $3,5 \mu \mathrm{L}$ de água milliQ autoclavada e 1,0 $\mu \mathrm{L}$ de Transcripitase reversa

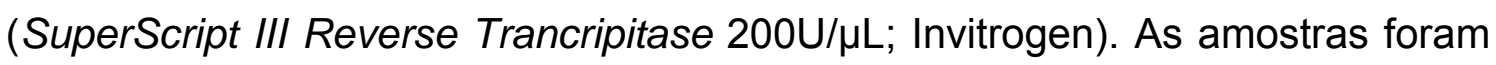
levemente homogeinizadas e incubadas por $5 \mathrm{~min}$ a $25^{\circ} \mathrm{C}, 60 \mathrm{~min}$. a $50^{\circ} \mathrm{C}$ e 15 $\min a 70^{\circ} \mathrm{C}$.

As amostras foram diluídas com TE e armazenadas a $-20^{\circ} \mathrm{C}$. 


\subsection{6-Reação de PCR em Tempo Real (Real Time PCR)}

Os níveis de expressão de RNAm do gene EGFR e do gene de referência endógena Hipoxantina Riboxil Transferase (HPRT) foram quantificados através da técnica de PCR em tempo real baseada na emissão de fluorescência SYBR Green I. Todas as reações foram realizadas no aparelho Gene Amp 7500 Sequence Detection System (Applied Biosystems).

As reações foram preparadas utilizando-se SYBR Green PCR Master Mix (Applied Biosystems) contendo SYBR Green, AmpliTaq Gold DNA Polimerase, dNTPs (com dUTP), uracil N-glicosilase (NG), referência passiva e tampão otimizado. O preparo e o armazenamento foram realizados segundo as instruções do fabricante, exceto pelo volume final de cada reação que foi de $12 \mu \mathrm{L}$, sendo utilizados $6 \mu \mathrm{L}$ de SybrR Green PCR Master Mix, 3,0 $\mu \mathrm{L}$ de cDNA e primers sense e antisense na concentração final de 200nM para HPRT e 200nM para EGFR. A seqüência de primes está apresentada na Tabela 5.

Tabela 5: Seqüência de primers para análise de expressão de EGFR e HPRT por PCR em tempo real

\begin{tabular}{cllc}
\hline Gene & \multicolumn{1}{c}{ Região } & \multicolumn{1}{c}{ Seqüência (5'-3') } & $\begin{array}{c}\text { Fragmento } \\
\mathbf{( p b )}\end{array}$ \\
\hline \multirow{2}{*}{ EGFR } & Exon 27 & F: TGCAGCGATACAGCTCAGACCC & 123 \\
& Exon 28 & R: TTTGGGAACGGACTGGTTTATG & \\
\multirow{2}{*}{ HPRT } & Exon 2 & F: TGAGGATTTGGAAAGGGTGT & 118 \\
& Exon 3 & R: GAGCACACAGAGGGCTACAA & \\
\hline
\end{tabular}


Os parâmetros do aparelho foram ajustados para digestão pela UNG a $50^{\circ} \mathrm{C}$ por 2 min., denaturação à $95^{\circ} \mathrm{C}$ por 10 min. e 40 ciclos de amplificação (15 seg. a $95^{\circ} \mathrm{C}$ e $60 \mathrm{seg}$. a $60^{\circ} \mathrm{C}$ ). No final de todas as reações foram analisadas as curvas de dissociação.

Cada amostra foi testada em duplicata e todas as reações de PCR consideradas para análise apresentaram eficiência igual ou superior a 95\%.

Para as análises de expressão gênica de tecido não tumoral de cérebro foi utilizado como agente calibrador. 


\subsection{7- Curva de Dissociação ("Melting Curve")}

As curvas de dissociação das amostras foram realizadas para análise de contaminação, formação de dímeros de primers, e amplificação inespecíficas. As curvas de dissociação de todos os produtos de PCR apresentam a mesma temperatura de dissociação. Após a amplificação do PCR em tempo real, programou-se o aparelho para realizar uma curva de dissociação. Nesta fase, a temperatura da reação foi elevada e o aparelho captou a mudança na emissão de fluorescência. No ponto de dissociação, as duas cadeias de cDNA se separaram e a fluorescência diminuiu gradativamente. O software do aparelho forneceu um gráfico que determinou a mudança de fluorescência emitida com a temperatura. A Figura 22 ilustra exemplos dascurvas de dissociação do EGFR.

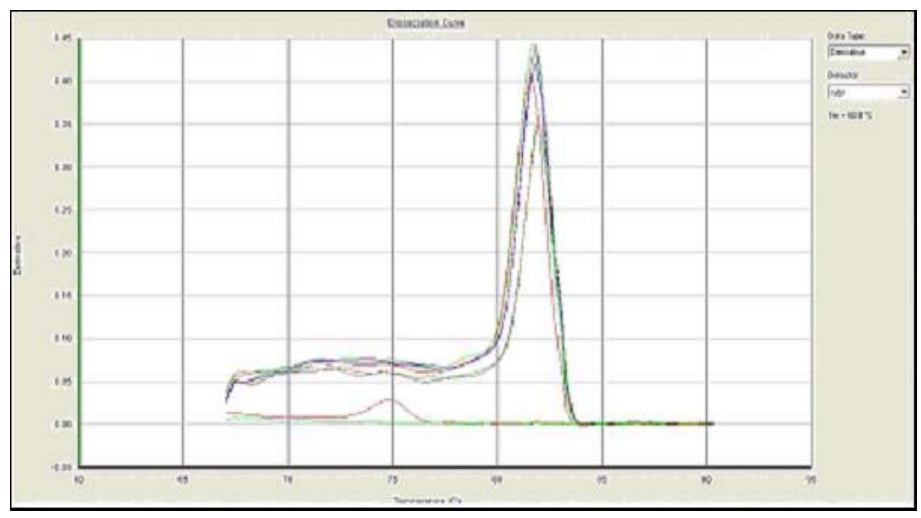

Figura 22: Curvas de dissociação dos produtos de PCR em tempo real do gene EGFR

No final de cada reação realizada a temperatura foi aumentada gradativamente para a determinação da curva de dissociação. As curvas mostram as derivadas de fluorescência nas reações com picos únicos dos produtos de PCR 
As amostras que apresentaram curvas de dissociação com temperaturas diferentes e/ou apresentaram mais de um ponto de dissociação foram desconsideradas e as reações foram repetidas para estas amostras. 


\subsection{8-Quantificação Relativa de Expressão de EGFR}

Os valores de $\mathrm{Ct}$ foram obtidos utilizando-se o threshold determinado individual e manualmente para cada gene. Foi utilizada a média aritmética dos valores de Ct encontrados para cada amostra testada em duplicata.

A equação $2^{-\Delta \Delta C t}$ foi utilizada para calcular a expressão do gene $E G F R$ em amostras de tumores em relação a média de expressão nos tecidos não tumorais, onde $\Delta \mathrm{Ct}=\mathrm{Ct} E G F R-\mathrm{Ct} H P R T$, e $\Delta \Delta \mathrm{Ct}=\Delta \mathrm{Ct}$ tumor - média $\Delta \mathrm{Ct}$ tecidos não tumorais (Livak, Schmittgen, 2001). Os resultados foram apresentados em escala $\log _{10}$ para melhor visualização. 


\section{3 - Análise Estatística}

O teste qui-quadrado $\left(\chi^{2}\right)$, cálculo de odds ratio $(\mathrm{OR})$ e intervalo de confiança de 95\% (IC95\%) foram utilizados para avaliar as associações entre os genótipos de polimorfismos de EGFR e EGF e o risco de desenvolver astrocitoma. As distribuições dos genótipos relacionados aos genes foram verificadas utilizando o teste de equilíbrio de Hardy-Weinberg. Estes cálculos estatísticos foram realizados utilizando-se o programa STATA versão 7 (STATA Corp., College Station, Texas, Estados Unidos).

O teste não paramétrico ( $t$ de Student) foi utilizado para avaliar o nível de expressão relativa do gene EGFR com os genótipos dos polimorfismos c.2073A $>$ T, c.-191C>A, c.-216G >T utilizando-se o programa GraphPad Prism versão 4 (San Diego, Califórnia, Estados Unidos). Valores de $p<0,05$ foram considerados com significância estatística.

A análise de sobrevida foi realizada através de curva de Kaplan-Meier, utilizando-se teste de long rank. Os cálculos foram realizados através do programa SPSS versão 10 (Chicago, Leinois, Estados Unidos). 


\section{4 - Resultados}

\section{1 - Distribuição demográfica dos casos e controles}

Foram analisadas 193 amostras de casos e 200 de controles pareados por gênero e idade. A Tabela 6 mostra a distribuição dos casos e controles quanto a idade e gênero.

Tabela 6: Distribuição por idade, gênero, em casos com astrocitomas difusamente infiltrativos e controles.

\begin{tabular}{lcccc}
\hline & Astrocitomas & $\%$ & Controles & $\%$ \\
\hline Pacientes & $\mathbf{1 9 3}$ & 100 & $\mathbf{2 0 0}$ & 100 \\
& & & & \\
Idade (anos) & & & & \\
$<30$ & $\mathbf{2 5}$ & 13,0 & $\mathbf{2 6}$ & 13,0 \\
$30-39$ & $\mathbf{3 7}$ & 19,2 & $\mathbf{4 1}$ & 20,5 \\
$40-49$ & $\mathbf{3 9}$ & 20,2 & $\mathbf{3 9}$ & 19,5 \\
$50-59$ & $\mathbf{4 0}$ & 20,7 & $\mathbf{3 6}$ & 18,0 \\
$60-69$ & $\mathbf{4 0}$ & 20,7 & $\mathbf{4 2}$ & 21,0 \\
$>70$ & $\mathbf{1 2}$ & 6,2 & $\mathbf{1 6}$ & 8,0 \\
Total & $\mathbf{1 9 3}$ & 100,0 & $\mathbf{2 0 0}$ & 100,0 \\
& & & & \\
Gênero & & & & \\
Masculino & $\mathbf{1 2 3}$ & 63,7 & $\mathbf{1 2 6}$ & 50,6 \\
Feminino & $\mathbf{7 0}$ & 36,3 & $\mathbf{7 4}$ & 51,4 \\
Total & $\mathbf{1 9 3}$ & 100,0 & $\mathbf{2 0 0}$ & 100,0 \\
\hline
\end{tabular}


4.2 - Determinação dos genótipos dos polimorfismos de EGFR e EGF

\subsection{1 - EGFR}

\section{A - Polimorfismo c.2073A>T}

A freqüência dos genótipos AA, AT, TT foi observada nos casos em uma percentagem de $16,6 \%$ (32/193), 51,8\% (100/193) e $31,6 \%(61 / 193)$, respectivamente. Já nos controles, os mesmos genótipos foram observados nas seguintes percentagens: $10,0 \%$ (20/200), 53,0\% (106/200) e $37,0 \%(74 / 200)$, respectivamente (Figura 23). Não houve diferença na distribuição genotípica entre casos e controles $(p=0,131)$.

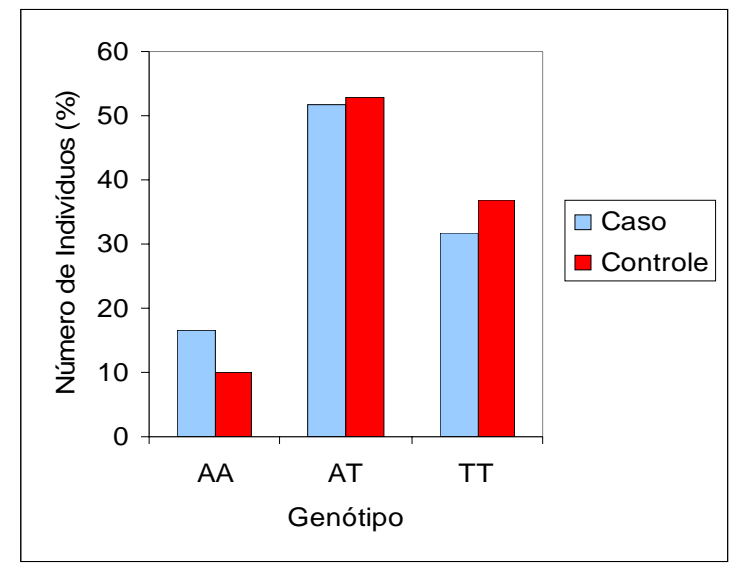

Figura 23: Distribuição dos genótipos do polimorfismo c. 2073 A>T do gene EGFR em casos e controles. 


\section{B - Polimorfismo c.-191C>A}

Nesse estudo foi observada a seguinte distribuição dos genótipos nos casos: $1,0 \%(2 / 193)$ de AA, 13,5\% (26/193) de CA, 85,5\% (165/193) CC. Nos controles a distribuição foi semelhante: 2,0\% (4/193) de AA, 13,0\% (26/193) de CA, 85,0\% (170/193) de CC (Figura 24). Não houve diferença na distribuição genotípica entre os casos e controles $(p=0,735)$.

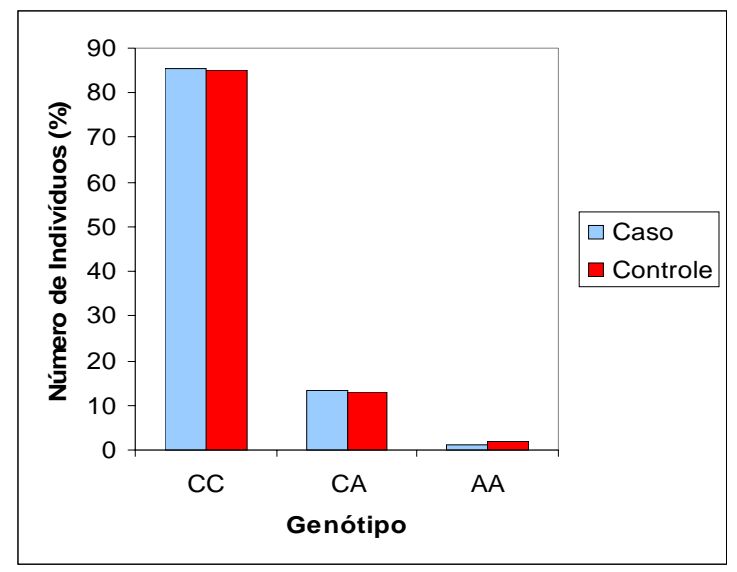

Figura 24: Distribuição dos genótipos do polimorfismo c.191C>A do gene EGFR em casos e controles. 


\section{C - Polimorfismo c.-216G>T}

A seguinte distribuição genotípica foi observada nos casos: GG, 48,2\% (93/193), TG, 49,2\% (95/193) e TT, 2,6\% (5/193). Nos controles os resultados foram similares: $50,0 \%$ de GG (100/150), 45,0\% de TG (90/193), 5,0\% de TT (10/200). Não houve diferença estatística entre os genótipos $(p=0,381)$ (Figura 25), nos casos e controles.

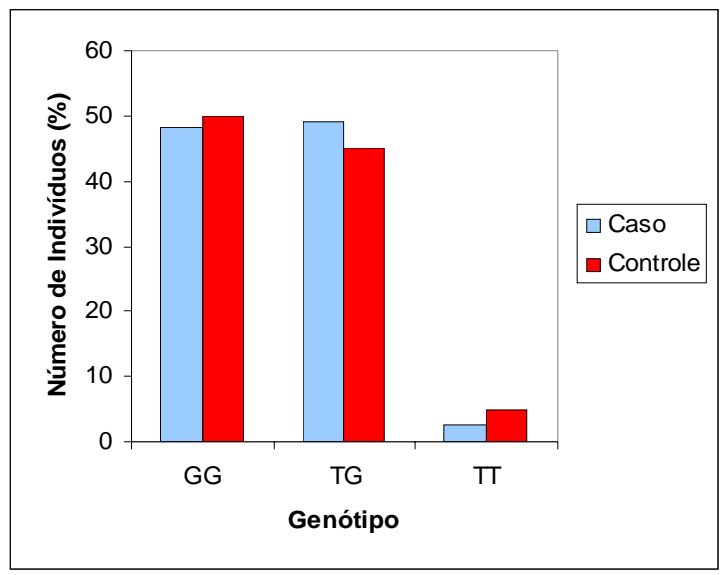

Figura 25: Distribuição dos genótipos do polimorfismo c.-216G>T do gene EGFR em casos e controles. 


\section{$4.2 .2-E G F$}

\section{A - Polimorfismo c. 61 A $>G$}

Com relação aos genótipos AA, AG, GG, foram observados nos casos em uma percentagem de 28,0\% (54/193), 63,2\% (122/193) e 8,8\% (17/193), respectivamente. Já nos controles, os mesmos genótipos foram observados nas seguintes percentagens: $28,5 \%$ (57/200), 62,0\% (124/200) e 9,5 (19/200), respectivamente $(p=0,959)$. A Figura 26 mostra a distribuição dos genótipos encontrada nos casos e controles.

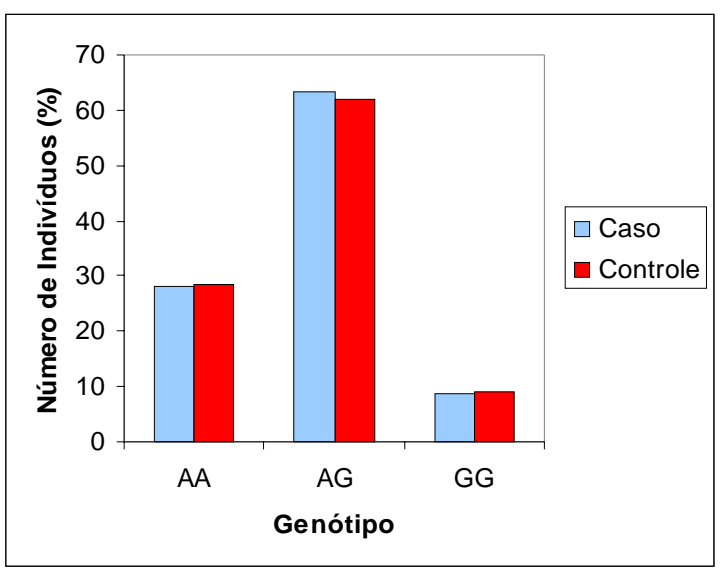

Gráfico 26: Distribuição dos genótipos do polimorfismo c.61 $A>G$ do gene EGF em casos e controles. 


\section{3- Freqüência Alélica}

A Tabela 7 apresenta os dados das freqüências alélicas dos quatro polimorfismos analisados.

Tabela 7 : Freqüências alélicas dos polimorfismos dos genes EGFR e EGF

\begin{tabular}{|c|c|c|c|c|}
\hline Freq. Alélica & Casos & $\%$ & Controles & $\%$ \\
\hline \multicolumn{5}{|c|}{ EGFR c.2073 A>T } \\
\hline A & 164 & 42,4 & 146 & 36,5 \\
\hline \multirow[t]{2}{*}{$\mathbf{T}$} & 222 & 57,6 & 254 & 63,5 \\
\hline & $p=0,403$ & & $p=0,043$ & \\
\hline \multicolumn{5}{|c|}{ EGFR c.-191 C>A } \\
\hline C & 356 & 92,0 & 366 & 91,5 \\
\hline \multirow[t]{2}{*}{$A$} & 30 & 8,0 & 34 & 8,5 \\
\hline & $p=0,402$ & & $p=0,020$ & \\
\hline \multicolumn{5}{|c|}{ EGFR c.-216 G>T } \\
\hline G & 281 & 72,8 & 290 & 72,5 \\
\hline \multirow[t]{2}{*}{$\mathbf{T}$} & 105 & 27,2 & 110 & 27,5 \\
\hline & $p=0,007$ & & $p=0,069$ & \\
\hline \multicolumn{5}{|l|}{ EGF c.61 $A>G$} \\
\hline$A$ & 230 & 59,6 & 238 & 59,5 \\
\hline G & $\begin{array}{c}156 \\
p=0,000\end{array}$ & 40,4 & $\begin{array}{c}162 \\
p=0,0001\end{array}$ & 40,5 \\
\hline
\end{tabular}

Foi observado que alguns polimorfismos estão em desequilíbrio para o teste de Hardy-Weinberg. A análise do gene EGFR apresentou alteração no polimorfismo c.2073A>T no grupo controle $(p=0,043)$, no polimorfismo c.191C $>$ A no grupo controle $(p=0,020)$ e no polimorfismo $c .-216 G>T$ no grupo de casos ( $p=0,007)$. Para o polimorfismo do gene $E G F$ ambos os grupos, casos e controles, apresentaram características de desequilíbrio menor que 0,05. 
Foi realizada a análise dos dados de distribuição dos casos de astrocitomas difusos comparados a controles quanto a idade, gênero, genótipo dos polimorfismos de EGFR e EGF. Observou-se um discreto predomínio de pacientes com idade menor que 50 anos do gênero masculino e estas proporções foram mantidas entre os controles (Tabela 8)

O cálculo de OR e IC95\% foi realizado para idade, gênero, genótipos dos polimorfismos de EGFR e EGF e, ainda, para a combinação de genótipos dos polimorfismos c.-191 C>A e c. -216 G>T, não resultando em dados estatisticamente relevantes no presente estudo, exceto pelo polimorfismo c.2073 A>T que apresentou fator de risco 51\% menor dos portadores do genótipo TT em desenvolver astrocitoma que os portadores do genótipo AA.

Não foram encontradas associações entre os demais polimorfismos isolados ou em conjunto analisados (EGFR c.-191C>A, c.-216G>T; EGF c. $61^{A}>$ G; associação c.-191C>A e c.-216G>T) e susceptibilidade no desenvolvimento de astrocitomas difusamente infiltrativos. 
Tabela 8: Razão de odds (OR) e 95\% de intervalo de confiança (95\% IC) entre casos de astrocitomas difusamente infiltrativos e controles de acordo com a idade, sexo, genótipo dos polimorfismos de EGFR e EGF.

\begin{tabular}{|c|c|c|c|c|c|c|}
\hline & $\begin{array}{l}\text { Astrocitomas } \\
\text { difusos }\end{array}$ & $\%$ & Controles & $\%$ & $p$ (valor) & OR (IC 95\% ) \\
\hline Total & 193 & & 200 & & & \\
\hline \multicolumn{7}{|l|}{ Idade (anos) } \\
\hline$\leq 50$ anos & 101 & 52,3 & 106 & 53,0 & 0,894 & 1 \\
\hline$>50$ anos & 92 & 47,7 & 94 & 47,0 & & $1(0,99-1,00)$ \\
\hline \multicolumn{7}{|l|}{ Sexo } \\
\hline Masculino & 123 & 63,7 & 126 & 63,0 & 0,881 & 1 \\
\hline Feminino & 70 & 36,3 & 74 & 37,0 & & $0,87(0,55-1,38)$ \\
\hline \multicolumn{7}{|c|}{ EGFR - A2073T } \\
\hline$A A$ & 32 & 16,6 & 20 & 10,0 & & 1 \\
\hline$A T$ & 100 & 51,8 & 106 & 53,0 & 0,131 & $0,59(0,32-1,09)$ \\
\hline$T T$ & 61 & 31,6 & 74 & 37,0 & & $0,51(0,27-0,99)$ \\
\hline$A T / T T$ & 161 & 83,4 & 180 & 90,0 & & $0,56(0,31-1,01)$ \\
\hline \multicolumn{7}{|c|}{ EGFR C-191A } \\
\hline$C C$ & 165 & 85,5 & 170 & 85,0 & & 1 \\
\hline$C A$ & 26 & 13,5 & 26 & 13,0 & 0,735 & $1,03(0,57-1,85)$ \\
\hline$A A$ & 2 & 1,0 & 4 & 2,0 & & $0,51(0,09-2,85)$ \\
\hline$C A / A A$ & 28 & 14,5 & 30 & 15,0 & & $0,96(0,55-1,68)$ \\
\hline \multicolumn{7}{|c|}{ EGFR G-216T } \\
\hline$G G$ & 93 & 48,2 & 100 & 50,0 & & 1 \\
\hline$T G$ & 95 & 49,2 & 90 & 45,0 & 0,381 & $1,13(0,76-1,70)$ \\
\hline$T T$ & 5 & 2,6 & 10 & 5,0 & & $0,54(0,18-1,63)$ \\
\hline$T G / T T$ & 100 & 51,8 & 100 & 50,0 & & $1,07(0,72-1,60)$ \\
\hline \multicolumn{7}{|c|}{ EGFR C-191A\&G-216T } \\
\hline$C C \& G G$ & 73 & 37,8 & 76 & 38,0 & & 1 \\
\hline$C A \& G G$ & 18 & 9,3 & 20 & 10,0 & 0,744 & $0,94(0,46-1,91)$ \\
\hline CA\&TG & 8 & 4,1 & 6 & 3,0 & & $1,39(0,46-4,19)$ \\
\hline CC\&TG & 87 & 45,1 & 84 & 42,0 & & $1,08(0,69-1,67)$ \\
\hline CC\&TT & 5 & 2,6 & 10 & 5,0 & & $0,52(0,17-1,59)$ \\
\hline$A A \& G G$ & 2 & 1,0 & 4 & 2,0 & & $0,52(0,92-2,93)$ \\
\hline \multicolumn{7}{|l|}{ EGF A61G } \\
\hline$A A$ & 54 & 28,0 & 57 & 28,5 & & 1 \\
\hline$A G$ & 122 & 63,2 & 124 & 62,0 & 0,959 & $1,03(0,66-1,63)$ \\
\hline GG & 17 & 8,8 & 19 & 9,5 & & $0,94(0,44-2,01)$ \\
\hline$A G / G G$ & 139 & 72,0 & 143 & 71,5 & & $1,02(0,66-1,59)$ \\
\hline
\end{tabular}

Idade calculada no dia da cirurgia

IC 95\%: intervalo de confiança de 95\%

OR: odds ratio 


\section{4 - Análise da expressão gênica do EGFR}

A análise de expressão gênica de EGFR foi efetuada com uma casuística de 85 pacientes do grupo AS3, subdividida em 18 astrocitomas grau II, 14 grau III, 53 grau IV. O grupo controle constituiu de 10 amostras cerebrais não neoplásicas. A Figura 27 mostra a distribuição de expressão relativa de EGFR nas amostras normais, astrocitoma grau II, grau III e grau IV. A tabela completa dos dados de expressão relativa pode ser analisada no Anexo I.

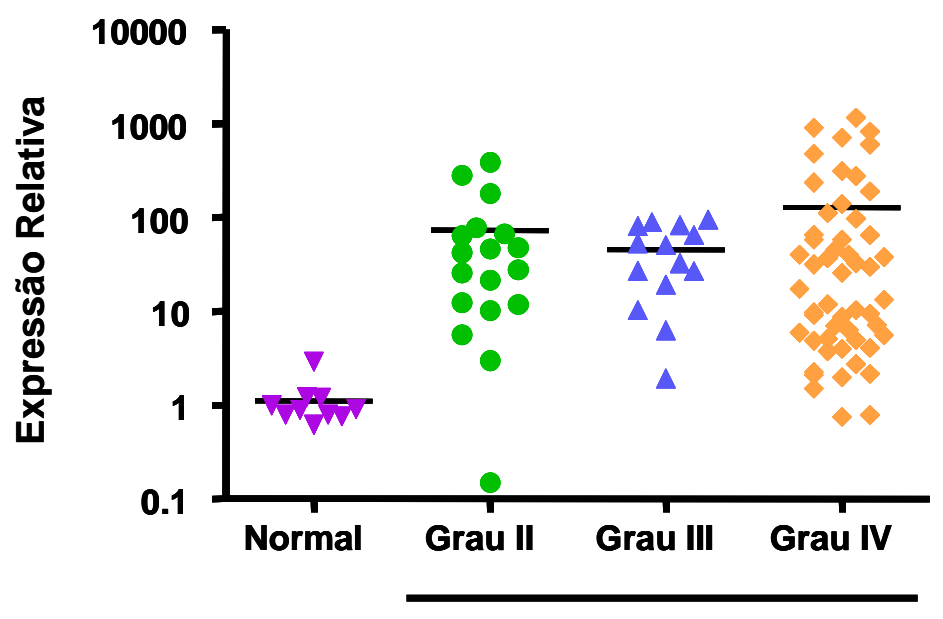

Astrocitomas

Figura 27: Expressão relativa do gene EGFR em astrocitomas 
Pode-se observar uma homogeneidade na expressão de EGFR em amostras normais, com uma baixa expressão do gene. As amostras tumorais, apresentam uma grande variação dos níveis de expressão relativa, com média de expressão aproximada entre os pacientes com astrocitoma grau II e III, e uma média mais elevada nos casos de GBM. 


\subsection{1 - Análise da expressão relativa de EGFR em relação aos genótipos do polimorfismo c. -191 C>A do EGFR.}

Os dados observados nesses gráficos ficaram difíceis de serem comparados nos casos, pois o genótipo AA é raro, impossibilitando o cálculo para análise estatística, uma vez que o programa não permite o cálculo para menos de 3.

Devido a insuficiência de amostras com genótipos AA e CA apresentados nos casos de astrocitoma grau II, não foi realizada a análise estatística.

Quando foi possível a análise, observou-se expressão relativa com uma média alta de $\mathrm{CC}$ em relação a CA. A análise estatística comparativa desses dois genótipos não mostrou resultado significante.

A expressão relativa nos casos de astrocitoma grau III apresentou uma média de expressão relativa maior em casos com genótipo $\mathrm{CC}$ do que $\mathrm{CA}$. $\mathrm{A}$ análise estatística comparativa desses dois genótipos não mostrou resultados significantes $(p=0,54)$. 
Embora a quantidade de pacientes com GBM fosse maior que a de pacientes com grau II e III, não foi encontrado nenhum paciente com genótipo AA. A média de expressão relativa de CA foi maior que $\mathrm{CC}$, porém sem diferenças estatísticas $(p=0,64)$.

Quando todos os casos de astrocitomas grau II e III foarm analisados juntamente, observou-se que os níveis de expressão de EGFR nos casos com genótipos CA e CC foram semelhantes $(p=0,41)$.

Entre todos os casos de astrocitoma graus II, III e IV, houve um único caso que apresentou genótipo AA. As médias de expressão relativa de EGFR das amostras de genótipo CA e CC foram semelhantes e o cálculo estatístico também não apresentou diferença $(p=0,54\}$.

Os níveis de expressão relativa de EGFR nos diferentes genótipos do polimorfismo c.-191C>A e nos grupos de astrocitoma podem ser visualizados na Figura 28. 


\section{Resultados}

Grau II

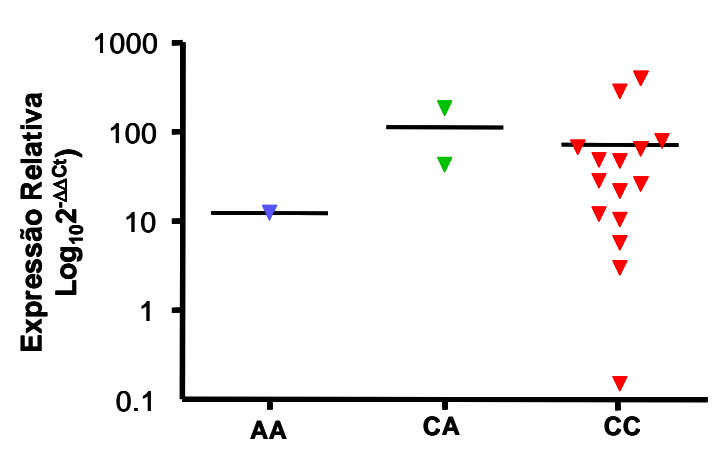

Grau IV

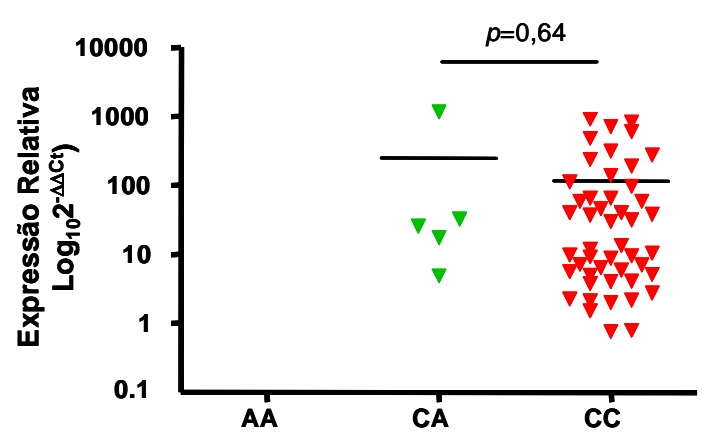

Grau II + III + IV

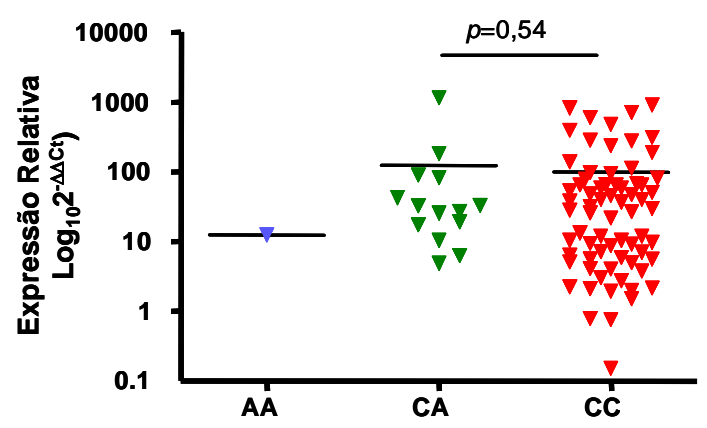

Grau III

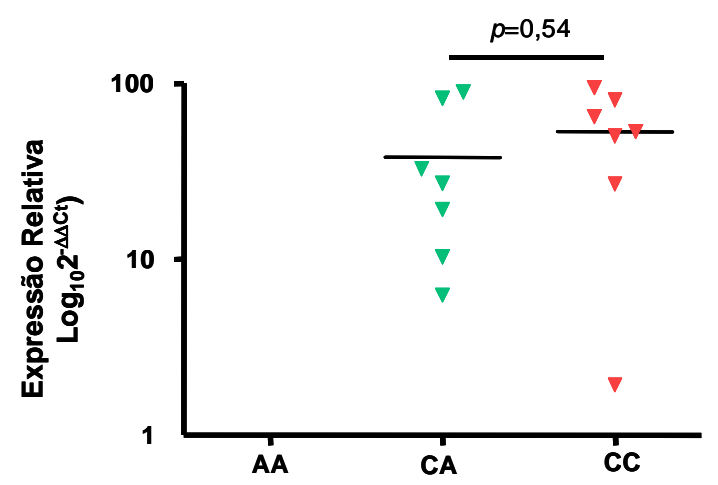

Grau III + Grau IV

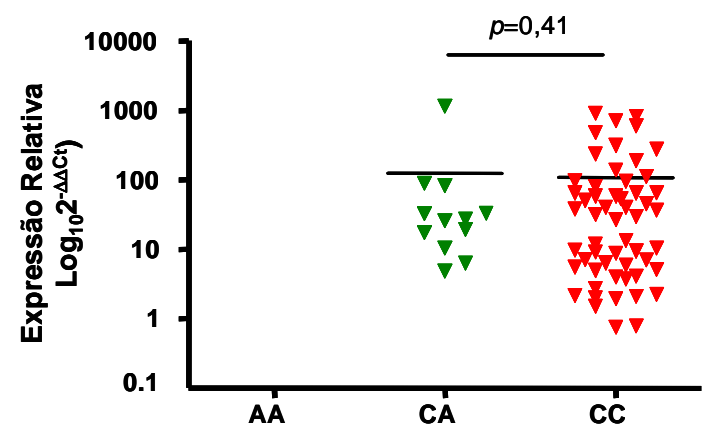

Figura 28: Expressão relativa de EGFR nos genótipos do polimorfismo c.-191 C>A de EGFR em astrocitomas de diferentes graus de malignidade 


\subsection{2 - Análise de expressão relativa de EGFR em relação aos genótipos no polimorfismo c.-216 G>T de EGFR.}

Nos casos de astrocitoma grau II, não foi encontrado o genótipo TT. Foram verificados diferentes níveis de expressão de EGFR entre os casos com genótipo GG e TG nos casos de astrocitoma grau II, mas sem diferença estatisticamente significativa. As médias das amostras nos dois genótipos foram diferentes, sendo a média de expressão relativa do genótipo GG mais elevada.

Analisando as amostras de astrocitoma grau III, observou-se que a média da expressão relativa nos genótipos GG e TG foram semelhantes $(p=0,75)$.

Nos casos de GBM, observou-se médias de expressão relativa de EGFR semelhante e alta $(\mathrm{p}=0,93)$.

Quando agrupadas as amostras de astrocitomas graus III e IV e subdivididas por genótipo, ou todos os graus, não foram encontradas diferenças nos níveis de expressão de EGFR entre os genótipos GG e TG ( $p=0,91$ e $p=0,55)$.

Os níveis de expressão relativa de EGFR nos diferentes genótipos no polimorfismo c.-216G>T e nos grupos de astrocitoma estão apresentados na Figura 29. 
Grau II

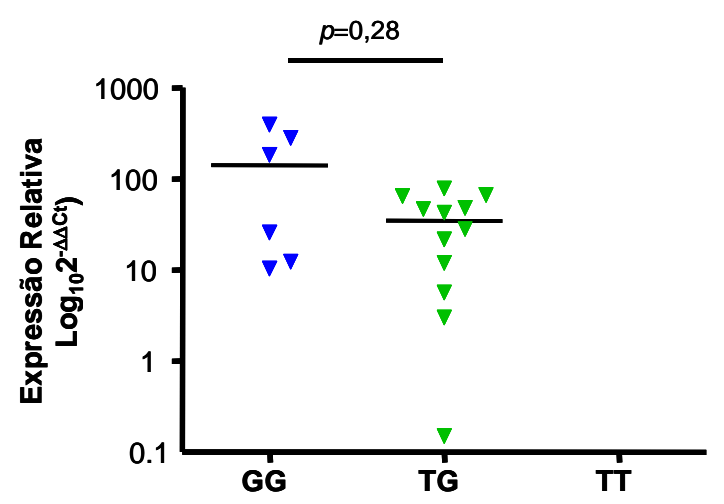

Grau IV

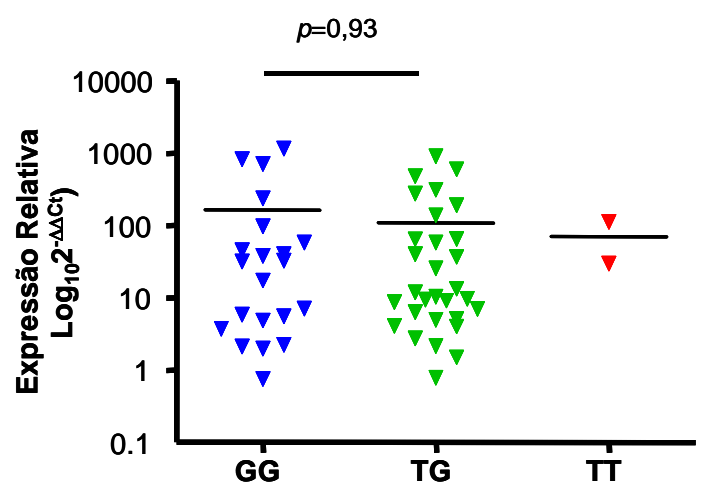

Grau III

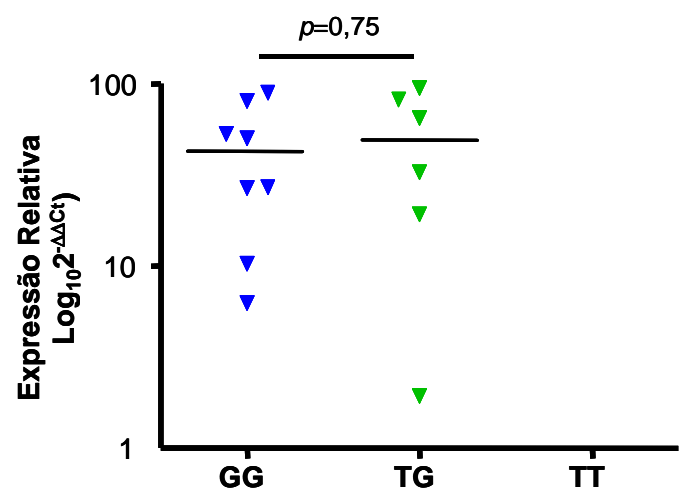

Grau III + Grau IV

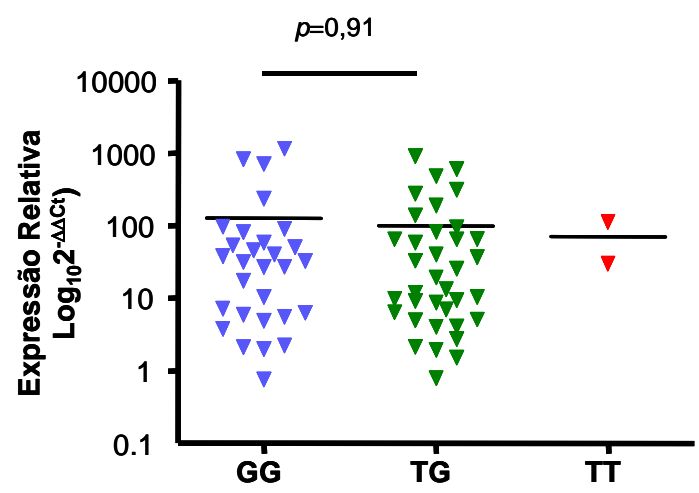

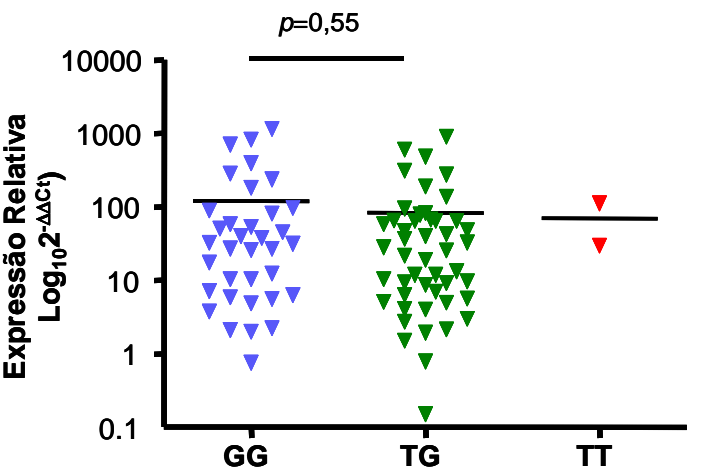

Figura 29: Expressão relativa de EGFR nos genótipos do polimorfismo c.-216 G>T de EGFR em astrocitomas de diferentes graus de malignidade. 


\subsection{3 - Análise da expressão relativa de EGFR em relação aos genótipos do polimorfismo c.2073 A>T do EGFR.}

A análise comparativa da distribuição dos genótipos polimórficos por grau de malignidade não demonstrou diferenças significativas entre os genótipos estudados.

Nos casos de astrocitoma grau II, a média de expressão relativa do EGFR foi maior nos casos com genótipo TT do que AA, porém sem diferenças estatísticas $(p=0,63)$. Não houve também diferença de expressão relativa entre os casos e controles com genótipo AA e AT $(p=0,76)$ e TT e AT $(p=0,39)$.

Com relação aos casos de astrocitoma grau III, a expressão gênica de EGFR foi maior nos casos heterozigotos AT, mas sem diferença em relação ao homozigoto TT $(p=0,21)$.

Os casos de GBM apresentaram uma expressão relativa de EGFR muito variada nos três genótipos possíveis, sendo a média de expressão dos casos com genótipos AA e TT bem semelhantes $(p=0,28$ e $p=0,29$ respectivamente).

Quando os casos de astrocitoma graus III e IV foram analisados juntos, resultados semelhantes ao GBM foram observados, sem diferença de expressão relativa de EGFR entre os genótipos: AA x AT, p=0,92; AA x TT, p=0,93; TT x AT, $p=0,72$. 
Quando todos os casos com astrocitomas graus II, III, IV foram analisados conjuntamente, não houve diferença de expressão relativa de EGFR $(p=0,57$ para AA $\times$ TT, $p=0,48$ para AA $\times$ AT e $p=0,94$ para TT $\times$ AT.

A Figura 30 mostra os níveis de expressão relativa de EGFR nos diferentes genótipos do polimorfismo c.2073A>T e nos astrocitomas de diferentes graus de malignidade. 


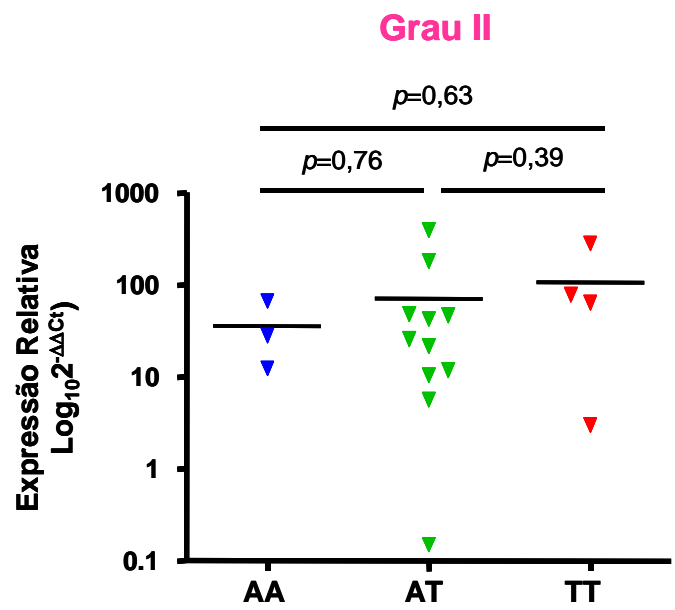

Grau III

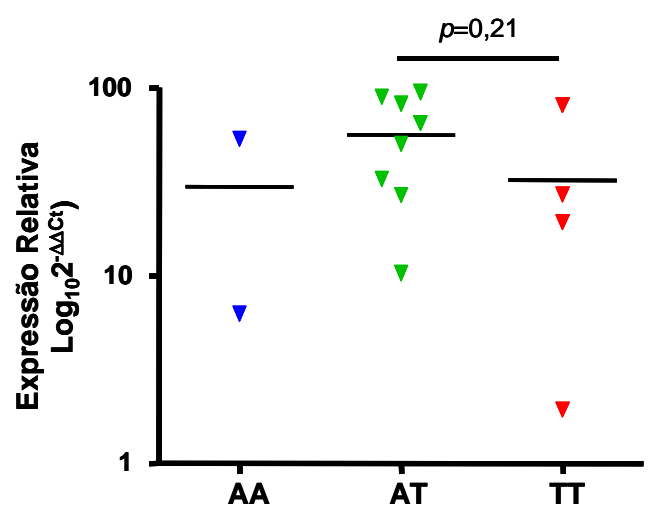

Grau IV

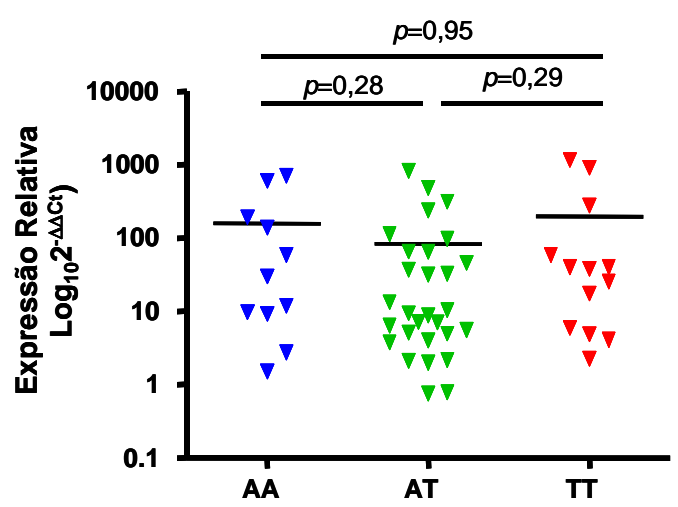

Grau II + III + IV

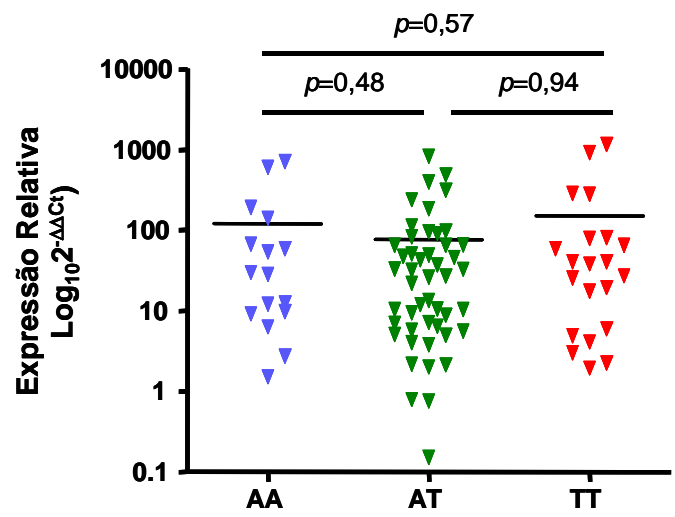

Figura 30: Expressão relativa de EGFR nos genótipos do polimorfismo c.2073 $A>T$ de EGFR em astrocitomas de diferentes graus de malignidade. 


\section{5 - Análise da sobrevida com relação ao genótipo}

Foi realizada análise para estabelecer a relação entre o tempo de sobrevida dos pacientes após ressecção cirúrgica e os genótipos dos diferentes polimorfismos analisados. Essa análise foi feita em pacientes com GBM.

As Figuras 31 a 34 apresentam os resultados das curvas de KaplanMeier dos pacientes com GBM em associação dos genótipos ou cada genótipo em separado. Não foi verificada correlação dos genótipos com a sobrevida dos pacientes. 

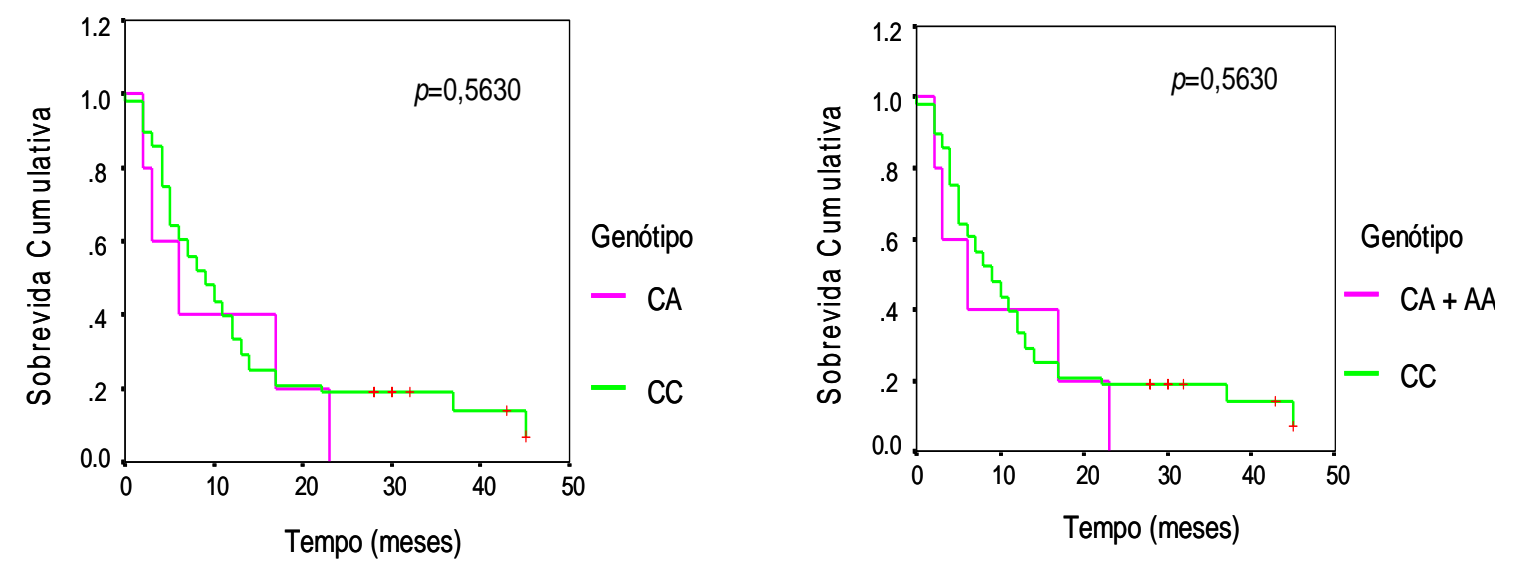

Figura 31: Kaplan-Meier dos casos de GBM no polimorfismo c.-191 C>A do EGFR.
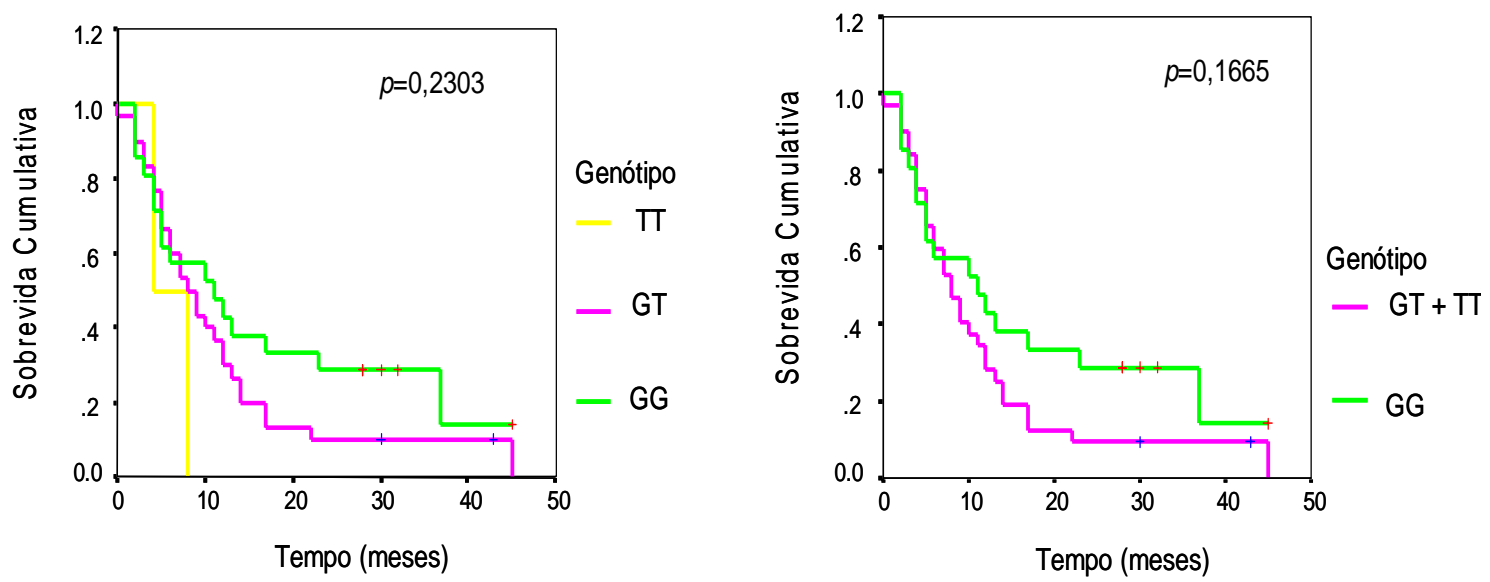

Figura 32: Kaplan-Meier dos casos de GMB no polimorfismo c.-216 G>T do EGFR. 
Resultados
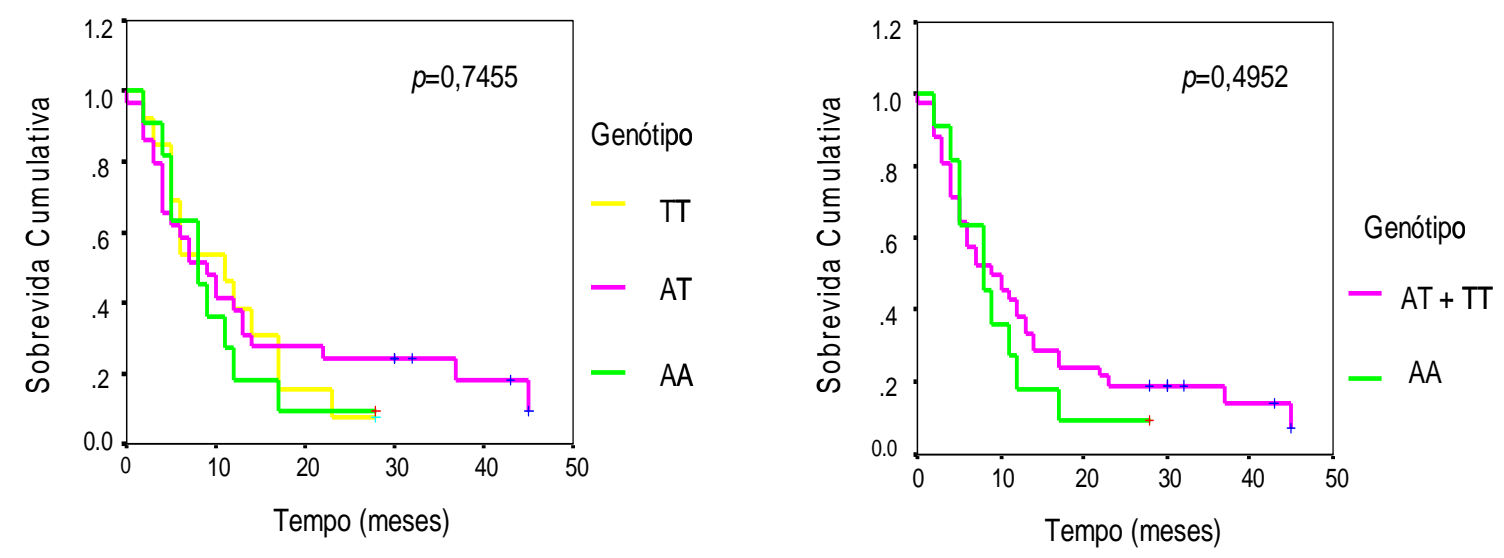

Figura 33: Kaplan-Meier dos casos de GBM no polimorfismo c.2073A>T do EGFR.
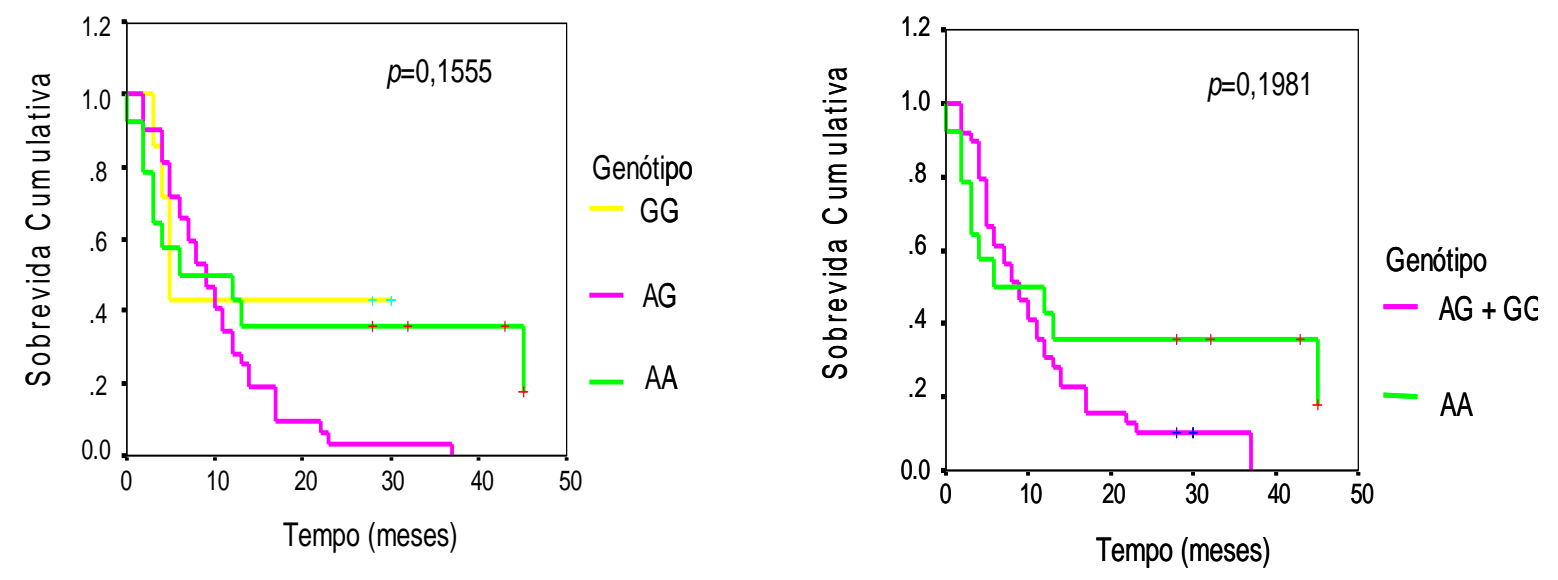

Figura 34: Kaplan-Meier dos casos de GBM no polimorfismo c.61 A>G do EGF. 


\section{5 - Discussão}

A comparação dos genótipos dos polimorfismos dos genes EGFR e EGF em pacientes com astrocitomas difusamente infiltrativos e controles mostrou que somente o polimorfismo c.2073 A>T do EGFR está associado com este tipo de câncer. Pacientes com genótipo TT apresentaram menor risco para desenvolver astrocitoma do que os com genótipo AA.

Para os outros polimorfismos analisados, (c.191C>A, c.216G>T, c. $61 \mathrm{~A}>\mathrm{G}$ ) não foram observadas diferenças significativas na distribuição dos genótipos entre os grupos de casos e de controles. 


\section{1 - Polimorfismos da Região Não Traduzida de EGFR}

O estudo dos polimorfismos c.-191C>A e c.-216G>T não revelou associação destes polimorfismos com expressão de EGFR e o tempo de sobrevida dos pacientes em nossa casuística. Uma possível explicação para esse resultado é a baixa freqüência dos genótipos AA (c.-191C>A) e TT (c.216G >T) na população estudada. Um aumento da casuística poderia ajudar na melhor análise da distribuição dos genótipos destes polimorfismos nos casos e controles.

Bandrés et al. (2006) analisaram 78 casos de pacientes da Espanha com tumor de cabeça e pescoço e não observaram associação dos genótipos destes polimorfismos com características clínicas, patológicas e de mortalidade, resultados semelhantes aos do presente estudo. A freqüência dos genótipos AA do polimorfismo c.-191C>A e TT do polimorfismo c.-216G >T encontrada nos pacientes espanhóis também foi baixa (10\% e $3 \%$, respectivamente).

Liu et al. (2005) descreveram pela primeira vez estes dois SNPs na região reguladora 5' do gene do EGFR (c.-216G>T e c.-191C>A) localizados em regiões essenciais de ligação de fatores para início da transcrição, sendo a região -216 localizada em um sítio de reconhecimento de Sp1. O principal papel de Sp1 na atividade promotora do EGFR já foi descrito (Ishii et al.,1985; Kageyama et al., 1988; Xu et al., 1993; Grinstein et al., 2002), sendo este fator de transcrição necessário para a ativação da região promotora de EGFR (Nomura et al., 2007 ; Merlino et al., 1985). 
Polimorfismos na região promotora, portanto, podem influenciar na atividade promotora do gene e, conseqüentemente, na expressão de EGFR. Liu et al. (2005) analisaram linhagens celulares e verificaram que os haplótipos -216T e -191C apresentam uma maior expressão de EGFR quando comparado com o haplótipo -216G e -191C.

Nomura et al. (2007) estudaram a freqüência dos polimorfismos c.191C>A e c.-216G>T em 556 casos de câncer de pulmão e comparou com 556 indivíduos normais de diversas etnias (336 asiáticos, 213 europeus, e 7 indivíduos de outras etnias). Os autores encontraram diferenças entre a freqüência dos polimorfismos e sua região de ocorrência, sendo o c.216G >T (GT e TT) e c.-191C>A (CA e AA) menos freqüentes em asiáticos que em europeus. Adicionalmente, um estudo in vitro, demonstrou um aumento da expressão do gene EGFR em culturas com os genótipos GT ou TT do polimorfismo c.-216G>T. Porém, nenhuma correlação entre os genótipos destes polimorfismos e a expressão do gene EGFR foi encontrada em câncer de cólon (Spindler et al., 2006), semelhante aos dados do presente estudo.

Em relação à associação do polimorfismo com a sobrevida, Nomura et al. (2007) não conseguiram demonstrar relação de nenhum dos dois polimorfismos isoladamente ou em combinação, mesmo ajustando idade, gênero, etnia, tabagismo e tipo histológico do tumor. Entretanto, o polimorfismo c.-216 G>T foi correlacionado com a resposta ao tratamento em pacientes com câncer de cólon; pacientes com alelo $T$ responderam melhor à radioterapia (Spindler et al., 2006). Em um estudo com pacientes 
com câncer de pulmão, Liu et al. (2005) encontraram uma correlação da presença do alelo $\mathrm{T}$ com maior sobrevida dos pacientes, bem como com uma melhor resposta ao tratamento com gefitinib, um inibidor de EGFR (Liu et al., 2007). 


\section{2- Polimorfismo do Exon 16 de EGFR}

Foi observado, no presente estudo, diferenças nas distribuições dos genótipos no polimorfismo c.2073 A>T do gene EGFR entre pacientes com astrocitomas difusamente infiltrativos e os controles. Pacientes com genótipo TT apresentaram menos risco para astrocitoma do que os pacientes com genótipo AA $(O R=0,51$ e IC95\%=0,27-0,99). Entretanto, a análise da sobrevida desses pacientes não mostrou correlação com os diferentes genótipos.

Este polimorfismo foi descrito por Shintani et al. (1999), comparandose queratinócitos normais e tumorais em cultura. $\mathrm{O}$ estudo mostrou que o alelo T estava correlacionado com tumor oral maligno e com a transcrição de um EGFR truncado a nível protéico. O possível mecanismo sugerido pelos autores é o de que a troca de A por T altera o códon da cisteína por um códon de parada prematura, interferindo possivelmente com a estrutura tridimencional do domínio transmembrânico do EGFR e, conseqüentemente, com a expressão de EGF e a função do receptor.

Os dados do presente trabalho mostraram que o genótipo TT é um fator protetor para o desenvolvimento de astrocitoma, possivelmente porque a presença de T na posição 2073 do gene EGFR leva à formação do códon de parada prematura e, como conseqüência, uma proteína truncada, menos funcional, alterando a via de sinalização do EGF e seu receptor. Entretanto, não se observou interferência dos genótipos na expressão do gene EGFR. 
Hsieh et al. (2005) analisaram 122 casos de endometriose, 159 casos de leiomioma e 139 controles normais de etnia chinesa. Os autores observaram que as freqüências dos genótipos e dos alelos foram diferentes nos grupos de endometriose e leiomioma em relação aos controles: maiores porcentagens de genótipos AT e TT foram encontrados nos indivíduos com endometriose e leiomioma comparados com os controles normais. Não houve diferença na distribuição dos genótipos nos grupos com endometriose e leiomioma. Entretanto, os dados não foram confirmados na população japonesa em pacientes com câncer de endométrio (Kitao et al., 2007) e endometriose (Inagaki et al., 2007).

O presente estudo, portanto, apresenta os primeiros dados da distribuição dos genótipos do polimorfismo c.2073A>T do gene EGFR em pacientes com astrocitoma e uma associação com o risco para este tipo de tumor. 


\section{3 - Polimorfismo da Região Não Traduzida de EGF}

O único polimorfismo funcional do gene EGFR consiste na substituição de um G por A na região 5' não traduzida do gene (Shabazi et al., 2002). Há vários trabalhos na literatura que estudaram a associação deste polimorfismo com diferentes tipos de câncer.

Shahbazi et al. (2002) foram os primeiros a identificar este polimorfismo em um estudo caso-controle de melanoma, demonstrando que indivíduos com genótipo GG apresentaram maior risco de desenvolver melanoma quando comparado com aqueles com genótipo AA. Além disso, os autores também mostraram que células de indivíduos homozigotos AA produzem menos EGF do que as de indivíduos homozigotos GG ou heterozigotos AG. Okamoto et al. (2006) confirmaram que o genótipo GG representa um fator de risco para melanoma e para sobrevida comparado com o genótipo AA. Outros estudos em melanoma, entretanto, não confirmaram estes achados (McCarron et al., 2003; Amend et al., 2004; James et al., 2004; Randerson-Moor et al., 2004), e o papel do genótipo de EGF na susceptibilidade ao melanoma ainda não é conclusivo (Howell, 2004).

Os resultados da análise deste polimorfismo em câncer gástrico também são controversos. Hamai et al. (2005) e Jim et al. (2007) encontraram associação do polimorfismo, enquanto que Goto et al. (2005) não confirmaram tal associação. 
Outras análises do papel do polimorfismo c.61 A>G do gene EGF foram realizadas em câncer de pulmão (Kang et al., 2007) e câncer de útero, sem encontrar qualquer associação dos genótipos e risco para estes tumores. Em um estudo recente, entretanto, Tanabe et al. (2008) demonstraram que o alelo G leva a uma maior produção de EGF do que aqueles com alelo A, além de apresentar um maior risco para carcinoma hepatocelular.

Dados controversos também são descritos em GBM. Bhowmick et al. (2004) relataram o papel do polimorfismo ao verificarem que pacientes com genótipo GG ou GA apresentam maiores níveis de EGF nos tumores, além de maior recidiva e menor sobrevida do que pacientes com genótipo AA. Embora Costa et al. (2007) tenham confirmado que o alelo $\mathrm{G}$ confere maior risco para GBMs, os autores não encontraram correlação com a sobrevida. Porém, estes mesmos autores demonstraram que o polimorfismo é funcional com experimentos in vitro de transfecção, ao verificaram que o alelo G leva a uma maior atividade do promotor de EGF. Este dado funcional foi confirmado por Vauleon et al. (2007), porém os autores não confirmaram que o polimorfismo é um fator de risco significante para GBM e que afete a sobrevida dos pacientes.

Os dados do presente estudo não demonstraram correlação entre os genótipos deste polimorfismo e o risco para astrocitoma, bem como com a sobrevida dos pacientes, semelhante aos dados encontrados por Vauleon et al. (2007), cujo trabalho apresenta a maior casuística de GBMs (209 casos), em comparação com os de Browmick et al. (2005) (42 casos) e Costa et al. 
(2007) (79 casos), o que poderia explicar os dados discrepantes. A mesma análise foi realizada no presente estudo somente nos casos de GBMs (129 casos). Não foi encontrada associação dos genótipos e risco para GBM. Não houve, também, correlação com a sobrevida. 


\section{6 - Conclusões}

Os genótipos dos polimorfismos da região não codificadora de EGFR (c.-191C>A e c.-216G>T) e EGF (c.61A>G) não mostraram diferenças entre os casos de astrocitomas e os controles.

O polimorfismo do exon 16 (c.2073 A>T) do gene EGFR apresentou uma distribuição de genótipos diferente entre o grupo de casos e de controles. Pacientes com genótipo TT apresentaram menor risco para astrocitoma do que com genótipo AA.

A análise de sobrevida não mostrou correlação dos genótipos e o tempo de sobrevida dos pacientes com GBM.

Os genótipos do gene EGFR não influenciam os níveis de expressão do gene. 


\begin{tabular}{|c|c|c|c|c|c|c|c|c|c|c|c|c|c|c|}
\hline \multicolumn{15}{|c|}{ Anexo I - Casos de Astrocitomas Difusos } \\
\hline \multirow{4}{*}{ Grupo } & \multirow{4}{*}{ Nome } & \multirow{4}{*}{ Sexo } & \multirow{4}{*}{ Idade } & \multirow{4}{*}{ Nasc } & \multirow{4}{*}{$\begin{array}{l}\text { Sobrevida } \\
\text { (meses) }\end{array}$} & \multirow{4}{*}{ Status } & \multirow{4}{*}{ Óbito } & \multirow{4}{*}{ Cirurgia } & \multirow{4}{*}{ Diag. Patológico } & \multirow{2}{*}{\multicolumn{3}{|c|}{ Polimorfis }} & mo & \multirow{4}{*}{\begin{tabular}{|c|} 
Expressão Relativa \\
EGFR \\
$2^{-\triangle \Delta C T}$
\end{tabular}} \\
\hline & & & & & & & & & & & & & EGF & \\
\hline & & & & & & & & & & \multirow{2}{*}{\begin{tabular}{|c|} 
Exon 16 \\
2073 \\
\end{tabular}} & \multicolumn{2}{|c|}{$\begin{array}{c}\text { Não } \\
\text { Codificadora }\end{array}$} & \multirow{2}{*}{\begin{tabular}{|c|} 
Não Codificadora \\
61 \\
\end{tabular}} & \\
\hline & & & & & & & & & & & -191 & -216 & & \\
\hline AS1 - 0002 & MMF & $\mathrm{F}$ & 49 & $15 / 08 / 52$ & 0 & 1 & $01 / 08 / 02$ & $29 / 07 / 02$ & GBM & TT & $\mathrm{CC}$ & TG & $A A$ & * \\
\hline AS1 - 0003 & SGS & $\mathrm{M}$ & 38 & $26 / 07 / 64$ & 6 & 1 & $08 / 02 / 03$ & $09 / 08 / 02$ & GBM & TT & $\mathrm{CC}$ & GG & $\mathrm{AA}$ & * \\
\hline AS1 - 0005 & VC & $\mathrm{F}$ & 67 & $02 / 09 / 34$ & 20 & 1 & $27 / 04 / 04$ & $13 / 08 / 02$ & GBM & TT & $\mathrm{CC}$ & TG & $A G$ & * \\
\hline AS1 - 0006 & NOG & $\mathrm{F}$ & 52 & $04 / 05 / 50$ & 11 & 1 & $23 / 08 / 03$ & $19 / 09 / 02$ & GBM & AT & $\mathrm{CC}$ & TG & $A G$ & * \\
\hline AS1 - 0008 & $\mathrm{CV}$ & $M$ & 25 & $25 / 09 / 77$ & 34 & 1 & $12 / 08 / 05$ & $09 / 10 / 02$ & GBM & AT & $\mathrm{CC}$ & TG & $\mathrm{AA}$ & * \\
\hline AS1 - 0011 & $\mathrm{AOB}$ & $M$ & 38 & $22 / 10 / 63$ & 59 & 0 & - & $03 / 10 / 02$ & Astrocitoma grau II & AT & $\mathrm{CC}$ & TT & $A G$ & * \\
\hline AS1 - 0013 & JTA & $\mathrm{M}$ & 62 & $02 / 10 / 40$ & 6 & 1 & $15 / 05 / 03$ & $21 / 11 / 02$ & GBM & TT & $\mathrm{CC}$ & GG & $A G$ & * \\
\hline AS1 - 0017 & EMO & $\mathrm{M}$ & 29 & $19 / 06 / 73$ & 2 & 1 & $02 / 02 / 03$ & $11 / 12 / 02$ & Astrocitoma grau II & TT & $\mathrm{CC}$ & TG & $A G$ & * \\
\hline AS1 - 0020 & ARG & $\mathrm{M}$ & 51 & $06 / 02 / 51$ & 12 & 1 & $30 / 01 / 04$ & $17 / 01 / 03$ & GBM & AT & $\mathrm{CC}$ & TG & $\mathrm{AA}$ & * \\
\hline AS1 - 0023 & $A C L$ & $\mathrm{M}$ & 42 & $06 / 05 / 59$ & 70 & 0 & - & $14 / 11 / 01$ & Astrocitoma grau III & TT & $\mathrm{CC}$ & TT & $A G$ & * \\
\hline AS1 - 0027 & AP & $\mathrm{M}$ & 30 & $21 / 06 / 72$ & 12 & 1 & $01 / 04 / 04$ & $14 / 03 / 03$ & Astrocitoma grau III & AT & $\mathrm{CC}$ & GG & $A G$ & * \\
\hline AS1 - 0029 & ER & $M$ & 65 & $02 / 12 / 37$ & 2 & 1 & $20 / 05 / 03$ & $20 / 03 / 03$ & Astrocitoma grau II & $\mathrm{AA}$ & $\mathrm{CC}$ & TG & $A G$ & * \\
\hline AS1 - 0030 & GR & $\mathrm{F}$ & 20 & $06 / 07 / 81$ & 2 & 1 & $12 / 04 / 02$ & $08 / 03 / 02$ & GBM & $\mathrm{AA}$ & $\mathrm{CA}$ & GG & GG & * \\
\hline AS1 - 0031 & CAF & $M$ & 74 & $15 / 02 / 29$ & 3 & 1 & $13 / 07 / 03$ & $02 / 04 / 03$ & GBM & TT & $\mathrm{CC}$ & TG & $A G$ & * \\
\hline AS1 - 0032 & GBS & $\mathrm{M}$ & 61 & $06 / 07 / 41$ & 29 & 1 & $31 / 10 / 05$ & $02 / 04 / 03$ & Astrocitoma grau III & TT & $\mathrm{CA}$ & GG & $A G$ & * \\
\hline AS1 - 0035 & JGN & $M$ & 64 & $06 / 08 / 38$ & 3 & 1 & $22 / 08 / 03$ & $08 / 05 / 03$ & GBM & AT & $\mathrm{CC}$ & GG & GG & * \\
\hline AS1 - 0036 & EGM & $\mathrm{F}$ & 56 & $28 / 10 / 46$ & 3 & 1 & $18 / 08 / 03$ & $23 / 05 / 03$ & GBM & AA & $\mathrm{CA}$ & GG & $A G$ & * \\
\hline AS1 - 0038 & PM & $M$ & 64 & $20 / 03 / 39$ & 9 & 1 & $27 / 02 / 04$ & $29 / 05 / 03$ & GBM & AA & $\mathrm{CC}$ & TG & $A G$ & * \\
\hline AS1 - 0043 & NJS & $\mathrm{M}$ & 39 & $16 / 04 / 64$ & 52 & 0 & - & $26 / 06 / 03$ & Astrocitoma grau II & $\mathrm{AA}$ & $\mathrm{CC}$ & GG & $A G$ & * \\
\hline AS1 - 0044 & MLFS & $\mathrm{F}$ & 76 & $13 / 07 / 27$ & 12 & 1 & $30 / 07 / 04$ & $10 / 07 / 03$ & GBM & TT & $\mathrm{CC}$ & GG & $A G$ & * \\
\hline AS1 - 0046 & MLAO & $\mathrm{F}$ & 45 & $18 / 09 / 57$ & 17 & 1 & $23 / 12 / 04$ & $21 / 07 / 03$ & GBM & $\mathrm{AA}$ & $\mathrm{CC}$ & GG & $\mathrm{AA}$ & * \\
\hline AS1 - 0050 & ILCM & $\mathrm{M}$ & 55 & $16 / 10 / 47$ & 8 & 1 & $18 / 04 / 04$ & $06 / 08 / 03$ & Astrocitoma grau II & AT & $\mathrm{CC}$ & GG & $\mathrm{AA}$ & * \\
\hline AS1 - 0051 & ACPF & $\mathrm{M}$ & 42 & $08 / 09 / 60$ & 49 & 0 & - & $06 / 08 / 03$ & Astrocitoma grau II & AT & $\mathrm{CC}$ & GG & GG & * \\
\hline AS1 - 0052 & $\mathrm{RB}$ & $M$ & 50 & $23 / 05 / 53$ & 17 & 1 & $07 / 01 / 05$ & $20 / 08 / 03$ & GBM & AT & $\mathrm{CC}$ & TG & $A G$ & * \\
\hline
\end{tabular}




\begin{tabular}{|c|c|c|c|c|c|c|c|c|c|c|c|c|c|c|}
\hline \multicolumn{15}{|c|}{ Anexo I (continuação)- Casos de Astrocitomas Difusos } \\
\hline \multirow{4}{*}{2073} & \multirow{4}{*}{-191} & \multirow{4}{*}{-216} & \multirow{4}{*}{61} & \multirow{4}{*}{ Nasc } & \multirow{4}{*}{ Sobrevida (meses) } & \multirow{4}{*}{ Status } & \multirow{4}{*}{ Óbito } & \multirow{4}{*}{ Cirurgia } & \multirow{4}{*}{ Diag. Patológico } & \multicolumn{4}{|c|}{ Polimorfismo } & \multirow{4}{*}{$\begin{array}{c}\text { Expressão Relativa } \\
\text { EGFR } \\
2^{-\Delta \Delta C T} \\
\end{array}$} \\
\hline & & & & & & & & & & \multirow{3}{*}{\begin{tabular}{|c|} 
Exon 16 \\
2073 \\
\end{tabular}} & \multicolumn{2}{|l|}{ EGFR } & \multirow{3}{*}{\begin{tabular}{|c|} 
EGF \\
Não Codificadora \\
61 \\
\end{tabular}} & \\
\hline & & & & & & & & & & & \multicolumn{2}{|c|}{$\begin{array}{c}\text { Não } \\
\text { Codificadora }\end{array}$} & & \\
\hline & & & & & & & & & & & -191 & -216 & & \\
\hline AS1 - 0059 & MBG & $M$ & 32 & $01 / 06 / 71$ & 47 & 0 & - & $16 / 10 / 03$ & Astrocitoma grau II & TT & $\mathrm{CC}$ & GG & AA & * \\
\hline AS1 - 0060 & RHS & $\mathrm{F}$ & 41 & $03 / 03 / 62$ & 18 & 1 & $25 / 05 / 05$ & $13 / 11 / 03$ & Astrocitoma grau III & TT & $\mathrm{CC}$ & GG & $A G$ & * \\
\hline AS1 - 0068 & FAL & $M$ & 25 & $04 / 07 / 78$ & 45 & 0 & - & $04 / 12 / 03$ & Astrocitoma grau III & AA & $\mathrm{CA}$ & TG & AA & * \\
\hline AS1- 0080 & MVB & $\mathrm{M}$ & 56 & $10 / 04 / 47$ & 37 & 1 & $11 / 02 / 07$ & $30 / 01 / 04$ & Astrocitoma grau III & AT & $\mathrm{CC}$ & TG & AA & * \\
\hline AS1- 0081 & CRP & $M$ & 47 & $09 / 01 / 57$ & 15 & 1 & $14 / 05 / 05$ & $22 / 01 / 04$ & GBM & AT & $\mathrm{CC}$ & GG & AA & * \\
\hline AS1- 0086 & AS & $\mathrm{M}$ & 54 & $29 / 08 / 49$ & 0 & 1 & $05 / 05 / 04$ & $16 / 04 / 04$ & GBM & AT & $\mathrm{CC}$ & GG & AA & * \\
\hline AS1- 0094 & JSC & $M$ & 51 & $14 / 11 / 52$ & 6 & 1 & $14 / 10 / 04$ & $15 / 04 / 04$ & GBM & TT & $\mathrm{CA}$ & GG & AA & * \\
\hline AS1- 0111 & RDS & $M$ & 40 & $15 / 05 / 64$ & 10 & 1 & $30 / 06 / 05$ & $25 / 08 / 04$ & Astrocitoma grau III & AA & $\mathrm{CA}$ & GG & $A G$ & * \\
\hline AS1- 0122 & PLC & $M$ & 49 & $04 / 08 / 55$ & 13 & 1 & $02 / 01 / 06$ & $29 / 11 / 04$ & GBM & TT & $\mathrm{CC}$ & GG & $A G$ & * \\
\hline AS2 - 0001 & $\mathrm{AOC}$ & $\mathrm{F}$ & 46 & $15 / 11 / 55$ & 12 & 1 & $20 / 07 / 03$ & $26 / 06 / 02$ & GBM & AT & $\mathrm{CC}$ & TG & $A G$ & * \\
\hline AS2 - 0002 & OSF & $\mathrm{F}$ & 67 & $02 / 02 / 35$ & 6 & 1 & $11 / 02 / 03$ & $16 / 07 / 02$ & GBM & $\mathrm{TT}$ & $\mathrm{CC}$ & TG & AA & * \\
\hline AS2 - 0004 & JRV & $\mathrm{M}$ & 40 & $05 / 11 / 62$ & 12 & 1 & $19 / 08 / 03$ & $08 / 08 / 02$ & GBM & $\mathrm{TT}$ & $\mathrm{CC}$ & TT & AA & * \\
\hline AS2 - 0010 & $\mathrm{JB}$ & $M$ & 44 & $01 / 04 / 58$ & 63 & 0 & - & $27 / 06 / 02$ & Astrocitoma grau II & AT & $\mathrm{CC}$ & GG & $A G$ & * \\
\hline AS2 - 0011 & MM & $\mathrm{M}$ & 62 & $23 / 03 / 40$ & 60 & 0 & - & $11 / 09 / 02$ & GBM & AT & $\mathrm{CC}$ & GG & $A G$ & * \\
\hline AS2 - 0012 & GLS & $\mathrm{F}$ & 71 & $04 / 12 / 30$ & 11 & 1 & $14 / 08 / 03$ & $19 / 09 / 02$ & GBM & AT & $\mathrm{CC}$ & GG & $A G$ & * \\
\hline AS2 - 0013 & MAGP & $\mathrm{F}$ & 44 & $14 / 02 / 58$ & 34 & 1 & $01 / 05 / 05$ & $25 / 07 / 02$ & Astrocitoma grau II & AT & $\mathrm{CC}$ & GG & $A G$ & * \\
\hline AS2 - 0015 & WJG & $M$ & 61 & $03 / 05 / 41$ & 19 & 1 & $01 / 08 / 04$ & $28 / 01 / 03$ & GBM & AT & $\mathrm{CA}$ & TG & $A G$ & * \\
\hline AS2 - 0016 & AV & $\mathrm{M}$ & 69 & $22 / 01 / 34$ & 19 & 1 & 09/10/04 & $13 / 03 / 03$ & GBM & AT & $\mathrm{CC}$ & TG & $A G$ & * \\
\hline AS2 - 0031 & JTFN & $M$ & 39 & $06 / 11 / 63$ & 35 & 1 & $09 / 02 / 06$ & $27 / 03 / 03$ & Astrocitoma grau III & TT & $\mathrm{CC}$ & GG & $A G$ & * \\
\hline AS2 - 0038 & $J R L$ & $M$ & 32 & $18 / 08 / 70$ & 9 & 1 & $24 / 01 / 04$ & $29 / 04 / 03$ & Astrocitoma grau III & TT & $\mathrm{CC}$ & TG & $A A$ & * \\
\hline AS2 - 0039 & ISS & $M$ & 55 & $15 / 03 / 48$ & 9 & 1 & $03 / 02 / 04$ & $08 / 05 / 03$ & GBM & AT & $\mathrm{CC}$ & GG & $A G$ & * \\
\hline AS2 - 0046 & ARM & $\mathrm{F}$ & 71 & $07 / 07 / 31$ & 0 & 1 & $03 / 06 / 03$ & $29 / 05 / 03$ & GBM & $\mathrm{TT}$ & $\mathrm{CC}$ & TG & $A G$ & * \\
\hline AS2 - 0054 & MLSB & $\mathrm{F}$ & 78 & $17 / 09 / 24$ & 12 & 1 & $31 / 07 / 04$ & $23 / 07 / 03$ & GBM & AA & $\mathrm{CC}$ & GG & $A G$ & * \\
\hline AS2 - 0059 & FML & $M$ & 32 & $23 / 05 / 79$ & 36 & 1 & $31 / 10 / 06$ & $16 / 10 / 03$ & GBM & AT & $\mathrm{CC}$ & TG & $A G$ & * \\
\hline AS2 - 0060 & JBV & $M$ & 47 & $23 / 06 / 56$ & 3 & 1 & $19 / 01 / 04$ & $30 / 10 / 03$ & GBM & TT & $\mathrm{CC}$ & GG & $A G$ & * \\
\hline AS2 - 0068 & MAFS & $\mathrm{F}$ & 64 & $06 / 11 / 39$ & 11 & 1 & 29/12/04 & $29 / 01 / 04$ & GBM & $\mathrm{TT}$ & $\mathrm{CC}$ & TG & $A G$ & * \\
\hline
\end{tabular}




\begin{tabular}{|c|c|c|c|c|c|c|c|c|c|c|c|c|c|c|}
\hline \multicolumn{15}{|c|}{ Anexo I (continuação)- Casos de Astrocitomas Difusos } \\
\hline \multirow{4}{*}{ Grupo } & \multirow{4}{*}{ Nome } & \multirow{4}{*}{ Sexo } & \multirow{4}{*}{ Idade } & \multirow{4}{*}{ Nasc } & \multirow{4}{*}{ Sobrevida (meses) } & \multirow{4}{*}{ Status } & \multirow{4}{*}{ Óbito } & \multirow{4}{*}{ Cirurgia } & \multirow{4}{*}{ Diag. Patológico } & \multicolumn{4}{|c|}{ Polimorfismo } & \multirow{4}{*}{$\begin{array}{c}\text { Expressão Relativa } \\
\text { EGFR } \\
2^{-\Delta \Delta C T} \\
\end{array}$} \\
\hline & & & & & & & & & & \multicolumn{3}{|c|}{ EGFR } & \multirow{3}{*}{\begin{tabular}{|c|} 
EGF \\
Não Codificadora \\
61 \\
\end{tabular}} & \\
\hline & & & & & & & & & & \multirow{2}{*}{\begin{tabular}{|c|} 
Exon 16 \\
2073 \\
\end{tabular}} & \multicolumn{2}{|c|}{$\begin{array}{c}\text { Não } \\
\text { Codificadora }\end{array}$} & & \\
\hline & & & & & & & & & & & -191 & -216 & & \\
\hline AS2 - 0069 & $J A B$ & $\mathrm{~F}$ & 54 & $02 / 10 / 49$ & 3 & 1 & $13 / 05 / 04$ & $18 / 02 / 04$ & GBM & AA & $\mathrm{CC}$ & GG & AA & * \\
\hline AS2 - 0072 & TVF & $M$ & 36 & $27 / 09 / 67$ & 42 & 0 & - & $09 / 03 / 04$ & GBM & AT & $\mathrm{CA}$ & GG & $A G$ & * \\
\hline AS2 - 0073 & LMF & $\mathrm{F}$ & 68 & $05 / 11 / 35$ & 16 & 1 & $14 / 07 / 05$ & $18 / 03 / 04$ & GBM & TT & $\mathrm{CC}$ & TG & AA & * \\
\hline AS2 - 0074 & RAP & $M$ & 42 & $15 / 08 / 61$ & 11 & 1 & $24 / 02 / 05$ & $17 / 03 / 04$ & Astrocitoma grau III & AT & $\mathrm{CC}$ & TG & $A G$ & * \\
\hline AS2 - 0075 & JAP & $\mathrm{M}$ & 66 & $13 / 10 / 37$ & 6 & 1 & 01/10/04 & $26 / 03 / 04$ & GBM & $\mathrm{TT}$ & $\mathrm{CC}$ & GG & $A G$ & * \\
\hline AS2 - 0078 & $\mathrm{JD}$ & $M$ & 63 & $23 / 06 / 40$ & 3 & 1 & $13 / 08 / 04$ & 06/05/04 & GBM & $\mathrm{TT}$ & $\mathrm{CC}$ & TG & AA & * \\
\hline AS2 - 0079 & MARM & $\mathrm{F}$ & 50 & $24 / 04 / 54$ & 5 & 1 & $03 / 11 / 04$ & $12 / 05 / 04$ & GBM & AT & $\mathrm{CC}$ & TG & AA & * \\
\hline AS2 - 0080 & MJC & $\mathrm{M}$ & 38 & $13 / 01 / 66$ & 16 & 1 & $14 / 10 / 05$ & $26 / 05 / 04$ & Astrocitoma grau II & AT & $\mathrm{CC}$ & GG & $A G$ & * \\
\hline AS2 - 0081 & AFLL & $\mathrm{F}$ & 50 & $18 / 12 / 53$ & 13 & 1 & $01 / 08 / 05$ & $22 / 06 / 04$ & GBM & AT & $\mathrm{CA}$ & TG & AA & * \\
\hline AS2 - 0082 & DF & $M$ & 69 & $24 / 06 / 35$ & 5 & 1 & $06 / 01 / 05$ & $04 / 08 / 04$ & GBM & AT & $\mathrm{CC}$ & GG & $A G$ & * \\
\hline AS2 - 0083 & HFL & $M$ & 18 & $01 / 09 / 85$ & 5 & 1 & $16 / 01 / 05$ & $29 / 07 / 04$ & GBM & TT & AA & GG & $A G$ & * \\
\hline AS2 - 0085 & ERS & $\mathrm{M}$ & 31 & $26 / 10 / 43$ & 3 & 1 & $16 / 02 / 05$ & $14 / 11 / 04$ & GBM & $\mathrm{TT}$ & $\mathrm{CC}$ & GG & $A G$ & * \\
\hline AS2 - 0086 & FDP & $M$ & 66 & $20 / 02 / 38$ & 4 & 1 & $15 / 03 / 05$ & $25 / 10 / 04$ & GBM & AT & $\mathrm{CC}$ & GG & AA & * \\
\hline AS2 - 0087 & ECMS & $\mathrm{F}$ & 28 & $25 / 07 / 76$ & 35 & 0 & - & $27 / 10 / 04$ & Astrocitoma grau II & $\mathrm{TT}$ & $\mathrm{CC}$ & TG & $A G$ & * \\
\hline AS3 - 0001 & AMM & $\mathrm{M}$ & 43 & $13 / 09 / 58$ & 65 & 0 & - & $01 / 04 / 02$ & Astrocitoma grau II & AT & $\mathrm{CC}$ & TG & $A G$ & 21,57 \\
\hline AS3 - 0002 & AMC & $\mathrm{F}$ & 46 & $02 / 08 / 55$ & 24 & 1 & $30 / 07 / 03$ & $23 / 07 / 01$ & Astrocitoma grau II & AT & $\mathrm{CC}$ & GG & $A G$ & 10,38 \\
\hline AS3 - 0003 & $A C$ & $\mathrm{M}$ & 32 & $27 / 12 / 69$ & 7 & 1 & $21 / 10 / 02$ & \begin{tabular}{|l|}
$08 / 03 / 02$ \\
\end{tabular} & Astrocitoma grau III & TT & $\mathrm{CC}$ & GG & $A G$ & 80,50 \\
\hline AS3 - 0004 & $\mathrm{BCJ}$ & $\mathrm{F}$ & 47 & $20 / 12 / 54$ & 17 & 1 & $27 / 09 / 03$ & $19 / 04 / 02$ & GBM & $\mathrm{TT}$ & $\mathrm{CC}$ & TG & $A G$ & 276,47 \\
\hline AS3 - 0005 & ESB & $M$ & 19 & $02 / 09 / 82$ & 76 & 0 & - & 03/05/01 & Astrocitoma grau III & $A A$ & $\mathrm{CC}$ & GG & $A G$ & * \\
\hline AS3 - 0006 & GAB & $M$ & 54 & $27 / 06 / 67$ & 83 & 0 & - & $30 / 10 / 00$ & Astrocitoma grau III & AT & $\mathrm{CC}$ & GG & $A G$ & 50,25 \\
\hline AS3 - 0007 & GSP & $\mathrm{M}$ & 11 & $31 / 08 / 90$ & 68 & 0 & - & $02 / 01 / 02$ & GBM & $\mathrm{TT}$ & $\mathrm{CC}$ & GG & $A G$ & * \\
\hline AS3 - 0008 & GPJ & $M$ & 37 & $25 / 08 / 65$ & 60 & 0 & - & $23 / 09 / 02$ & Astrocitoma grau III & AT & $\mathrm{CA}$ & TG & $A G$ & 81,91 \\
\hline AS3 - 0009 & JS & $\mathrm{M}$ & 74 & $17 / 06 / 28$ & 12 & 1 & $23 / 08 / 03$ & $30 / 08 / 02$ & GBM & TT & $\mathrm{CC}$ & TG & $A G$ & 58,32 \\
\hline AS3 - 0010 & JNO & $\mathrm{F}$ & 24 & $25 / 10 / 77$ & 75 & 0 & - & $04 / 06 / 01$ & Astrocitoma grau II & AT & $\mathrm{CC}$ & GG & $A G$ & 392,35 \\
\hline AS3 - 0011 & LKH & $\mathrm{F}$ & 37 & $21 / 01 / 65$ & 14 & 1 & $14 / 10 / 03$ & $05 / 08 / 02$ & Astrocitoma grau III & AA & $\mathrm{CC}$ & GG & $A A$ & 53,11 \\
\hline AS3 - 0012 & MPS & $M$ & 54 & $25 / 11 / 47$ & 46 & 1 & $25 / 09 / 04$ & $24 / 11 / 00$ & GBM & AT & $\mathrm{CC}$ & TG & $A A$ & 6,95 \\
\hline
\end{tabular}




\begin{tabular}{|c|c|c|c|c|c|c|c|c|c|c|c|c|c|c|}
\hline \multicolumn{15}{|c|}{ Anexo I (continuação)- Casos de Astrocitomas Difusos } \\
\hline \multirow{4}{*}{ Grupo } & \multirow{4}{*}{ Nome } & \multirow{4}{*}{ Sexo } & \multirow{4}{*}{ Idade } & \multirow{4}{*}{ Nasc } & \multirow{4}{*}{ Sobrevida (meses) } & \multirow{4}{*}{ Status } & \multirow{4}{*}{ Óbito } & \multirow{4}{*}{ Cirurgia } & \multirow{4}{*}{ Diag. Patológico } & \multicolumn{4}{|c|}{ Polimorfismo } & \multirow{3}{*}{$\begin{array}{c}\text { Expressão Relativa } \\
\text { EGFR } \\
2^{-\Delta \Delta \mathrm{CT}} \\
\end{array}$} \\
\hline & & & & & & & & & & \multicolumn{3}{|c|}{ EGFR } & \multirow{3}{*}{\begin{tabular}{|c|} 
EGF \\
Não Codificadora \\
61
\end{tabular}} & \\
\hline & & & & & & & & & & \multirow{2}{*}{\begin{tabular}{|c|} 
Exon 16 \\
2073 \\
\end{tabular}} & \multicolumn{2}{|c|}{$\begin{array}{c}\text { Não } \\
\text { Codificadora }\end{array}$} & & \\
\hline & & & & & & & & & & & -191 & -216 & & \\
\hline AS3 - 0013 & NV & $M$ & 63 & $05 / 07 / 39$ & 15 & 1 & $27 / 10 / 03$ & $01 / 07 / 02$ & GBM & AT & $\mathrm{CC}$ & $\mathrm{TG}$ & $A G$ & * \\
\hline AS3 - 0014 & ML & $M$ & 28 & $04 / 12 / 73$ & 32 & 1 & $04 / 12 / 05$ & $23 / 03 / 01$ & Astrocitoma grau II & AA & $\mathrm{CC}$ & TG & AA & 67,00 \\
\hline AS3 - 0015 & $\mathrm{CHR}$ & $\mathrm{M}$ & 39 & $18 / 04 / 63$ & 62 & 0 & - & $17 / 07 / 02$ & Astrocitoma grau II & AT & $\mathrm{CC}$ & TG & $A G$ & 0,15 \\
\hline AS3 - 0016 & RTP & $M$ & 23 & $03 / 06 / 79$ & 61 & 0 & - & $15 / 08 / 02$ & Astrocitoma grau II & TT & $\mathrm{CC}$ & TG & AA & 2,99 \\
\hline AS3 - 0017 & WCS & $M$ & 15 & $20 / 04 / 87$ & 61 & 0 & - & $19 / 08 / 02$ & Astrocitoma grau III & $\mathrm{TT}$ & $\mathrm{CC}$ & TG & $A G$ & 1,93 \\
\hline AS3 - 0018 & ISCK & $\mathrm{F}$ & 32 & $04 / 07 / 70$ & 60 & 0 & - & $13 / 09 / 02$ & Astrocitoma grau III & AT & $\mathrm{CA}$ & TG & $A G$ & 32,70 \\
\hline AS3 - 0019 & WAS & $M$ & 45 & $12 / 07 / 57$ & 14 & 1 & $04 / 11 / 03$ & $27 / 09 / 02$ & GBM & AT & $\mathrm{CC}$ & $\mathrm{TG}$ & $A G$ & 13,32 \\
\hline AS3 - 0020 & CSS & $M$ & 45 & $27 / 04 / 57$ & 5 & 1 & $14 / 03 / 03$ & $25 / 10 / 02$ & GBM & AT & $\mathrm{CC}$ & TG & $A G$ & 64,49 \\
\hline AS3 - 0021 & IPP & $\mathrm{F}$ & 54 & $16 / 03 / 48$ & 13 & 1 & $06 / 12 / 03$ & $07 / 11 / 02$ & GBM & TT & $\mathrm{CC}$ & TG & $A G$ & 4,07 \\
\hline AS3 - 0022 & ARV & $\mathrm{F}$ & 38 & $09 / 05 / 64$ & 58 & 0 & - & $11 / 11 / 02$ & Astrocitoma grau II & AA & AA & GG & $A A$ & 12,39 \\
\hline AS3 - 0023 & MVC & $\mathrm{F}$ & 40 & $22 / 11 / 62$ & 14 & 1 & $22 / 01 / 04$ & $18 / 11 / 02$ & GBM & $\mathrm{TT}$ & $\mathrm{CC}$ & TG & $A G$ & 907,65 \\
\hline AS3 - 0024 & MCS & $\mathrm{F}$ & 58 & $08 / 12 / 43$ & 5 & 1 & $30 / 04 / 03$ & $20 / 11 / 02$ & GBM & $\mathrm{TT}$ & $\mathrm{CC}$ & GG & $A G$ & 2,22 \\
\hline AS3 - 0025 & DS & $M$ & 54 & $13 / 10 / 48$ & 5 & 1 & $18 / 04 / 03$ & $29 / 11 / 02$ & GBM & AT & $\mathrm{CC}$ & TG & $A G$ & * \\
\hline AS3 - 0026 & PMP & $\mathrm{F}$ & 19 & $02 / 01 / 83$ & 23 & 1 & $28 / 09 / 04$ & $28 / 10 / 02$ & Astrocitoma grau III & AT & $\mathrm{CC}$ & GG & AA & * \\
\hline AS3 - 0027 & ASCS & $\mathrm{F}$ & 61 & $25 / 06 / 41$ & 13 & 1 & $15 / 02 / 04$ & 08/01/03 & GBM & TT & $\mathrm{CC}$ & GG & $A G$ & * \\
\hline AS3 - 0028 & AJS & $\mathrm{F}$ & 51 & $11 / 11 / 51$ & 5 & 1 & $13 / 07 / 03$ & $23 / 01 / 03$ & GBM & AA & $\mathrm{CC}$ & TG & $A G$ & 9,10 \\
\hline AS3 - 0029 & MJO & $\mathrm{F}$ & 71 & $22 / 12 / 30$ & 2 & 1 & $15 / 09 / 02$ & $24 / 06 / 02$ & GBM & AT & $\mathrm{CC}$ & TG & $A G$ & 3,99 \\
\hline AS3 - 0030 & VAS & $\mathrm{F}$ & 36 & $14 / 03 / 66$ & 16 & 1 & $12 / 10 / 03$ & $10 / 06 / 02$ & GBM & AT & $\mathrm{CC}$ & TG & $A G$ & * \\
\hline AS3 - 0031 & APC & $M$ & 56 & $01 / 02 / 46$ & 0 & 1 & $27 / 06 / 02$ & \begin{tabular}{|l|}
$05 / 06 / 02$ \\
\end{tabular} & GBM & TT & $\mathrm{CA}$ & GG & $A G$ & * \\
\hline AS3 - 0032 & MMLP & $\mathrm{F}$ & 46 & $24 / 10 / 54$ & 3 & 1 & $11 / 09 / 02$ & $28 / 05 / 02$ & GBM & AT & $\mathrm{CC}$ & TG & $A G$ & * \\
\hline AS3 - 0033 & MCE & $\mathrm{F}$ & 78 & $14 / 06 / 23$ & 12 & 1 & $02 / 05 / 03$ & $23 / 05 / 02$ & GBM & AA & $\mathrm{CC}$ & TG & $A G$ & 598,83 \\
\hline AS3 - 0034 & $\mathrm{OE}$ & $\mathrm{M}$ & 60 & $02 / 08 / 41$ & 14 & 1 & $17 / 07 / 03$ & \begin{tabular}{|l|}
$09 / 05 / 02$ \\
\end{tabular} & GBM & $A A$ & $\mathrm{CC}$ & GG & $A G$ & * \\
\hline AS3 - 0035 & ASM & $M$ & 52 & $27 / 05 / 49$ & 3 & 1 & $04 / 08 / 02$ & $30 / 04 / 02$ & GBM & $\mathrm{TT}$ & $\mathrm{CC}$ & GG & $A G$ & * \\
\hline AS3 - 0036 & ELAD & $\mathrm{F}$ & 65 & $28 / 02 / 37$ & 0 & 1 & $18 / 04 / 02$ & $12 / 04 / 02$ & GBM & AT & $\mathrm{CC}$ & TG & $A A$ & 479,70 \\
\hline AS3 - 0037 & CDS & $M$ & 41 & $25 / 11 / 60$ & 2 & 1 & $14 / 06 / 02$ & $21 / 03 / 02$ & GBM & $\mathrm{TT}$ & $\mathrm{CC}$ & GG & $A G$ & 39,97 \\
\hline AS3 - 0038 & MGSJ & $\mathrm{F}$ & 24 & $18 / 06 / 77$ & 44 & 1 & $18 / 11 / 05$ & $15 / 03 / 02$ & Astrocitoma grau II & AT & $\mathrm{CC}$ & TG & AA & 46,56 \\
\hline
\end{tabular}




\begin{tabular}{|c|c|c|c|c|c|c|c|c|c|c|c|c|c|c|}
\hline \multicolumn{15}{|c|}{ Anexo I (continuação)- Casos de Astrocitomas Difusos } \\
\hline \multirow{4}{*}{ Grupo } & \multirow{4}{*}{ Nome } & \multirow{4}{*}{ Sexo } & \multirow{4}{*}{ Idade } & \multirow{4}{*}{ Nasc } & \multirow{4}{*}{ Sobrevida (meses) } & \multirow{4}{*}{ Status } & \multirow{4}{*}{ Óbito } & \multirow{4}{*}{ Cirurgia } & \multirow{4}{*}{ Diag. Patológico } & \multicolumn{4}{|c|}{ Polimorfismo } & \multirow{4}{*}{$\begin{array}{c}\text { Expressão Relativa } \\
\text { EGFR } \\
2^{-\Delta \Delta C T}\end{array}$} \\
\hline & & & & & & & & & & \multirow{3}{*}{\begin{tabular}{|c|} 
Exon 16 \\
2073 \\
\end{tabular}} & \multicolumn{2}{|c|}{ EGFR } & \multirow{3}{*}{\begin{tabular}{|c|} 
EGF \\
Não Codificadora \\
61 \\
\end{tabular}} & \\
\hline & & & & & & & & & & & \multicolumn{2}{|c|}{$\begin{array}{c}\text { Não } \\
\text { Codificadora }\end{array}$} & & \\
\hline & & & & & & & & & & & -191 & -216 & & \\
\hline AS3 - 0039 & MBC & $\mathrm{F}$ & 30 & $25 / 08 / 71$ & 13 & 1 & $22 / 04 / 03$ & $11 / 03 / 02$ & Astrocitoma grau II & AT & $\mathrm{CC}$ & TG & GG & 5,66 \\
\hline AS3 - 0040 & JRA & $\mathrm{M}$ & 56 & $25 / 07 / 45$ & 67 & 0 & - & $22 / 02 / 02$ & Astrocitoma grau II & AT & $\mathrm{CA}$ & GG & $A G$ & 182,40 \\
\hline AS3 - 0041 & OAA & $\mathrm{F}$ & 58 & $12 / 07 / 43$ & 1 & 1 & $16 / 03 / 02$ & $15 / 02 / 02$ & Astrocitoma grau III & TT & $\mathrm{CA}$ & TG & $A G$ & 19,17 \\
\hline AS3 - 0042 & MRC & $\mathrm{F}$ & 67 & $02 / 10 / 34$ & 4 & 1 & $10 / 06 / 02$ & $18 / 01 / 02$ & GBM & $\mathrm{AA}$ & $\mathrm{CC}$ & TG & GG & 138,24 \\
\hline AS3 - 0043 & EFC & $\mathrm{M}$ & 62 & 09/08/39 & 6 & 1 & $24 / 07 / 02$ & $04 / 01 / 02$ & GBM & AT & $\mathrm{CC}$ & TG & $A G$ & 4,93 \\
\hline AS3 - 0044 & $B L$ & $\mathrm{~F}$ & 71 & $01 / 10 / 39$ & 7 & 1 & 06/08/02 & $21 / 12 / 01$ & GBM & AT & $\mathrm{CC}$ & TG & $A G$ & 8,70 \\
\hline AS3 - 0045 & MRPS & $\mathrm{F}$ & 49 & $01 / 01 / 30$ & 31 & 1 & $02 / 07 / 04$ & $14 / 12 / 01$ & GBM & TT & $\mathrm{CC}$ & TG & $\mathrm{AA}$ & * \\
\hline AS3 - 0046 & OB & $\mathrm{M}$ & 71 & $29 / 05 / 30$ & 22 & 1 & 01/10/03 & $30 / 11 / 01$ & GBM & AT & $\mathrm{CC}$ & TG & $A G$ & 311,05 \\
\hline AS3 - 0047 & MTC & $\mathrm{F}$ & 56 & $07 / 04 / 45$ & 5 & 1 & $31 / 03 / 02$ & $26 / 10 / 01$ & GBM & $\mathrm{AA}$ & $\mathrm{CC}$ & TG & $A G$ & 2,72 \\
\hline AS3 - 0048 & ACO & $\mathrm{M}$ & 50 & $20 / 06 / 51$ & 7 & 1 & $10 / 06 / 02$ & $19 / 10 / 01$ & GBM & AT & $\mathrm{CC}$ & TG & $A G$ & 5,08 \\
\hline AS3 - 0049 & MJAS & $\mathrm{F}$ & 49 & $30 / 11 / 52$ & 38 & 1 & $21 / 06 / 04$ & $26 / 04 / 01$ & GBM & AT & $\mathrm{CC}$ & GG & $A G$ & 45,44 \\
\hline AS3 - 0050 & UC & $M$ & 75 & $25 / 10 / 26$ & 17 & 1 & $29 / 08 / 02$ & $19 / 03 / 01$ & GBM & TT & $\mathrm{CA}$ & GG & $A G$ & 1152,86 \\
\hline AS3 - 0051 & MCV & $\mathrm{F}$ & 25 & $08 / 04 / 76$ & 77 & 1 & $19 / 03 / 07$ & $16 / 03 / 01$ & Astrocitoma grau III & AT & $\mathrm{CA}$ & GG & $A G$ & 89,33 \\
\hline AS3 - 0052 & NNS & $\mathrm{M}$ & 36 & $20 / 06 / 67$ & 32 & 1 & 01/08/06 & $13 / 05 / 03$ & Astrocitoma grau II & TT & $\mathrm{CC}$ & TG & $A G$ & 64,49 \\
\hline AS3 - 0053 & MGCJ & $\mathrm{M}$ & 19 & $06 / 09 / 82$ & 82 & 0 & - & $20 / 11 / 00$ & Astrocitoma grau III & AT & $\mathrm{CC}$ & TG & $\mathrm{AA}$ & 94,75 \\
\hline AS3 - 0054 & JCPS & $\mathrm{M}$ & 34 & $11 / 0468$ & 11 & 1 & $05 / 02 / 04$ & $07 / 02 / 03$ & GBM & $\mathrm{AA}$ & $\mathrm{CC}$ & GG & $A G$ & 704,77 \\
\hline AS3 - 0055 & MSS & $\mathrm{M}$ & 68 & $12 / 05 / 34$ & 4 & 1 & $18 / 06 / 03$ & $17 / 02 / 03$ & GBM & AT & $\mathrm{CC}$ & GG & $\mathrm{AA}$ & 31,36 \\
\hline AS3 - 0056 & VRS & $\mathrm{M}$ & 56 & $11 / 10 / 46$ & 23 & 1 & $28 / 05 / 05$ & $10 / 06 / 03$ & GBM & TT & $\mathrm{CA}$ & GG & $A G$ & 4,86 \\
\hline AS3 - 0058 & CMT & $\mathrm{F}$ & 61 & $26 / 08 / 41$ & 14 & 1 & $13 / 05 / 04$ & $06 / 03 / 03$ & GBM & AT & $\mathrm{CC}$ & TG & $A G$ & 10,35 \\
\hline AS3 - 0059 & VAP & $\mathrm{F}$ & 41 & $15 / 08 / 62$ & 28 & 1 & $23 / 03 / 06$ & $13 / 11 / 03$ & GBM & AT & $\mathrm{CC}$ & GG & $A G$ & * \\
\hline AS3 - 0060 & JOJ & $\mathrm{M}$ & 28 & $23 / 12 / 74$ & 54 & 0 & - & $11 / 03 / 03$ & Astrocitoma grau II & TT & $\mathrm{CC}$ & TG & AA & 78,30 \\
\hline AS3 - 0061 & MAA & $\mathrm{M}$ & 60 & $23 / 04 / 42$ & 3 & 1 & $15 / 07 / 03$ & $16 / 03 / 03$ & GBM & TT & $\mathrm{CA}$ & TG & $\mathrm{AA}$ & 25,47 \\
\hline AS3 - 0062 & MRS & $\mathrm{M}$ & 41 & $15 / 11 / 61$ & 54 & 0 & - & $10 / 03 / 03$ & Astrocitoma grau II & AT & $\mathrm{CC}$ & TG & $A G$ & 48,20 \\
\hline AS3 - 0063 & MAM & $\mathrm{F}$ & 41 & $25 / 10 / 61$ & 30 & 1 & $06 / 09 / 06$ & $27 / 03 / 03$ & Astrocitoma grau II & $A A$ & $\mathrm{CC}$ & TG & $A G$ & 28,07 \\
\hline AS3 - 0064 & ASM & $\mathrm{M}$ & 38 & $12 / 11 / 66$ & 21 & 1 & $12 / 01 / 05$ & $11 / 04 / 03$ & Astrocitoma grau III & AT & $\mathrm{CA}$ & GG & $A G$ & 10,31 \\
\hline AS3 - 0065 & GP & $\mathrm{F}$ & 17 & $06 / 02 / 86$ & 4 & 1 & $15 / 10 / 03$ & $23 / 05 / 03$ & GBM & AT & $\mathrm{CC}$ & TT & $A G$ & 111,89 \\
\hline
\end{tabular}




\begin{tabular}{|c|c|c|c|c|c|c|c|c|c|c|c|c|c|c|}
\hline \multicolumn{15}{|c|}{ Anexo I (continuação)- Casos de Astrocitomas Difusos } \\
\hline \multirow{4}{*}{ Grupo } & \multirow{4}{*}{ Nome } & \multirow{4}{*}{ Sexo } & \multirow{4}{*}{ Idade } & \multirow{4}{*}{ Nasc } & \multirow{4}{*}{ Sobrevida (meses) } & \multirow{4}{*}{ Status } & \multirow{4}{*}{ Óbito } & \multirow{4}{*}{ Cirurgia } & \multirow{4}{*}{ Diag. Patológico } & \multicolumn{4}{|c|}{ Polimorfismo } & \multirow{4}{*}{$\begin{array}{c}\text { Expressão Relativa } \\
\text { EGFR } \\
2^{-\Delta \Delta C T}\end{array}$} \\
\hline & & & & & & & & & & \multirow{3}{*}{\begin{tabular}{|c|} 
Exon 16 \\
2073 \\
\end{tabular}} & \multicolumn{2}{|l|}{ EGFR } & \multirow{3}{*}{\begin{tabular}{|c|} 
EGF \\
Não Codificadora \\
61 \\
\end{tabular}} & \\
\hline & & & & & & & & & & & \multicolumn{2}{|c|}{$\begin{array}{c}\text { Não } \\
\text { Cofificadora } \\
\end{array}$} & & \\
\hline & & & & & & & & & & & -191 & -216 & & \\
\hline AS3 - 0066 & JRF & $\mathrm{M}$ & 63 & $17 / 07 / 39$ & 2 & 1 & $25 / 08 / 03$ & $02 / 06 / 03$ & GBM & $\mathrm{AA}$ & $\mathrm{CC}$ & TG & $A G$ & 9,65 \\
\hline AS3 - 0067 & AAS & $M$ & 29 & $04 / 08 / 73$ & 57 & 0 & - & $19 / 12 / 02$ & Astrocitoma grau III & AT & $\mathrm{CC}$ & GG & $A G$ & 26,74 \\
\hline AS3 - 0068 & LZ & $\mathrm{M}$ & 45 & $07 / 03 / 58$ & 10 & 1 & $28 / 12 / 04$ & $16 / 02 / 04$ & GBM & AT & $\mathrm{CC}$ & TG & $A G$ & 9,36 \\
\hline AS3 - 0069 & MFC & $M$ & 48 & $20 / 05 / 55$ & 12 & 1 & $20 / 07 / 04$ & $27 / 06 / 03$ & GBM & AT & $\mathrm{CC}$ & GG & AA & 5,53 \\
\hline AS3 - 0070 & ZFR & $\mathrm{F}$ & 59 & $05 / 11 / 43$ & 8 & 1 & $11 / 03 / 04$ & $30 / 06 / 03$ & GBM & $\mathrm{AA}$ & $\mathrm{CC}$ & TT & $A G$ & 29,57 \\
\hline AS3 - 0071 & SASC & $\mathrm{F}$ & 57 & $30 / 10 / 45$ & 8 & 1 & $25 / 01 / 04$ & $22 / 05 / 03$ & GBM & $\mathrm{AA}$ & $\mathrm{CC}$ & TG & $A G$ & 188,84 \\
\hline AS3 - 0072 & ASS & $M$ & 67 & $18 / 02 / 36$ & 6 & 1 & $30 / 11 / 03$ & $01 / 05 / 03$ & GBM & TT & CA & GG & $\mathrm{AA}$ & 17,28 \\
\hline AS3 - 0073 & LFF & $\mathrm{M}$ & 37 & $10 / 11 / 65$ & 51 & 0 & - & $16 / 06 / 03$ & Astrocitoma grau III & TT & $\mathrm{CA}$ & GG & $A G$ & 26,93 \\
\hline AS3 - 0074 & AA & $M$ & 71 & $15 / 08 / 31$ & 13 & 1 & $15 / 09 / 04$ & $31 / 07 / 03$ & GBM & AT & $\mathrm{CC}$ & GG & $A A$ & 0,75 \\
\hline AS3 - 0075 & ATO & $\mathrm{M}$ & 39 & $10 / 12 / 63$ & 4 & 1 & $19 / 10 / 03$ & $13 / 06 / 03$ & GBM & TT & $\mathrm{CC}$ & GG & $A G$ & * \\
\hline AS3 - 0076 & VFC & $\mathrm{M}$ & 47 & $12 / 03 / 48$ & 2 & 1 & $28 / 01 / 04$ & $20 / 11 / 03$ & GBM & AT & $\mathrm{CC}$ & GG & $\mathrm{AA}$ & 2,11 \\
\hline AS3 - 0077 & EM & $M$ & 50 & $14 / 11 / 52$ & 9 & 1 & 04/06/04 & $03 / 09 / 03$ & GBM & AT & $\mathrm{CC}$ & $\mathrm{TG}$ & $A G$ & 6,35 \\
\hline AS3 - 0078 & RNN & $\mathrm{F}$ & 35 & $08 / 10 / 67$ & 48 & 0 & - & 09/05/03 & Astrocitoma grau II & TT & $\mathrm{CC}$ & GG & $A G$ & 282,28 \\
\hline AS3 - 0079 & MRKMB & $\mathrm{F}$ & 41 & $01 / 10 / 62$ & 48 & 0 & - & $24 / 09 / 03$ & GBM & AT & $\mathrm{CC}$ & GG & $\mathrm{AA}$ & 3,75 \\
\hline AS3 - 0080 & ERL & $\mathrm{M}$ & 58 & $25 / 09 / 45$ & 9 & 1 & $15 / 12 / 04$ & $27 / 02 / 04$ & GBM & $\mathrm{AA}$ & $\mathrm{CC}$ & TG & $A G$ & 1,50 \\
\hline AS3 - 0081 & JRSR & $M$ & 68 & $12 / 05 / 35$ & 16 & 1 & $04 / 05 / 05$ & $12 / 12 / 03$ & GBM & AT & $\mathrm{CC}$ & GG & $A G$ & * \\
\hline AS3 - 0082 & NDT & $\mathrm{M}$ & 43 & $18 / 12 / 60$ & 17 & 1 & $04 / 05 / 05$ & $21 / 11 / 03$ & GBM & $\mathrm{AA}$ & $\mathrm{CC}$ & TG & $A G$ & 11,88 \\
\hline AS3 - 0083 & SMGN & $\mathrm{F}$ & 40 & $14 / 04 / 63$ & 44 & 0 & - & $29 / 01 / 04$ & GBM & TT & $\mathrm{CC}$ & TG & AA & * \\
\hline AS3 - 0084 & AFP & $\mathrm{M}$ & 66 & $11 / 12 / 37$ & 8 & 1 & 06/08/04 & $05 / 12 / 03$ & GBM & TT & $\mathrm{CC}$ & TG & $\mathrm{AA}$ & * \\
\hline AS3 - 0085 & JLS & $M$ & 64 & $25 / 06 / 38$ & 14 & 1 & $15 / 01 / 05$ & $11 / 11 / 03$ & GBM & AT & $\mathrm{CC}$ & TG & $A A$ & 0,78 \\
\hline AS3 - 0086 & LPS & $\mathrm{F}$ & 59 & $12 / 12 / 44$ & 5 & 1 & $13 / 05 / 04$ & $26 / 03 / 04$ & GBM & TT & $\mathrm{CC}$ & GG & GG & 5,88 \\
\hline AS3 - 0087 & ADM & $\mathrm{F}$ & 56 & $15 / 12 / 47$ & 3 & 1 & $15 / 05 / 04$ & $12 / 02 / 04$ & GBM & AT & $\mathrm{CC}$ & TG & $\mathrm{AA}$ & 36,53 \\
\hline AS3 - 0088 & AOE & $\mathrm{F}$ & 27 & $26 / 10 / 76$ & 9 & 1 & $10 / 01 / 05$ & $22 / 03 / 04$ & Astrocitoma grau II & AT & $\mathrm{CC}$ & GG & $A G$ & 25,74 \\
\hline AS3 - 0089 & MAP & $\mathrm{F}$ & 38 & $21 / 03 / 64$ & 80 & 0 & - & $02 / 01 / 01$ & Astrocitoma grau II & AT & $\mathrm{CC}$ & TG & $A G$ & 11,84 \\
\hline AS3 - 0090 & $\mathrm{JCN}$ & $\mathrm{M}$ & 38 & $15 / 06 / 76$ & 10 & 1 & $18 / 07 / 05$ & $22 / 08 / 04$ & GBM & AT & $\mathrm{CC}$ & GG & $A G$ & 96,74 \\
\hline AS3 - 0091 & BMJ & $\mathrm{F}$ & 66 & $31 / 12 / 36$ & 4 & 1 & $06 / 05 / 04$ & $08 / 12 / 03$ & GBM & $A A$ & $\mathrm{CA}$ & GG & GG & * \\
\hline
\end{tabular}




\begin{tabular}{|c|c|c|c|c|c|c|c|c|c|c|c|c|c|c|}
\hline \multicolumn{15}{|c|}{ Anexo I (continuação)- Casos de Astrocitomas Difusos } \\
\hline \multirow{4}{*}{ Grupo } & \multirow{4}{*}{ Nome } & \multirow{4}{*}{ Sexo } & \multirow{4}{*}{ Idade } & \multirow{4}{*}{ Nasc } & \multirow{4}{*}{ Sobrevida (meses) } & \multirow{4}{*}{ Status } & \multirow{4}{*}{ Óbito } & \multirow{4}{*}{ Cirurgia } & \multirow{4}{*}{ Diag. Patológico } & \multicolumn{4}{|c|}{ Polimorfismo } & \multirow{3}{*}{$\begin{array}{c}\text { Expressão Relativa } \\
\text { EGFR } \\
2^{-\Delta \Delta C T} \\
\end{array}$} \\
\hline & & & & & & & & & & \multirow{3}{*}{\begin{tabular}{|c|} 
Exon 16 \\
2073 \\
\end{tabular}} & \multicolumn{2}{|c|}{ EGFR } & \multirow{3}{*}{\begin{tabular}{|c|} 
EGF \\
Não Codificadora \\
61 \\
\end{tabular}} & \\
\hline & & & & & & & & & & & \multicolumn{2}{|c|}{$\begin{array}{c}\text { Não } \\
\text { Codificadora } \\
\end{array}$} & & \\
\hline & & & & & & & & & & & -191 & -216 & & \\
\hline AS3 - 0092 & FCRN & $M$ & 58 & $04 / 10 / 80$ & 56 & 0 & - & $24 / 01 / 03$ & Astrocitoma grau III & AT & $\mathrm{CC}$ & TG & $A G$ & 64,71 \\
\hline AS3 - 0093 & ESM & $M$ & 39 & $08 / 02 / 65$ & 37 & 0 & - & 05/08/04 & Astrocitoma grau II & AT & $\mathrm{CA}$ & TG & $A G$ & 42,40 \\
\hline AS3 - 0094 & ACB & $\mathrm{M}$ & 64 & $10 / 02 / 40$ & 6 & 1 & $08 / 04 / 05$ & $14 / 10 / 04$ & GBM & AT & $\mathrm{CC}$ & TG & $A G$ & * \\
\hline AS3 - 0095 & GFS & $M$ & 45 & $17 / 06 / 58$ & 35 & 0 & - & $27 / 10 / 04$ & GBM & AT & $\mathrm{CC}$ & GG & AA & 823,71 \\
\hline AS3 - 0096 & JBF & $\mathrm{M}$ & 49 & $25 / 01 / 55$ & 4 & 1 & $22 / 04 / 05$ & $07 / 12 / 04$ & GBM & AT & $\mathrm{CC}$ & GG & $A G$ & 236,55 \\
\hline AS3 - 0097 & IS & $M$ & 34 & $21 / 12 / 69$ & 1 & 1 & $14 / 01 / 05$ & $16 / 07 / 04$ & GBM & AT & $\mathrm{CC}$ & TG & GG & 2,14 \\
\hline AS3 - 0098 & ILR & $\mathrm{F}$ & 52 & $15 / 01 / 52$ & 28 & 1 & $08 / 04 / 07$ & $10 / 12 / 04$ & GBM & AT & $\mathrm{CC}$ & TG & GG & 65,16 \\
\hline AS3 - 0099 & AM & $M$ & 61 & $27 / 07 / 43$ & 3 & 1 & $18 / 03 / 05$ & $02 / 12 / 04$ & GBM & AT & $\mathrm{CC}$ & GG & GG & 7,09 \\
\hline AS3 - 0100 & SRS & $\mathrm{M}$ & 31 & $14 / 07 / 72$ & 41 & 0 & - & $27 / 04 / 04$ & Astrocitoma grau III & $\mathrm{AA}$ & $\mathrm{CA}$ & GG & $A G$ & 6,26 \\
\hline AS3 - 0101 & NR & $M$ & 51 & $23 / 09 / 52$ & 6 & 1 & $25 / 11 / 04$ & $13 / 05 / 04$ & GBM & TT & $\mathrm{CC}$ & TG & $A G$ & 39,97 \\
\hline AS3 - 0102 & MCF & $\mathrm{F}$ & 58 & $27 / 11 / 46$ & 22 & 1 & $15 / 10 / 06$ & $14 / 12 / 04$ & GBM & AT & $\mathrm{CC}$ & GG & $\mathrm{AA}$ & * \\
\hline AS3 - 0103 & $A G$ & $M$ & 60 & $19 / 08 / 44$ & 3 & 1 & $12 / 02 / 05$ & $22 / 10 / 04$ & GBM & AT & $\mathrm{CC}$ & GG & GG & 1,99 \\
\hline AS3 - 0104 & GMS & $\mathrm{M}$ & 16 & $07 / 11 / 88$ & 2 & 1 & $12 / 03 / 05$ & $05 / 01 / 05$ & GBM & AT & $\mathrm{CA}$ & GG & $A A$ & 32,47 \\
\hline AS3 - 0105 & MRS & $\mathrm{M}$ & 45 & $01 / 01 / 59$ & 7 & 1 & $03 / 07 / 05$ & $23 / 12 / 04$ & GBM & AT & $\mathrm{CC}$ & TG & $\mathrm{AA}$ & * \\
\hline AS3 - 0106 & PMO & $M$ & 40 & $08 / 09 / 64$ & 13 & 1 & $22 / 03 / 06$ & $25 / 02 / 05$ & GBM & AA & $\mathrm{CC}$ & GG & AA & 58,12 \\
\hline AS3 - 0107 & ASA & $M$ & 26 & $01 / 10 / 78$ & 30 & 0 & - & $03 / 03 / 05$ & GBM & TT & $\mathrm{CC}$ & GG & GG & 37,69 \\
\hline AS3 - 0108 & PGO & $M$ & 64 & $23 / 02 / 41$ & 13 & 1 & $18 / 04 / 06$ & $18 / 03 / 05$ & GBM & TT & $\mathrm{CC}$ & GG & $A G$ & * \\
\hline AS3 - 0109 & AS & $\mathrm{F}$ & 65 & $07 / 04 / 40$ & 5 & 1 & $28 / 10 / 05$ & $13 / 05 / 05$ & GBM & AT & $\mathrm{CC}$ & GG & $A G$ & * \\
\hline AS3 - 0110 & DGS & $\mathrm{F}$ & 68 & $25 / 03 / 37$ & 4 & 1 & $30 / 11 / 05$ & $17 / 07 / 05$ & GBM & AT & $\mathrm{CC}$ & GG & $A G$ & * \\
\hline AS3 - 0111 & GSS & $M$ & 56 & $08 / 02 / 49$ & 22 & 1 & $29 / 11 / 06$ & $11 / 01 / 05$ & GBM & AT & $\mathrm{CC}$ & TG & $A G$ & * \\
\hline AS3 - 0112 & MMC & $\mathrm{M}$ & 40 & $29 / 01 / 65$ & 8 & 1 & $04 / 10 / 05$ & $15 / 07 / 05$ & GBM & TT & $\mathrm{CC}$ & GG & $A G$ & * \\
\hline AS3 - 0113 & ALOB & $\mathrm{F}$ & 38 & $07 / 08 / 67$ & 17 & 1 & $12 / 03 / 06$ & $22 / 07 / 05$ & Astrocitoma grau II & AT & $\mathrm{CC}$ & TG & $A G$ & * \\
\hline AS3 - 0114 & MAPL & $\mathrm{F}$ & 38 & $25 / 10 / 66$ & 32 & 0 & - & $25 / 07 / 05$ & GBM & AT & $\mathrm{CC}$ & TG & AA & * \\
\hline AS3 - 0115 & JWMS & $M$ & 26 & $19 / 08 / 79$ & 32 & 0 & - & $12 / 07 / 05$ & Astrocitoma grau II & AT & $\mathrm{CC}$ & TG & AA & * \\
\hline AS3 - 0116 & EMN & $M$ & 28 & $15 / 10 / 76$ & 28 & 0 & - & $18 / 05 / 05$ & Astrocitoma grau III & TT & $\mathrm{CC}$ & TG & $A G$ & * \\
\hline
\end{tabular}




\begin{tabular}{|c|c|c|c|c|c|c|c|c|c|c|c|c|c|c|}
\hline \multicolumn{15}{|c|}{ Anexo I (continuação)- Casos de Astrocitomas Difusos } \\
\hline \multirow{4}{*}{ Grupo } & \multirow{4}{*}{ Nome } & \multirow{4}{*}{ Sexo } & \multirow{4}{*}{ Idade } & \multirow{4}{*}{ Nasc } & \multirow{4}{*}{ Sobrevida (meses) } & \multirow{4}{*}{ Status } & \multirow{4}{*}{ Óbito } & \multirow{4}{*}{ Cirurgia } & \multirow{4}{*}{ Diag. Patológico } & \multicolumn{4}{|c|}{ Polimorfismo } & \multirow{3}{*}{$\begin{array}{c}\text { Expressão Relativa } \\
\text { EGFR } \\
2^{-\Delta \Delta C T}\end{array}$} \\
\hline & & & & & & & & & & \multicolumn{3}{|c|}{ EGFR } & \multirow{3}{*}{\begin{tabular}{|c|} 
EGF \\
Não Codificadora \\
61 \\
\end{tabular}} & \\
\hline & & & & & & & & & & \multirow{2}{*}{\begin{tabular}{|c|} 
Exon 16 \\
2073 \\
\end{tabular}} & \multicolumn{2}{|c|}{$\begin{array}{c}\text { Não } \\
\text { Codificadora } \\
\end{array}$} & & \\
\hline & & & & & & & & & & & -191 & -216 & & \\
\hline AS3 - 0117 & FD & $\mathrm{M}$ & 57 & $25 / 10 / 47$ & 14 & 1 & $28 / 01 / 06$ & $10 / 06 / 05$ & GBM & AT & $\mathrm{CC}$ & GG & GG & * \\
\hline AS3 - 0118 & JS & $\mathrm{M}$ & 63 & $11 / 03 / 42$ & 3 & 1 & $02 / 11 / 05$ & $05 / 08 / 05$ & GBM & AT & $\mathrm{CC}$ & GG & $A G$ & * \\
\hline AS3 - 0119 & ES & $\mathrm{M}$ & 36 & $12 / 06 / 69$ & 25 & 0 & - & $01 / 08 / 05$ & Astrocitoma grau II & AA & $\mathrm{CC}$ & TG & AA & * \\
\hline AS3 - 0120 & MDT & $\mathrm{F}$ & 46 & $19 / 07 / 59$ & 2 & 1 & $12 / 12 / 05$ & $10 / 09 / 05$ & Astrocitoma grau III & AT & $\mathrm{CC}$ & GG & $A G$ & * \\
\hline AS3 - 0121 & ANS & $\mathrm{F}$ & 29 & $02 / 06 / 76$ & 24 & 0 & - & $08 / 09 / 05$ & Astrocitoma grau III & AT & $\mathrm{CC}$ & GG & GG & * \\
\hline AS3 - 0122 & ILO & $\mathrm{M}$ & 33 & $25 / 07 / 73$ & 30 & 0 & - & $12 / 03 / 05$ & GBM & TT & $\mathrm{CC}$ & TG & GG & * \\
\hline AS3 - 0123 & AJ & $M$ & 56 & $18 / 04 / 51$ & 6 & 1 & $07 / 07 / 06$ & $13 / 01 / 06$ & GBM & AT & $\mathrm{CC}$ & GG & GG & * \\
\hline AS3 - 0124 & $\mathrm{RP}$ & $\mathrm{F}$ & 69 & $26 / 12 / 38$ & 20 & 0 & - & 10.01 .06 & GBM & $\mathrm{TT}$ & $\mathrm{CC}$ & TG & AA & * \\
\hline AS3 - 0125 & VMP & $M$ & 56 & 04.01 .51 & 7 & 1 & $28 / 08 / 06$ & 16.01 .06 & GBM & $\mathrm{TT}$ & $\mathrm{CC}$ & TG & AA & * \\
\hline AS3 - 0126 & JAS & $\mathrm{M}$ & 62 & 07.01 .45 & 19 & 0 & - & 17.02 .06 & GBM & AT & $\mathrm{CA}$ & GG & AA & * \\
\hline AS3 - 0127 & JPS & $M$ & 34 & 08.12 .73 & 19 & 0 & - & 10.02 .06 & Astrocitoma grau II & AT & $\mathrm{CC}$ & TG & $A G$ & * \\
\hline AS3 - 0128 & WJGS & $\mathrm{M}$ & 58 & 05.09 .49 & 11 & 1 & $01 / 09 / 07$ & 03.02 .06 & GBM & AT & $\mathrm{CC}$ & GG & GG & * \\
\hline AS3 - 0129 & MGSA & $\mathrm{F}$ & 34 & 06.03 .73 & 19 & 0 & - & 07.02 .06 & Astrocitoma grau II & AA & $\mathrm{CC}$ & TG & $A G$ & * \\
\hline
\end{tabular}

Status: $0=$ vivo $1=$ morto

Tempo de Sobrevida em meses atualizada até 09/2007 


\begin{tabular}{|c|c|c|c|c|c|c|c|c|}
\hline \multicolumn{9}{|c|}{ Anexo II - Controles } \\
\hline \multirow{3}{*}{ Grupo } & \multirow{3}{*}{ Nome } & \multirow{3}{*}{ Sexo } & \multirow{3}{*}{ Idade } & \multirow{3}{*}{ Nasc } & \multicolumn{3}{|c|}{ EGFR } & \multirow{3}{*}{$\begin{array}{c}\text { EGF } \\
\text { Não Codificadora } \\
61 \\
\end{array}$} \\
\hline & & & & & \multirow{2}{*}{$\begin{array}{c}\text { Exon } 16 \\
2073 \\
\end{array}$} & \multicolumn{2}{|c|}{ Não Codificadora } & \\
\hline & & & & & & -191 & -216 & \\
\hline AS1/0004 & TFRM & $\mathrm{F}$ & 69 & $12 / 04 / 1933$ & $\mathrm{TT}$ & $\mathrm{CC}$ & TG & $A G$ \\
\hline AS1/0007 & MCM & $\mathrm{F}$ & 42 & $10 / 02 / 1960$ & $\mathrm{TT}$ & $\mathrm{CC}$ & TG & GG \\
\hline AS1/0009 & FAK & $M$ & 23 & 09/11/1978 & AT & $\mathrm{CC}$ & $\mathrm{TG}$ & AA \\
\hline AS1/0010 & NLS & M & 37 & 06/06/1965 & $\mathrm{TT}$ & $\mathrm{CC}$ & $\mathrm{TT}$ & $\mathrm{AA}$ \\
\hline AS1/0012 & PMS & M & 36 & 29/06/1966 & TT & $\mathrm{CC}$ & GG & $A G$ \\
\hline AS1/0016 & AEC & $\mathrm{M}$ & 62 & $30 / 07 / 1940$ & AT & $\mathrm{CA}$ & GG & $\mathrm{AA}$ \\
\hline AS1/0022 & ASB & M & 30 & $16 / 07 / 1972$ & $\mathrm{TT}$ & $\mathrm{CC}$ & GG & $A G$ \\
\hline AS1/0025 & GM & M & 55 & $15 / 05 / 1947$ & AT & $\mathrm{CC}$ & TG & AA \\
\hline AS1/0026 & AP & $\mathrm{F}$ & 38 & 05/07/1964 & TT & $\mathrm{CC}$ & GG & $A G$ \\
\hline AS1/0033 & TT & M & 73 & 03/03/1930 & $A A$ & $\mathrm{CC}$ & GG & $\mathrm{AA}$ \\
\hline AS1/0039 & GSSJ & $\mathrm{M}$ & 43 & $15 / 06 / 1959$ & $\mathrm{TT}$ & $\mathrm{CA}$ & TG & GG \\
\hline AS1/0040 & NS & M & 61 & 03/09/1941 & AT & $\mathrm{CC}$ & GG & GG \\
\hline AS1/0041 & EEF & $M$ & 36 & $12 / 12 / 1966$ & AT & $\mathrm{CC}$ & TG & $A G$ \\
\hline AS1/0047 & MJVS & $\mathrm{F}$ & 48 & $20 / 09 / 1954$ & AA & $\mathrm{CA}$ & GG & $A G$ \\
\hline AS1/0053 & MAG & $M$ & 48 & $13 / 10 / 1954$ & TT & $\mathrm{CC}$ & TG & $A G$ \\
\hline AS1/0064 & AMSL & $\mathrm{F}$ & 39 & $16 / 02 / 1964$ & AT & $\mathrm{CC}$ & GG & $\mathrm{AA}$ \\
\hline AS1/0066 & FPCC & M & 35 & 06/06/1968 & AT & $\mathrm{CC}$ & TG & $A G$ \\
\hline AS1/0070 & JMTS & $\mathrm{M}$ & 51 & $24 / 05 / 1952$ & TT & $\mathrm{CC}$ & TG & $A G$ \\
\hline AS1/0071 & EAS & $\mathrm{M}$ & 32 & $26 / 07 / 1971$ & $\mathrm{TT}$ & $\mathrm{CC}$ & GG & $\mathrm{AA}$ \\
\hline AS1/0072 & ECS & $M$ & 65 & 07/09/1938 & $\mathrm{TT}$ & $\mathrm{CC}$ & GG & $A G$ \\
\hline AS1/0073 & PPS & $M$ & 69 & 20/04/1934 & $\mathrm{TT}$ & $\mathrm{CC}$ & GG & $A G$ \\
\hline AS1/0087 & IBFP & M & 24 & $30 / 03 / 1979$ & AT & $\mathrm{CA}$ & GG & GG \\
\hline AS1/0090 & SDC & $\mathrm{F}$ & 47 & 03/10/1956 & AT & $\mathrm{CC}$ & TT & $A G$ \\
\hline AS1/0121 & FRTS & $\mathrm{M}$ & 61 & 06/08/1943 & $\mathrm{TT}$ & $\mathrm{CC}$ & TG & AA \\
\hline AS1/0124 & DP & $\mathrm{M}$ & 55 & $31 / 12 / 1948$ & AT & AA & GG & AA \\
\hline AS1/0125 & ABB & $\mathrm{F}$ & 77 & 04/10/1927 & AT & $\mathrm{CC}$ & TG & $A G$ \\
\hline AS1/0126 & MCRS & $\mathrm{F}$ & 28 & $21 / 08 / 1976$ & AT & $\mathrm{CC}$ & TG & $\mathrm{AA}$ \\
\hline AS1/0127 & LBA & $\mathrm{M}$ & 28 & $21 / 01 / 1976$ & TT & $\mathrm{CC}$ & TG & $A G$ \\
\hline AS1/0128 & JFA & $M$ & 76 & $15 / 06 / 1928$ & $A A$ & $\mathrm{CC}$ & $\mathrm{TT}$ & $A G$ \\
\hline AS1/0131 & MJLS & $M$ & 25 & $01 / 12 / 1979$ & AT & CA & GG & $A G$ \\
\hline AS1/0132 & FBL & $\mathrm{F}$ & 63 & $22 / 09 / 1941$ & $\mathrm{TT}$ & $\mathrm{CC}$ & GG & $A G$ \\
\hline AS1/0133 & TJS & $\mathrm{F}$ & 76 & $21 / 04 / 1928$ & AT & $\mathrm{CC}$ & GG & $A G$ \\
\hline AS1/0135 & MVS & M & 34 & $20 / 06 / 1970$ & $\mathrm{TT}$ & $\mathrm{CC}$ & GG & $\mathrm{AA}$ \\
\hline AS1/0136 & ws & $\mathrm{M}$ & 59 & $10 / 02 / 1945$ & AT & $\mathrm{CA}$ & TG & $A G$ \\
\hline AS2/0501 & CGCJ & $M$ & 43 & $30 / 05 / 60$ & AT & $\mathrm{CC}$ & TG & AA \\
\hline AS2/0502 & EA & $M$ & 39 & $31 / 03 / 62$ & TT & $\mathrm{CC}$ & TG & $A G$ \\
\hline AS2/0503 & AMFF & $\mathrm{F}$ & 47 & $14 / 01 / 56$ & TT & $\mathrm{CC}$ & TT & $A G$ \\
\hline AS2/0504 & MACS & $\mathrm{M}$ & 47 & $29 / 09 / 55$ & AT & $\mathrm{CC}$ & GG & $A G$ \\
\hline AS2/0505 & IFC & $\mathrm{F}$ & 46 & $01 / 04 / 57$ & AT & $\mathrm{CC}$ & TG & $A G$ \\
\hline AS2/0506 & AARJ & $M$ & 32 & $01 / 03 / 71$ & AA & $\mathrm{CC}$ & TG & $A G$ \\
\hline AS2/0507 & FS & $M$ & 38 & $28 / 10 / 64$ & $\mathrm{TT}$ & $\mathrm{CC}$ & GG & $A G$ \\
\hline AS2/0508 & FOP & $M$ & 35 & $06 / 03 / 68$ & TT & $\mathrm{CC}$ & GG & $A G$ \\
\hline AS2/0509 & RBR & $M$ & 38 & $14 / 05 / 65$ & AT & $\mathrm{CC}$ & TG & $A G$ \\
\hline AS2/0510 & NMLM & $\mathrm{F}$ & 44 & $13 / 01 / 59$ & AT & $\mathrm{CC}$ & GG & $A G$ \\
\hline
\end{tabular}




\begin{tabular}{|c|c|c|c|c|c|c|c|c|}
\hline \multicolumn{9}{|c|}{ Anexo II (continuação) - Controles } \\
\hline \multirow{3}{*}{ Grupo } & \multirow{3}{*}{ Nome } & \multirow{3}{*}{ Sexo } & \multirow{3}{*}{ Idade } & \multirow{3}{*}{ Nasc } & \multicolumn{3}{|c|}{ EGFR } & \multirow{3}{*}{$\begin{array}{c}\text { EGF } \\
\text { Não Codificadora } \\
61 \\
\end{array}$} \\
\hline & & & & & \multirow{2}{*}{$\begin{array}{c}\text { Exon } 16 \\
2073\end{array}$} & \multicolumn{2}{|c|}{ Não Codificadora } & \\
\hline & & & & & & -191 & -216 & \\
\hline AS2/0511 & APL & $M$ & 55 & $01 / 12 / 47$ & AT & $\mathrm{CA}$ & GG & AA \\
\hline AS2/0512 & VAPA & $\mathrm{F}$ & 49 & $28 / 02 / 54$ & AT & $\mathrm{CA}$ & GG & $A G$ \\
\hline AS2/0513 & $\mathrm{s}$ & $M$ & 62 & $10 / 08 / 41$ & AT & $\mathrm{CC}$ & TG & $A G$ \\
\hline AS2/0514 & HJS & $\mathrm{M}$ & 63 & $21 / 06 / 40$ & AT & $\mathrm{CC}$ & TG & $A G$ \\
\hline AS2/0515 & ARP & $\mathrm{F}$ & 66 & $22 / 02 / 37$ & AT & $\mathrm{CC}$ & GG & $A A$ \\
\hline AS2/0516 & DG & $\mathrm{F}$ & 62 & 09/06/41 & AT & $\mathrm{CC}$ & TG & $A G$ \\
\hline AS2/0517 & SB & $M$ & 67 & $25 / 09 / 35$ & TT & $\mathrm{CC}$ & TG & $\mathrm{AA}$ \\
\hline AS2/0518 & MPS & $\mathrm{F}$ & 71 & $22 / 02 / 1932$ & AT & $\mathrm{CC}$ & TG & GG \\
\hline AS2/0519 & ASS & $\mathrm{F}$ & 73 & $12 / 04 / 31$ & $A A$ & $\mathrm{CC}$ & TT & $A G$ \\
\hline AS2/0520 & GPG & $\mathrm{F}$ & 76 & $25 / 07 / 27$ & AA & $\mathrm{CA}$ & TG & $A G$ \\
\hline AS2/0521 & TM & $M$ & 60 & $26 / 08 / 43$ & AA & $\mathrm{CC}$ & GG & AA \\
\hline AS2/0522 & $\mathrm{BIC}$ & $\mathrm{F}$ & 66 & $15 / 08 / 37$ & AT & $\mathrm{CA}$ & GG & $A G$ \\
\hline AS2/0523 & PLO & $M$ & 56 & $29 / 06 / 47$ & AT & $\mathrm{CC}$ & TG & GG \\
\hline AS2/0524 & SRS & $M$ & 37 & $15 / 01 / 66$ & AT & $\mathrm{CC}$ & TT & $A A$ \\
\hline AS2/0525 & HAP & $M$ & 37 & $01 / 11 / 66$ & AT & $\mathrm{CC}$ & TG & $A G$ \\
\hline AS2/0526 & MLGBS & $\mathrm{F}$ & 52 & $18 / 02 / 51$ & AT & $\mathrm{CC}$ & TG & $A G$ \\
\hline AS2/0527 & SOB & $M$ & 42 & $15 / 03 / 61$ & AT & $\mathrm{CC}$ & GG & GG \\
\hline AS2/0528 & ADR & $\mathrm{F}$ & 26 & $26 / 03 / 77$ & AT & $\mathrm{CC}$ & TG & $A G$ \\
\hline AS2/0529 & JLPM & $M$ & 63 & $17 / 05 / 40$ & AT & $\mathrm{CC}$ & TG & GG \\
\hline AS2/0530 & VFM & $M$ & 17 & $28 / 12 / 86$ & $A A$ & $\mathrm{CC}$ & GG & $A G$ \\
\hline AS2/0531 & JAAJ & $M$ & 61 & $17 / 07 / 42$ & TT & $\mathrm{CC}$ & GG & $A G$ \\
\hline AS2/0532 & WGAB & $M$ & 22 & $28 / 09 / 81$ & AT & $\mathrm{CC}$ & TG & $A G$ \\
\hline AS2/0533 & VLT & $\mathrm{F}$ & 47 & $20 / 07 / 53$ & AT & $\mathrm{CC}$ & GG & $A G$ \\
\hline AS2/0534 & $\mathrm{HF}$ & $M$ & 64 & $06 / 02 / 39$ & AT & $\mathrm{CC}$ & GG & $A G$ \\
\hline AS2/0535 & JDB & $M$ & 64 & $29 / 07 / 39$ & AT & $\mathrm{CC}$ & GG & $A G$ \\
\hline AS2/0536 & RTN & $\mathrm{F}$ & 71 & $11 / 02 / 32$ & $\mathrm{TT}$ & $\mathrm{CC}$ & TG & AA \\
\hline AS2/0537 & NS & $M$ & 67 & $05 / 11 / 36$ & AA & $\mathrm{CC}$ & TG & $A G$ \\
\hline СТО/0001 & MAK & $\mathrm{M}$ & 32 & $20 / 09 / 1970$ & TT & $\mathrm{CC}$ & GG & $\mathrm{AA}$ \\
\hline CTO/0003 & FS & $\mathrm{M}$ & 63 & $15 / 07 / 1939$ & AT & $\mathrm{CC}$ & TG & AA \\
\hline CTO/0006 & ALA & $M$ & 54 & $10 / 12 / 1948$ & TT & $\mathrm{CC}$ & GG & $A G$ \\
\hline СТО/0007 & ARG & $\mathrm{M}$ & 17 & $26 / 05 / 1985$ & $\mathrm{TT}$ & $\mathrm{CC}$ & TG & $A G$ \\
\hline СТО/0008 & TMS & M & 58 & 09/02/1944 & $\mathrm{TT}$ & $\mathrm{CC}$ & GG & $\mathrm{AA}$ \\
\hline СТО/0010 & JPC & $\mathrm{M}$ & 63 & 16/11/1939 & AT & $\mathrm{CC}$ & GG & $A G$ \\
\hline СТО/0011 & MZPS & $\mathrm{F}$ & 39 & 03/06/1963 & TT & $\mathrm{CC}$ & TG & AA \\
\hline СТО/0012 & CCA & $\mathrm{F}$ & 46 & $17 / 04 / 1956$ & AT & $\mathrm{CC}$ & TG & $\mathrm{AA}$ \\
\hline Сто/0013 & EAS & $M$ & 35 & $14 / 06 / 1967$ & $\mathrm{TT}$ & $\mathrm{CC}$ & TG & AA \\
\hline СТО/0014 & AFS & $\mathrm{M}$ & 68 & $22 / 06 / 1934$ & $\mathrm{TT}$ & $\mathrm{CC}$ & TG & $\mathrm{AA}$ \\
\hline СТО/0015 & LL & $\mathrm{M}$ & 20 & 07/06/1982 & AT & $\mathrm{CC}$ & TG & GG \\
\hline СТО/0016 & MGA & $\mathrm{F}$ & 38 & $24 / 04 / 1964$ & TT & $\mathrm{CA}$ & GG & $A G$ \\
\hline СТО/0018 & EK & $\mathrm{M}$ & 28 & $15 / 01 / 1974$ & TT & $\mathrm{CC}$ & GG & GG \\
\hline СТО/0024 & JSBM & M & 62 & $29 / 09 / 1940$ & AT & $\mathrm{CA}$ & GG & $A G$ \\
\hline СТО/0026 & JMG & $\mathrm{F}$ & 42 & $01 / 12 / 1960$ & $\mathrm{TT}$ & $\mathrm{CC}$ & GG & $A G$ \\
\hline СТО/0029 & RMRF & $\mathrm{F}$ & 49 & $15 / 01 / 1953$ & AT & $\mathrm{CC}$ & TG & GG \\
\hline СТО/0030 & AF & $\mathrm{F}$ & 47 & $30 / 04 / 1955$ & $\mathrm{TT}$ & $\mathrm{CC}$ & GG & AA \\
\hline СТО/0032 & $A B F$ & M & 45 & 08/04/1957 & $A A$ & $\mathrm{CC}$ & TG & AA \\
\hline
\end{tabular}




\begin{tabular}{|c|c|c|c|c|c|c|c|c|}
\hline \multicolumn{9}{|c|}{ Anexo II (continuação) } \\
\hline \multirow{3}{*}{ Grupo } & \multirow{3}{*}{ Nome } & \multirow{3}{*}{ Sexo } & \multirow{3}{*}{ Idade } & \multirow{3}{*}{ Nasc } & \multicolumn{3}{|c|}{ EGFR } & \multirow{3}{*}{$\begin{array}{c}\text { EGF } \\
\text { Não Codificadora } \\
61 \\
\end{array}$} \\
\hline & & & & & \multirow{2}{*}{$\begin{array}{c}\text { Exon } 16 \\
2073 \\
\end{array}$} & \multicolumn{2}{|c|}{ Não Codificadora } & \\
\hline & & & & & & -191 & 2073 & \\
\hline СТО/0036 & AJS & $\mathrm{M}$ & 54 & $20 / 02 / 1948$ & $\mathrm{TT}$ & $\mathrm{CC}$ & TG & AG \\
\hline СТО/0037 & DTB & $\mathrm{F}$ & 57 & $20 / 06 / 1945$ & $\mathrm{TT}$ & $\mathrm{CC}$ & GG & AA \\
\hline СТО/0038 & CKM & $\mathrm{F}$ & 40 & $13 / 10 / 1962$ & AT & $\mathrm{CC}$ & GG & GG \\
\hline СТО/0039 & MDC & $\mathrm{M}$ & 21 & $11 / 12 / 1981$ & AT & $\mathrm{CC}$ & GG & $A G$ \\
\hline СТО/0046 & ARC & $\mathrm{F}$ & 67 & $23 / 02 / 1935$ & AT & $\mathrm{CC}$ & TG & $A G$ \\
\hline СTO/0047 & JNVS & $M$ & 50 & $17 / 05 / 1952$ & AT & $\mathrm{CC}$ & TG & AA \\
\hline СТО/0048 & SAC & M & 36 & 20/01/1967 & AT & $\mathrm{CC}$ & GG & $A G$ \\
\hline СТО/0052 & AAS & $\mathrm{F}$ & 65 & 10/10/1937 & AT & $\mathrm{CA}$ & GG & $A G$ \\
\hline СТО/0055 & MJLS & $\mathrm{F}$ & 46 & $19 / 03 / 1956$ & AT & $\mathrm{CC}$ & GG & AA \\
\hline СTO/0057 & HRG & M & 42 & $13 / 01 / 1961$ & AT & $\mathrm{CC}$ & TG & $A G$ \\
\hline СТО/0058 & MÊS & $\mathrm{F}$ & 58 & $02 / 07 / 1944$ & AT & $\mathrm{CC}$ & GG & $A G$ \\
\hline СТО/0062 & TMS & $\mathrm{F}$ & 51 & $19 / 08 / 1951$ & AT & $\mathrm{CA}$ & GG & $A G$ \\
\hline СТО/0066 & APP & $M$ & 75 & $12 / 10 / 1927$ & AT & $\mathrm{CC}$ & TG & $A G$ \\
\hline СТО/0067 & ANFA & $\mathrm{F}$ & 25 & $30 / 03 / 1977$ & AT & $\mathrm{CC}$ & TG & $A G$ \\
\hline СТО/0068 & ADA & $\mathrm{M}$ & 33 & 01/03/1969 & $\mathrm{TT}$ & $\mathrm{CC}$ & GG & $\mathrm{AA}$ \\
\hline СТО/0070 & EAA & $M$ & 40 & $14 / 07 / 1962$ & AT & $\mathrm{CC}$ & GG & $A G$ \\
\hline СТО/0071 & CRSO & $M$ & 30 & $22 / 03 / 1972$ & TT & $\mathrm{CC}$ & GG & $A G$ \\
\hline СТО/0074 & MJSR & $\mathrm{F}$ & 62 & $13 / 07 / 1940$ & AT & $\mathrm{CC}$ & TG & $\mathrm{AA}$ \\
\hline СТО/0076 & FPS & $\mathrm{M}$ & 23 & $22 / 03 / 1979$ & AT & $\mathrm{CA}$ & GG & $\mathrm{AA}$ \\
\hline СТО/0078 & MNB & $\mathrm{F}$ & 44 & $14 / 12 / 1958$ & AT & $\mathrm{CC}$ & GG & $A G$ \\
\hline СТО/0080 & FGM & $\mathrm{F}$ & 70 & $13 / 12 / 1932$ & AT & $\mathrm{CC}$ & GG & $\mathrm{AA}$ \\
\hline СТО/0087 & DCS & $M$ & 19 & $31 / 05 / 1983$ & AT & $\mathrm{CC}$ & GG & $A G$ \\
\hline СТО/0088 & JCF & $\mathrm{M}$ & 44 & $16 / 04 / 1958$ & AT & $\mathrm{CC}$ & TG & $\mathrm{AA}$ \\
\hline СТО/0090 & $\mathrm{JCA}$ & $\mathrm{M}$ & 51 & $26 / 07 / 1951$ & $\mathrm{TT}$ & $\mathrm{CC}$ & TG & $A G$ \\
\hline СТО/0092 & AUL & $M$ & 57 & 03/11/1945 & TT & $\mathrm{CA}$ & GG & $A G$ \\
\hline СТО/0098 & MDP & $\mathrm{F}$ & 60 & $14 / 12 / 1942$ & $\mathrm{AA}$ & $\mathrm{CC}$ & GG & $A G$ \\
\hline СТО/0099 & APS & M & 29 & $30 / 10 / 1973$ & AT & $\mathrm{CA}$ & GG & $A G$ \\
\hline СТО/0103 & TLS & $\mathrm{M}$ & 21 & 29/11/1981 & AT & $\mathrm{CC}$ & GG & $A G$ \\
\hline СТО/0104 & RNO & M & 40 & $20 / 07 / 1962$ & AT & $\mathrm{CC}$ & TG & AA \\
\hline СТО/0107 & $\mathrm{JV}$ & $\mathrm{M}$ & 47 & $15 / 03 / 1956$ & TT & $\mathrm{CC}$ & GG & $A G$ \\
\hline СТО/0112 & JS & $M$ & 35 & $10 / 12 / 1967$ & $\mathrm{TT}$ & $\mathrm{CC}$ & TG & $\mathrm{AA}$ \\
\hline СТО/0114 & JVS & M & 43 & $14 / 01 / 1960$ & AT & AA & GG & AA \\
\hline СТО/0115 & GSS & $\mathrm{F}$ & 18 & 02/09/1984 & $\mathrm{TT}$ & $\mathrm{CC}$ & GG & $A G$ \\
\hline СТО/0119 & APG & M & 68 & $17 / 05 / 1934$ & AA & $\mathrm{CC}$ & $\mathrm{TT}$ & $A G$ \\
\hline СТО/0122 & $\mathrm{HS}$ & $M$ & 57 & 02/04/1946 & $\mathrm{TT}$ & $\mathrm{CC}$ & GG & $A G$ \\
\hline СТО/0127 & ANC & $\mathrm{F}$ & 23 & $12 / 08 / 1979$ & $\mathrm{TT}$ & $\mathrm{CC}$ & TG & $\mathrm{AA}$ \\
\hline СТО/0128 & CS & $\mathrm{F}$ & 42 & $01 / 05 / 1960$ & AT & $\mathrm{CC}$ & TG & GG \\
\hline СТО/0132 & GM & $\mathrm{M}$ & 26 & $27 / 06 / 1976$ & $\mathrm{TT}$ & $\mathrm{CC}$ & GG & $A G$ \\
\hline СТО/0134 & DFS & $\mathrm{M}$ & 61 & 05/02/1942 & AT & $\mathrm{CC}$ & GG & $A G$ \\
\hline СТО/0135 & MMB & M & 44 & $18 / 08 / 1958$ & TT & $\mathrm{CC}$ & GG & $A G$ \\
\hline СТО/0136 & MAF & $\mathrm{F}$ & 58 & 04/05/1945 & $A A$ & $A A$ & GG & $A G$ \\
\hline СТО/0139 & VDS & $\mathrm{M}$ & 19 & 01/10/1983 & AT & $\mathrm{CC}$ & TG & $A G$ \\
\hline
\end{tabular}




\begin{tabular}{|c|c|c|c|c|c|c|c|c|}
\hline \multicolumn{9}{|c|}{ Anexo II (continuação) - Controles } \\
\hline \multirow{3}{*}{ Grupo } & \multirow{3}{*}{ Nome } & \multirow{3}{*}{ Sexo } & \multirow{3}{*}{ Idade } & \multirow{3}{*}{ Nasc } & \multicolumn{3}{|c|}{ EGFR } & \multirow{3}{*}{$\begin{array}{c}\text { EGF } \\
\text { Não Codificadora } \\
61 \\
\end{array}$} \\
\hline & & & & & \multirow{2}{*}{$\begin{array}{c}\text { Exon } 16 \\
2073 \\
\end{array}$} & \multicolumn{2}{|c|}{ Nao Codificadora } & \\
\hline & & & & & & -191 & 2073 & \\
\hline СТО/0140 & PTS & $\mathrm{M}$ & 38 & $18 / 12 / 1964$ & AT & $\mathrm{CC}$ & GG & $\mathrm{AA}$ \\
\hline СТО/0142 & JEL & $M$ & 56 & 05/04/1934 & AT & $\mathrm{CC}$ & GG & $A G$ \\
\hline СТО/0143 & SLD & $\mathrm{M}$ & 58 & $22 / 08 / 1946$ & AT & $\mathrm{CA}$ & TG & $\mathrm{AA}$ \\
\hline СТО/0144 & OAA & $M$ & 37 & $13 / 06 / 1944$ & AT & $\mathrm{CA}$ & GG & $A G$ \\
\hline СТО/0146 & VRS & $\mathrm{M}$ & 36 & $11 / 06 / 1965$ & $\mathrm{TT}$ & $\mathrm{CC}$ & TG & $A G$ \\
\hline СТО/0147 & LGR & $M$ & 74 & $26 / 01 / 1929$ & AT & $\mathrm{CC}$ & $\mathrm{TG}$ & $A G$ \\
\hline СТО/0149 & IV & $M$ & 68 & 08/06/1960 & TT & $\mathrm{CC}$ & TG & GG \\
\hline СТО/0151 & FRM & $\mathrm{F}$ & 32 & $13 / 08 / 1934$ & AT & $\mathrm{CC}$ & TG & $\mathrm{AA}$ \\
\hline СТО/0155 & MS & $M$ & 54 & $07 / 04 / 1930$ & TT & $\mathrm{CC}$ & GG & AA \\
\hline СТО/0156 & $\mathrm{HR}$ & $M$ & 61 & 29/11/1970 & $\mathrm{AA}$ & $\mathrm{CC}$ & GG & GG \\
\hline СТО/0158 & SMJ & $\mathrm{F}$ & 30 & $07 / 08 / 1972$ & AT & $\mathrm{CC}$ & TG & $A G$ \\
\hline СТО/0161 & DVLM & $\mathrm{M}$ & 58 & $26 / 07 / 1944$ & AT & $\mathrm{CC}$ & TG & $A G$ \\
\hline СТО/0162 & VCOB & $\mathrm{F}$ & 40 & $15 / 07 / 1962$ & AT & AA & GG & $A G$ \\
\hline СТО/0164 & LGSCH & $\mathrm{M}$ & 48 & $30 / 10 / 1954$ & AT & $\mathrm{CC}$ & GG & $A G$ \\
\hline СТО/0166 & JMO & $\mathrm{M}$ & 62 & $25 / 09 / 1940$ & AA & $\mathrm{CC}$ & TG & $A G$ \\
\hline СТО/0167 & LPC & $\mathrm{M}$ & 64 & $13 / 04 / 1939$ & $\mathrm{TT}$ & $\mathrm{CC}$ & TG & $A G$ \\
\hline СТО/0169 & EAS & $\mathrm{F}$ & 26 & 02/09/1977 & AT & $\mathrm{CC}$ & TG & $\mathrm{AA}$ \\
\hline СТО/0172 & ARC & M & 52 & $11 / 06 / 1951$ & $\mathrm{TT}$ & $\mathrm{CC}$ & GG & $\mathrm{AA}$ \\
\hline СТО/0177 & MRS & $\mathrm{F}$ & 52 & $25 / 12 / 1950$ & $\mathrm{TT}$ & $\mathrm{CC}$ & TG & $A G$ \\
\hline СТО/0178 & MTAC & $\mathrm{F}$ & 59 & 08/05/1944 & AA & $\mathrm{CC}$ & TG & $A G$ \\
\hline СТО/0185 & NQT & $\mathrm{F}$ & 33 & $18 / 05 / 1970$ & AT & $\mathrm{CC}$ & GG & $A G$ \\
\hline СТО/0187 & LAD & $\mathrm{F}$ & 60 & $23 / 10 / 1942$ & $\mathrm{TT}$ & $\mathrm{CC}$ & GG & $\mathrm{AA}$ \\
\hline СТО/0188 & MPN & $\mathrm{F}$ & 41 & $11 / 01 / 1962$ & AT & $\mathrm{CC}$ & TG & $A G$ \\
\hline СТО/0192 & RRS & $\mathrm{F}$ & 37 & $13 / 07 / 1966$ & AT & $\mathrm{CA}$ & GG & $A G$ \\
\hline СТО/0196 & MVSC & $\mathrm{F}$ & 56 & $12 / 03 / 1947$ & TT & $\mathrm{CC}$ & GG & $A G$ \\
\hline СТО/0208 & WBS & $\mathrm{M}$ & 38 & $23 / 01 / 1965$ & $\mathrm{TT}$ & $\mathrm{CC}$ & TG & $A G$ \\
\hline СТО/0210 & SJL & M & 60 & $31 / 10 / 1943$ & $\mathrm{TT}$ & $\mathrm{CC}$ & GG & AA \\
\hline СТО/0211 & JCS & $\mathrm{M}$ & 43 & $02 / 06 / 1960$ & $\mathrm{TT}$ & $\mathrm{CC}$ & TG & $\mathrm{AA}$ \\
\hline СТО/0212 & VAAMO & $\mathrm{F}$ & 35 & $24 / 02 / 1968$ & AT & $\mathrm{CC}$ & GG & $A G$ \\
\hline СТО/0213 & MSOC & $\mathrm{F}$ & 49 & $27 / 07 / 1954$ & AA & $\mathrm{CC}$ & TG & AA \\
\hline СТО/0214 & BRS & $\mathrm{M}$ & 29 & $25 / 02 / 1974$ & AT & $\mathrm{CC}$ & GG & AG \\
\hline СТО/0215 & ZFS & $\mathrm{F}$ & 56 & $20 / 06 / 1947$ & AT & $\mathrm{CA}$ & TG & $A G$ \\
\hline СТО/0227 & DPS & $\mathrm{M}$ & 64 & 05/08/1939 & AT & $\mathrm{CC}$ & $\mathrm{TT}$ & $A G$ \\
\hline СТО/0229 & JLSS & M & 39 & $15 / 02 / 1964$ & AT & $\mathrm{CC}$ & GG & $A G$ \\
\hline СТО/0233 & EASC & $\mathrm{F}$ & 54 & 29/10/1949 & $\mathrm{TT}$ & $\mathrm{CC}$ & GG & $A G$ \\
\hline СТО/0235 & JPO & $M$ & 67 & $17 / 11 / 1936$ & AA & $\mathrm{CC}$ & TG & $A G$ \\
\hline СТО/0238 & DG & $\mathrm{F}$ & 19 & $30 / 07 / 1984$ & $\mathrm{AA}$ & $\mathrm{CC}$ & GG & $A G$ \\
\hline СТО/0239 & DLO & $\mathrm{F}$ & 24 & 08/01/1979 & $\mathrm{TT}$ & $\mathrm{CC}$ & GG & $\mathrm{AA}$ \\
\hline СТО/0241 & SBR & $M$ & 41 & $26 / 09 / 1962$ & $\mathrm{TT}$ & $\mathrm{CC}$ & GG & $\mathrm{AA}$ \\
\hline СТО/0246 & APSS & $\mathrm{F}$ & 51 & $11 / 04 / 1952$ & AT & $\mathrm{CC}$ & TT & $\mathrm{AA}$ \\
\hline СТО/0250 & JPS & $\mathrm{M}$ & 45 & $24 / 01 / 1958$ & $\mathrm{TT}$ & $\mathrm{CC}$ & TG & $A G$ \\
\hline СТО/0262 & LSS & $\mathrm{M}$ & 56 & 20/09/1947 & $\mathrm{TT}$ & $\mathrm{CC}$ & TG & $A G$ \\
\hline
\end{tabular}




\begin{tabular}{|c|c|c|c|c|c|c|c|c|}
\hline \multicolumn{9}{|c|}{ Anexo II (continuação) - Controles } \\
\hline \multirow{3}{*}{ Grupo } & \multirow{3}{*}{ Nome } & \multirow{3}{*}{ Sexo } & \multirow{3}{*}{ Idade } & \multirow{3}{*}{ Nasc } & \multicolumn{3}{|c|}{ EGFR } & \multirow{3}{*}{$\begin{array}{c}\text { EGF } \\
\text { Não Codificadora } \\
61 \\
\end{array}$} \\
\hline & & & & & \multirow{2}{*}{$\begin{array}{c}\text { Exon } 16 \\
2073 \\
\end{array}$} & \multicolumn{2}{|c|}{ Não Codificadora } & \\
\hline & & & & & & -191 & 2073 & \\
\hline СТО/0265 & NNS & M & 50 & $22 / 02 / 1953$ & $\mathrm{TT}$ & $\mathrm{CC}$ & TG & $A G$ \\
\hline СТО/0266 & JDF & M & 63 & 06/10/1940 & $\mathrm{TT}$ & $\mathrm{CC}$ & TG & $A G$ \\
\hline СТО/0268 & JBP & M & 53 & $07 / 08 / 1950$ & $\mathrm{TT}$ & $\mathrm{CC}$ & GG & $\mathrm{AA}$ \\
\hline СТО/0274 & IBC & $\mathrm{F}$ & 77 & $20 / 06 / 1926$ & AT & $\mathrm{CA}$ & GG & $A G$ \\
\hline СТО/0292 & $\mathrm{PO}$ & $\mathrm{M}$ & 66 & $06 / 02 / 1938$ & AA & $\mathrm{CC}$ & TG & AG \\
\hline СТО/0304 & HCSS & $\mathrm{F}$ & 65 & $17 / 07 / 1938$ & AT & $\mathrm{CC}$ & GG & $A G$ \\
\hline СТО/0305 & MM & $\mathrm{F}$ & 71 & 01/03/1933 & TT & $\mathrm{CC}$ & TG & $A G$ \\
\hline СТО/0306 & MO & $\mathrm{F}$ & 66 & $21 / 12 / 1937$ & AT & $\mathrm{CC}$ & GG & $A G$ \\
\hline CTO/0308 & MRP & $\mathrm{F}$ & 71 & $16 / 11 / 1932$ & AT & $\mathrm{CC}$ & TG & $A G$ \\
\hline СТО/0323 & MAC & $M$ & 71 & $31 / 08 / 1932$ & AT & $\mathrm{CC}$ & TG & $A G$ \\
\hline Сто/0325 & DRS & M & 71 & 03/10/1932 & AT & $\mathrm{CC}$ & GG & $\mathrm{AA}$ \\
\hline СТО/0346 & FALS & $\mathrm{M}$ & 35 & $20 / 11 / 1968$ & AT & $\mathrm{CC}$ & TG & $A G$ \\
\hline СТО/0348 & $\mathrm{CB}$ & $\mathrm{M}$ & 40 & $13 / 07 / 1964$ & AT & $\mathrm{CA}$ & GG & $A G$ \\
\hline СТО/0354 & MLGR & $\mathrm{M}$ & 28 & $18 / 12 / 1975$ & $\mathrm{TT}$ & $\mathrm{CC}$ & GG & $A G$ \\
\hline Сто/0372 & AAC & $M$ & 35 & $13 / 09 / 1968$ & $\mathrm{TT}$ & $\mathrm{CC}$ & $\mathrm{TG}$ & GG \\
\hline СТО/0378 & RRV & $\mathrm{F}$ & 39 & $23 / 05 / 1965$ & AT & $\mathrm{CC}$ & GG & $A G$ \\
\hline Сто/0380 & VF & $M$ & 33 & $17 / 05 / 1971$ & AT & $\mathrm{CC}$ & TG & $A G$ \\
\hline СТО/0386 & RCBG & $\mathrm{F}$ & 37 & 02/10/1967 & $\mathrm{TT}$ & $\mathrm{CA}$ & GG & $A G$ \\
\hline СТО/0394 & APJTC & $\mathrm{F}$ & 35 & $16 / 08 / 1969$ & $\mathrm{TT}$ & $\mathrm{CC}$ & TG & GG \\
\hline СТО/0407 & AMLMB & $\mathrm{F}$ & 34 & $21 / 08 / 1970$ & AT & $\mathrm{CA}$ & GG & AA \\
\hline СТО/0409 & APJ & $\mathrm{F}$ & 62 & 05/11/1941 & $\mathrm{TT}$ & $\mathrm{CA}$ & TG & GG \\
\hline СТО/0413 & $\mathrm{JOC}$ & $\mathrm{M}$ & 46 & $03 / 02 / 1958$ & $\mathrm{TT}$ & $\mathrm{CC}$ & TG & $A G$ \\
\hline СТО/0415 & GR & $M$ & 48 & $03 / 06 / 1956$ & AT & $\mathrm{CC}$ & TG & $A G$ \\
\hline СТО/0419 & EAS & $\mathrm{M}$ & 54 & $26 / 07 / 1950$ & AT & $\mathrm{CC}$ & $\mathrm{TT}$ & $A G$ \\
\hline СТО/0423 & JRSM & $M$ & 59 & 20/10/1945 & TT & $\mathrm{CC}$ & GG & GG \\
\hline СТО/0450 & MAS & $\mathrm{M}$ & 55 & $21 / 04 / 1950$ & AT & $\mathrm{CC}$ & TG & $\mathrm{AA}$ \\
\hline СТО/0456 & DS & $M$ & 55 & 03/05/1950 & AT & $\mathrm{CC}$ & GG & AA \\
\hline
\end{tabular}


Anexo III

Tabela de Diagnósticos a Serem Exclusos dos Controles

$>$ Qualquer tipo de Câncer

$>$ Doenças Relacionadas com Fumo e Álcool

- Doença Pulmonar Crônica

- Doença Coronariana Crônica

- $\quad$ Trombose Venosa

- Hepatite

- Cirrose

$>$ Doenças Ocupacionais

- $\quad$ Asma

- Pneumoconiose

- $\quad$ Anemia Aplástica Adquirida

$>$ Doenças Crônicas Não-Neoplásicas da Cavidade Oral, Faringe e Laringe.

- $\quad$ Gengivite e Periodontite Crônica

- Glossite, Estomatite e Laringite Crônica

- Leucoplasia

- $\quad$ Sinusite, Tonsilite e Laringite Crônica

- Pólipos da Corda Vocal e da Laringe

- $\quad$ Abcesso da Faringe 


\section{Continuação - Anexo III}

$>$ Doenças Crônicas Não-Neoplásicas do Trato Digestivo

- Esofagite de Refluxo Crônica

- Esôfago de Barrett

- $\quad$ Gastrite Atrófica

- Doença de Crohn

- Colite Ulcerativa

- Isquemia Mesentérica Crônica

- Pólipos Adenomatosos

$>$ Condições Crônicas

- Diabetes

$>$ Imunodeficiência

- Doenças Auto-imunes

$>$ Doenças Mentais

- Condições Psicóticas Senis ou Presenis

- $\quad$ Outras psicoses, Retardo Mental

$>$ Doenças do Sistema Nervoso Central

- $\quad$ Infecções

- Doenças Hereditárias ou Degenerativas

- Doença Cérebro-Vascular

- Tumores Cerebrais

$>$ Enfermidade Grave ou Incapacidade para Compreender ou Responder 


\section{Anexo IV}

\section{Municípios da Região Metropolitana de São Paulo}

1. Arujá

2. Barueri

3. Biritiba Mirim

4. Caieiras

5. Cajamar

6. Carapicuíba

7. Cotia

8. Diadema

9. Embu

10. Embú-Guaçu

11. Ferraz de Vasconcelos

12. Francisco Morato

13. Franco da Rocha

14. Guararema

15. Guarulhos

16. Itapecerica da Serra

17. Itapevi

18. Itaquaquecetuba

19. Jandira

20. Juquitiba
21. Mairiporã

22. Mauá

23. Mogi das Cruzes

24. Osasco

25. Pirapora do Bom Jesus

26. Poá

27. Ribeirão Pires

28. Rio Grande da Serra

29. Salesópolis

30. Santa Izabel

31. Santana do Parnaíba

32. Santo André

33. São Bernardo do Campo

34. São Caetano do Sul

35. São Lourenço da Serra

36. São Paulo

37. Suzano

38. Taboão da Serra

39. Vargem Grande Paulista 


\section{Anexo V}

MESUYTHE DAS CLINICAS

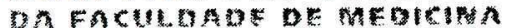

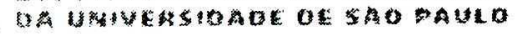

\section{APROVAÇÃO}

A Comissão de Ética para Análise de Projetos de Pesquisa - CAPPesq da Diretoria Clínica do Hospital das Clínicas e da Faculdade de Medicina da Universidade de São Paulo, em sessão de 13.04.05, APROVOU o Protocolo de Pesquisa $n^{\circ}$ 209/05, intitulado: "Estudo de polimorfismos em tumores do sistema nervoso central" apresentado pelo Departamento de NEUROLOGIA, inclusive o Termo de Consentimento Livre e Esclarecido.

Cabe ao pesquisador elaborar e apresentar à CAPPesq, os relatórios parciais e final sobre a pesquisa (Resolução do Conselho Nacional de Saúde n 196, de 10.10.1996, inciso IX.2, ietra "c").

Pesquisador(a) Responsável: Profa. Dra. Suely Kazue Nagahashi Marie Pesquisador(a) Executante: Sra. Keila Cardoso Barbosa

CAPPesq, 13 de Abril de 2005.

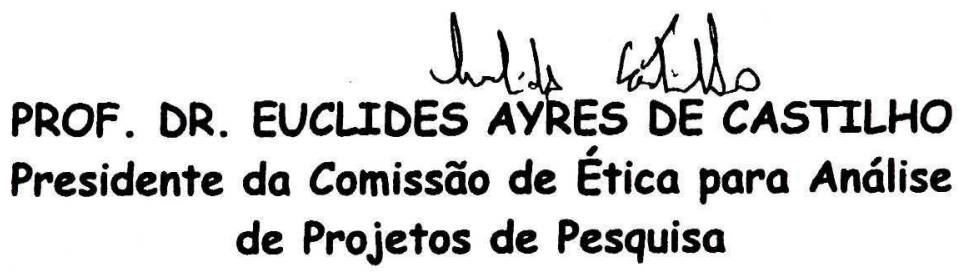




\section{Anexo VI}

\section{HOSPITAL DAS CLÍNICAS}

DA

FACULDADE DE MEDICINA DA UNIVERSIDADE DE SÃO PAULO

TERMO DE CONSENTIMENTO LIVRE E ESCLARECIDO

\section{I - DADOS DE IDENTIFICAÇÃO DO SUJEITO DA PESQUISA OU RESPONSÁVEL LEGAL}

1. NOME DO PACIENTE

DOCUMENTO DE IDENTIDADE N ${ }^{\circ}$ : SEXO: .M F

DATA NASCIMENTO: ........................

ENDEREÇO

$\mathrm{N}^{\mathrm{O}}$

APTO:

BAIRRO:

CIDADE

CEP:.

TELEFONE: DDD

..)

2.RESPONSÁVEL LEGAL

NATUREZA (grau de parentesco, tutor, curador etc.)

DOCUMENTO DE IDENTIDADE

SEXO: M F

DATA NASCIMENTO.: .....................

ENDEREÇO:

$\mathrm{N}^{\circ}$

APTO:

BAIRRO:

CIDADE:

CEP

TELEFONE: DDD

..).

\section{II - DADOS SOBRE A PESQUISA CIENTÍFICA}

1. TÍTULO DO PROTOCOLO DE PESQUISA:

PESQUISADOR:

CARGO/FUNÇÃO:

INSCRIÇÃO CONSELHO REGIONAL No:

UNIDADE DO HCFMUSP:

3. AVALIAÇÃO DO RISCO DA PESQUISA:

$\begin{array}{ll}\text { SEM RISCO } & \text { RISCO MÍNIMO } \mathbf{X} \text { RISCO MÉdIO } \\ \text { RISCO BAIXO } & \text { RISCO MAIOR }\end{array}$

(probabilidade de que o indivíduo sofra algum dano como conseqüência imediata ou tardia do estudo) 4.DURAÇÃO DA PESQUISA : 3 anos 


\section{III - REGISTRO DAS EXPLICAÇÕES DO PESQUISADOR AO PACIENTE OU SEU REPRESENTANTE LEGAL SOBRE A PESQUISA CONSIGNANDO:}

1. justificativa e os objetivos da pesquisa

Senhor(a) esta sendo admitido nesse hospital para tratamento de doença do sistema nervoso central. Como parte de seu tratamento, o senhor será submetido a um exame de sangue. Este sangue será utilizado em exames clínico laboratoriais, necessários para um diagnóstico definitivo.

Para obter um maior conhecimento clínico e científico das doenças de sistema nervoso central, o corpo clínico deste hospital (médicos e pesquisadores) desenvolve pesquisa clínica e científica. Através dessa pesquisa é possível conhecer melhor os mecanismos da doença e, portanto oferecer novas possibilidades de diagnóstico e tratamento. Ainda mais, este trabalho envolve a busca de lesões genéticas em genes já existentes.

O objetivo desse trabalho é analisar a quantidade e o tipo de polimorfismo (lesões/alterações em genes) encontrados em um grupo de pacientes com tumor de sistema nervoso central e comparar com um grupo de indivíduos não portadores de tumor.

2. procedimentos que serão utilizados e propósitos, incluindo a identificação dos procedimentos que são experimentais

Será realizada a coleta de sangue para extração de DNA e conseqüente análise de polimorfismos a partir de técnicas moleculares laboratoriais.

Todas as amostras utilizadas nessa pesquisa serão identificadas no laboratório por código formado por números e letras e, portanto, sua privacidade e identidade serão preservadas. A eventual inclusão dos resultados em publicação científica será feita de modo a manter o anonimato do paciente.

\section{3. desconfortos e riscos esperados}

O único desconforto esperado do exame de coleta de sangue é o da introdução da agulha na sua veia.

O risco é mínimo, podendo o senhor(a) apresentar tonturas e mal estar devido ao medo desse procedimento.

4. benefícios que poderão ser obtidos

Através da pesquisa é possível conhecer melhor os mecanismos da doença (tumor de sistema nervoso central), e assim poder oferecer novas possibilidades de diagnóstico e tratamento.

5. procedimentos alternativos que possam ser vantajosos para o indivíduo

\section{IV - ESCLARECIMENTOS DADOS PELO PESQUISADOR SOBRE GARANTIAS DO SUJEITO DA PESQUISA CONSIGNANDO:}

1. acesso, a qualquer tempo, às informações sobre procedimentos, riscos e benefícios relacionados à pesquisa, inclusive para dirimir eventuais dúvidas.

2. liberdade de retirar seu consentimento a qualquer momento e de deixar de participar do estudo, sem que isto traga prejuízo à continuidade da assistência. 
3. salvaguarda da confidencialidade, sigilo e privacidade.

4. disponibilidade de assistência no HCFMUSP, por eventuais danos à saúde, decorrentes da pesquisa.

5. viabilidade de indenização por eventuais danos à saúde decorrentes da pesquisa.

\section{INFORMAÇÕES DE NOMES, ENDEREÇOS E TELEFONES DOS RESPONSÁVEIS PELO ACOMPANHAMENTO DA PESQUISA, PARA CONTATO EM CASO DE INTERCORRÊNCIAS CLÍNICAS E REAÇÕES ADVERSAS.}

\section{OBSERVAÇÕES COMPLEMENTARES:}

\section{VII - CONSENTIMENTO PÓS-ESCLARECIDO}

Declaro que, após convenientemente esclarecido pelo pesquisador e ter entendido o que me foi explicado, consinto em participar do presente Protocolo de Pesquisa

São Paulo, 01 de JULHO de 2003.

assinatura do sujeito da pesquisa ou responsável legal

assinatura do pesquisado

(carimbo ou nome Legível) 


\section{Anexo VII \\ HOSPITAL DAS CLÍNICAS \\ DA}

FACULDADE DE MEDICINA DA UNIVERSIDADE DE SÃO PAULO

TERMO DE CONSENTIMENTO LIVRE E ESCLARECIDO

\section{I - DADOS DE IDENTIFICAÇÃO DO SUJEITO DA PESQUISA OU RESPONSÁVEL LEGAL}

1. NOME DO PACIENTE

DOCUMENTO DE IDENTIDADE No :

SEXO: .M F

DATA NASCIMENTO: ........................

ENDEREÇO

$\mathrm{N}^{\mathrm{O}}$

APTO

BAIRRO:

CIDADE

CEP:

TELEFONE: DDD ( ..)

2.RESPONSÁVEL LEGAL

NATUREZA (grau de parentesco, tutor, curador etc.)

DOCUMENTO DE IDENTIDADE :

SEXO: $M \quad F$

DATA NASCIMENTO.: .....................

ENDEREÇO:

$\mathrm{N}^{\mathrm{O}}$

APTO:

BAIRRO

CIDADE:

CEP:

TELEFONE: DDD

.).

\section{II - DADOS SOBRE A PESQUISA CIENTÍFICA}

1. TÍTULO DO PROTOCOLO DE PESQUISA:

PESQUISADOR:

CARGO/FUNÇÃO:

INSCRIÇÃO CONSELHO REGIONAL No:

UNIDADE DO HCFMUSP:

3. AVALIAÇÃO DO RISCO DA PESQUISA:

$$
\begin{aligned}
& \text { SEM RISCO } \\
& \text { RISCO BAIXO }
\end{aligned}
$$$$
\text { RISCO MÍNIMO } \mathbf{X}
$$

RISCO MÉDIO

RISCO MAIOR

(probabilidade de que o indivíduo sofra algum dano como conseqüência imediata ou tardia do estudo) 4.DURAÇÃO DA PESQUISA : 3 anos 


\section{III - REGISTRO DAS EXPLICAÇÕES DO PESQUISADOR AO PACIENTE OU SEU REPRESENTANTE LEGAL SOBRE A PESQUISA CONSIGNANDO:}

1. justificativa e os objetivos da pesquisa

Senhor(a) esta sendo admitido nesse hospital para tratamento de epilepsia. Como parte de seu tratamento, o senhor será submetido a um exame de sangue. Este sangue será utilizado em exames clínico laboratoriais, necessários para um diagnóstico definitivo.

Para obter um maior conhecimento clínico e científico sobre o câncer, o corpo clínico deste hospital (médicos e pesquisadores) desenvolve pesquisa clínica e científica. Através dessa pesquisa é possível conhecer melhor os mecanismos da doença e, portanto oferecer novas possibilidades de diagnóstico e tratamento. Ainda mais, este trabalho envolve a busca de novos genes ou de lesões genéticas em genes já existentes.

Para fazer este estudo é necessário comparar os resultados obtidos em pacientes que têm câncer com aqueles de pessoas que não têm câncer, como o senhor(a). Por isso, o senhor(a) está sendo convidado a colaborar com este estudo, autorizando que quando se coletar sangue para exames de laboratório, seja colhida uma pequena amostra adicional para pesquisa científica. O uso deste material não implicará riscos adicionais para o senhor(a), nem exigirá que se submeta a qualquer procedimento adicional. Este projeto de pesquisa foi aprovado pelo Comitê de Ética em Pesquisa do Hospital das Clínicas da Faculdade de Medicina da USP, de acordo com o processo $n^{\circ} 830 / 01$, e todo estudo que vier a utilizar este material será previamente apresentado à apreciação do Comitê de Ética em Pesquisa do Hospital.

O objetivo desse trabalho é analisar a quantidade e o tipo de polimorfismo (lesões/alterações em genes) encontrados em um grupo de pacientes com tumor de sistema nervoso central e comparar com um grupo de indivíduos não portadores de tumor.

2. procedimentos que serão utilizados e propósitos, incluindo a identificação dos procedimentos que são experimentais

Será realizada a coleta de sangue para extração de DNA e conseqüente análise de polimorfismos a partir de técnicas moleculares laboratoriais.

Todas as amostras utilizadas nessa pesquisa serão identificadas no laboratório por código formado por números e letras e, portanto, sua privacidade e identidade serão preservadas. A eventual inclusão dos resultados em publicação científica será feita de modo a manter o anonimato do paciente.

3. desconfortos e riscos esperados

O único desconforto esperado do exame de coleta de sangue é o da introdução da agulha na sua veia.

O risco é mínimo, podendo o senhor(a) apresentar tonturas e mal estar devido ao medo desse procedimento.

4. benefícios que poderão ser obtidos

Através da pesquisa é possível conhecer melhor os mecanismos da doença (tumor de sistema nervoso central), e assim poder oferecer novas possibilidades de diagnóstico e tratamento. 
5. procedimentos alternativos que possam ser vantajosos para o indivíduo

\section{IV - ESCLARECIMENTOS DADOS PELO PESQUISADOR SOBRE GARANTIAS DO SUJEITO DA PESQUISA CONSIGNANDO:}

1. acesso, a qualquer tempo, às informações sobre procedimentos, riscos e benefícios relacionados à pesquisa, inclusive para dirimir eventuais dúvidas.

2. liberdade de retirar seu consentimento a qualquer momento e de deixar de participar do estudo, sem que isto traga prejuízo à continuidade da assistência.

3. salvaguarda da confidencialidade, sigilo e privacidade.

4. disponibilidade de assistência no HCFMUSP, por eventuais danos à saúde, decorrentes da pesquisa.

5. viabilidade de indenização por eventuais danos à saúde decorrentes da pesquisa.

\section{INFORMAÇÕES DE NOMES, ENDEREÇOS E TELEFONES DOS RESPONSÁVEIS PELO ACOMPANHAMENTO DA PESQUISA, PARA CONTATO EM CASO DE INTERCORRÊNCIAS CLÍNICAS E REAÇÕES ADVERSAS.}

\section{OBSERVAÇÕES COMPLEMENTARES:}

\section{VII - CONSENTIMENTO PÓS-ESCLARECIDO}

Declaro que, após convenientemente esclarecido pelo pesquisador e ter entendido o que me foi explicado, consinto em participar do presente Protocolo de Pesquisa

São Paulo, 01 de JULHO de 2003.

$\overline{\text { assinatura do sujeito da pesquisa ou responsável legal }}$ 


\section{6 - Bibliografias}

Amend KL, Elder JT, Tomsho LP, Bonner JD, Johnson TM, Schwartz J, Berwick M, Gruber SB. EGF gene polymorphism and the risk of incident primary melanoma. Cancer Res. 2004; 64: 2668-2672.

Anderson U, Guo G, Bergebheim BMAT, Hedman TBH, Henriksson R. Epidermal growth factor receptor family (EGFR, ErbB2-4) in gliomas and meningiomas. Acta Neuropathol. 2004; 108:35-142.

Antonarakis SE. The Nomenclature Working Group.Recommendations for a nomenclature for a system for human gene mutations. Hum Mutat. 1998; 11:1-3.

Araújo A, Ribeiro R, Azevedo I, Coelho A, Soares M, Sousa B, Pinto D, Lopes C, Medeiros R, Scagliotti GV. Genetic polymorphisms of the epidermal growth factor and related receptor in non-small cell lung cancer--a review of the literature. Oncologist. 2007; 12(2):201-210.

Artega CL. Epidermal growth factor receptor dependence in human tumors: more than just expression? Oncologist. 2002; 4:31-39.

Bandrés E, Barricarte R, Cantero C, Honorato B, Malumbres R, Zárate Ruth, Alcalde J, Garcia-Foncillas J. Epidermal growth factor receptor (EGFR) polymorphism and survival in head and neck cancer patients. Oral Oncology. 2006; 1-7.

Bhowmick DA, Zhuang Z, Wait SD, Weil RJ. A functional polymorphism in the EGF gene is found with increased frequency in glioblastoma multiforme patients and is associated with more aggressive disease. Cancer Res. 2004; 64(4):1220-1223. 
Carpenter G, Cohen S. Epidermal growth factor. J Biol Chem. 1990; 265(14):7709-7712.

Cavanee Wk, Furnari FB, Nagane M, Huang HJS, Newcomb EW, Bigner DD. Diffusely infiltrating astrocytomas. In: Kleihues P, Cavanee WK. editors. Pathology and genetics of tumors of the nervous system. Lyon: IARC Press; 2000; 9-52.

Ciardiello F, Tortora G. Epidermal growth factor receptor (EGFR) as a target in cancer therapy: understanding the role of receptor expression and other molecular determinants that could influence the response to anti-EGFR drugs. Eur J Cancer. 2003; 39(10):1348-1354.

Collins VP, James CD. Gene and chromosomal alterations associated with the development of human gliomas. FASEB J. 1993; 7(10):926-930.

Costa BM, Ferreira P, Costa S, Canedo P, Oliveira P, Silva A, Pardal F, Suriano G, Machado JC, Lopes JM, Reis RM. Association between functional $E G F+61$ polymorphism and glioma risk. Clin Cancer Res. 2007; 13(9): 26212626.

Daumas-Duport C, Scheithauer B, O'Fallon J, Kelly P. Grading of astrocytomas. A simple and reproducible methos. Cancer. 1988; 62(10):2152-2165.

Ekstrand AJ, Sugawa N, James CD, Collins VP. Amplified and rearranged epidermal growth factor receptor genes in human glioblastomas revel deletions of sequences encoding portions of the $\mathrm{N}$ and $\mathrm{C}$-terminal tails. Proc Natl Acad Sci USA. 1992; 89(10):4309-4313. 
Evans WE, Johnson, JA. Pharmacogenomics: the inherited basis for interindividual differences in drug response. Annu Rev Genomics Hum Genet. 2001; 2:9-39.

Frederick L, Wang XY, Eley G, James CD. Diversity and frequency of epidermal growth factor receptor mutations in human glioblastomas. Cancer Res. 2000; 60(5):1383-1387.

Furnari FB, Huang HJ, Cavenee WK. Molecular biology of malignant degeneration of astrocytoma. Pediatr Neurosurg. 1996; 24(1):41-49.

Grandis JR, Sok JC. Signaling through the epidermal growth factor receptor during the development of malignancy. Pharmacol Ther. 2004; 102(1):37-46.

Grinstein E, Jundt F, Weinert I, Wernet P, Royer HD. Sp1 as G1 cell cycle phase specific transcription factor in epithelial cells. Oncogene. 2002; 21(10):1485-1492.

Hamai Y, Matsumura S, Matsusaki K, et al. A single nucleotide polymorphism in the 5' untranslated region of the EGF gene is associated with occurrence and malignant progression of gastric cancer. Pathobiology. 2005; 72: 133138.

HolbroT, Hynes NE. ErbB receptors: directing key signaling networks throughout life. Annu. Rev.Pharmacol. Toxicol. 2004; 44:195-217.

Howell WM. Epidermal growth factor gene polymorphism and development of cutaneous melanoma. J Invest Dermatol. 2004; 123: xx-xxi [medline].

Hsieh YY, Chang CC, Tsai FJ, Lin CC, Tsai CH. T homozygote and allele of epidermal growth factor receptor 2073 gene polymorphism are associated 
with higher susceptibility to endometriosis and leiomyomas. Fertil Steril. 2005; 83(3):796-799.

Inagaki M, Yoshida S, Kennedy S, Takemura N, Deguchi M, Ohara N, Maruo T. Association study between epidermal growth factor receptor and epidermal growth factor polymorphisms and endometriosis in a japanese population. Gynecol Endocrinol. 2007; 1-5.

Ishii S, Xu YH, Stratton RH, Roe BA, Merlino GT, Pastan I. Characterization and sequence of the promoter region of the human epidermal growth factor receptor gene. Proc Natl Acad Sci U S A. 1985; 82(15):4920-4924.

James MR, Hayward NK, Dumenil T, Montgomery GW, Martin NG, Duffy DL. Epidermal growth factor gene (EGF) polymorphism and risk of melanocytic neoplasia. J Invest Dermatol. 2004; 123: 760-762.

Jin G, Miao R, Deng Y, Hu Z, Zhou Y, Tan Y, Wang J, Hua Z, Ding W, Wang L, Chen W, Shen J, Wang X, Xu Y, Shen H. Variant genotypes and haplotypes of the epidermal growth factor gene promoter are associated with a decrease risk of gastric cancer in a high-risk chinese population. Cancer Sci. 2007; 98(6): 864-868.

Kageyama R, Merlino GT, Pastan I. Epidermal growth factor (EGF) receptor gene transcription. Requirement for Sp1 and an EGF receptor-specific factor. J Biol Chem. 1988; 263(13):6329-6336.

Kang HG, Choi JE, Lee WK, Kam S, Cha SI, Kim CH, Jung TH, Park JY. $+61 \mathrm{~A}>\mathrm{G}$ polymorphism in the EGF gene does not increase the risk of long cancer. Respirology. 2007; 12: 902-905.

Kapoor GS, O'Rourke DM. Mitogenic signaling cascades in glial tumors. Neurosurgery. 2003; 52(6):1425-1434. 
Kitange GJ, Templeton KL, Jenkins RB. Recent advances in the molecular genetics of primary gliomas. Curr Opin Oncol. 2003; 15(3):197-203.

Kitao K, Yoshida S, Kennedy S, Takemura N, Sugimoto M, Deguchi M, Ohara N, Maruo T. Epidermal growth factor receptor and human epidermal growth factor receptor 2 gene polymorphisms in endometrial câncer in a japanese population. Reprodutive Sciences. 2007; 14: 349-356.

Kleihues $\mathrm{P}$, Ohgaki $\mathrm{H}$. Primary and secondary glioblastomas: from concept to clinical diagnosis. Neuro Oncol. 1999; 1(1):44-51.

Kleihues P, Cavenee WK. Pathology \& Genetics Tumors of the Nervous System. Lyon: IARC/WHO; 2000.

Kuan CT Wikstrand CJ, Bigner DD. EGF mutant receptor vIII as a molecular target in cancer therapy. Endocr Relat Cancer. 2001; 8(2):83-86.

Laurence DJ, Gusterson BA. The epidermal growth factor. A review of structural and functional relationships in the normal organism and in cancer cells. Tumour Biol. 1990; 11(5):229-261.

Libermann TA, Nusbaum HR, Razon N, Kris R, Lax I, Soreq H, Whittle N, Waterfield MD, Ullrich A, Schlessinger J. Amplification, enhanced expression and possible rearrangement of EGF receptor gene in primary human brain tumours of glial origin. Nature. 1985; 313(5998):144-147.

Liu W, Innocenti F, Wu MH, Desai AA, Dolan ME, Cook EH, Ratain MJ. A functional common polymorphism in a Sp1 recognition site of the epidermal growth factor receptor gene promoter. Cancer Res. 2005; 65(1):46-53. 
Livak KJ, Schmittgen TD. Analysis of relative gene expression data using real-time quantitative PCR and the $2^{-\Delta \Delta C t}$ method. Methods. 2001; 25: 402408.

Louis D.N, Gusella JF. A tiger behind many doors: multiple genetic pathways to malignant glioma. Trends Genet. 1995; 11(10):412-415.

Louis DN, Ohgaki H, Wiestler OD, Cavenee WK, Burger PC, Jouvet A, Scheithauer BW, Kleihues P. The 2007 WHO classification of tumors of the central nervous system. Acta Neuropathol. 2007; 114(2):97-109.

McCarron SL, Bateman AC, Theaker JM, Howell WM. EGF +61 gene polymorphism and susceptibility to and prognostic markers in cutaneous malignant melanoma. Int J Cancer. 2003; 107(4):673-675.

Maher EA, Furnari FB, Bachoo RM, Rowitch DH, Louis DN, Cavenee WK, DePinho RA. Malignant glioma: genetics and biology of a grave matter. Genes Dev. 2001; 15(11):1311-1333.

Mattei S, Colombo MP, Melani C, Silvani A, Parmiani G, Herley M. Expression of cytokine/growth factors and their receptors in human melanoma and melanocytes. Int J Cancer. 1994; 56: 853-857.

Merlino GT, Ishii S, Whang-Peng J, Knutsen T, Xu YH, et al. Structure and localization of genes enconding aberrant and normal epidermal growth factor receptor RNAs from A431 human carcinoma cells. Mol Cell Biol. 1985; 5: 1722-1734.

Moulder SL, Muthuswamy SK, Bianco R, Simpson JF, Arteaga CL. Epidermal growth factor receptor (HER1) tyrosine kinase inhibitor ZD1839 (Iressa) inhibits HER2/neu (erbB2)-overexpressing breast cancer cells in vitro and in vivo. Cancer Res. 2001; 61(24):8887-8895. 
Nishikawa R, Ji XD, Harmon RC, Lazar CS, Gill GN, Cavenee WK, Huang HJ. A mutant epidermal growth factor receptor common in human glioma confers enhanced tumorigenicity. Proc Natl Acad Sci U S A. 1994; 91(16):7727-7731.

Nomura M, Shigematsu H, Li L, Suzuki M, Takahashi T, Estess P, Siegelman M, Feng Z, Kato H, Marchetti A, Shay JW, Spitz MR, Wistuba II, Minna JD, Gazdar AF. Polymorphism, Mutations, and Amplifications of the EGFR gene in Non-Small Cell Lung Cancers. Plosmedicine. 2007; 4: 715-727.

Nozaki M, Tada M, Kobayashi H, Zhang CL, Sawamura Y, Abe H, Ishii N, Van Meir EG. Roles of the functional loss of p53 and other genes in astrocytoma tumorigenesis and progression. Neuro Oncol. 1999; 1(2):124137.

Ohgaki H, Watanabe K, Peraud A, Biernat W, von Deimling A, Yasargil MG, Yonekawa $Y$, Kleihues $\mathrm{P}$. A case history of glioma progression. Acta Neuropathol. 1999; 97(5):525-532.

Okamoto I, Roka F, Krögler J, Endler G, Kaufmann S, Tockner S, Marsik C, Jilma B, Mannhalter C, Wagner O, Pehamberger $H$. The EGF A61G polymorphism is associated with disease-free period and survival in malignant melanoma. J Invest Dermatol. 2006;127(4):969-970.

Pedersen MW, Meltorn M, Damstrup L, Poulsen HS. The type III epidermal growth factor receptor mutation. Biological significance and potential target for anti-cancer therapy. Ann Oncol. 2001; 12(6):745-760.

Randerson-Moor JA, Gaut R, Turner F, Whitaker L, Barrett JH, Silva IS, Swerdlow A, Bishop DT, Newton Bishop JA. The relationship between the 
epidermal growth factor (EGF) 5'UTR variant A61G and melanoma/nevus susceptibility. J Invest Dermatol. 2004; 123(4):755-759.

Risch NJ. Searching for genetic determinants in the new millennium. Nature. 2000; 405(6788):847-856.

Rocha-Lima CA, Soares HP, Raez LE, Singal R. EGFR Target of Solid Tumors. Cancer Control. 2007; 14: 295-304.

Roskoski RJr. The ErbB/HER receptor protein-tyrosine kinase and cancer. Biochemical and Biophisical Research Communications. 2004; 319:(1) 1-11.

Scherer HJ. Cerebral astrocytomas and their derivatives. Am J Cancer. 1940; 40:159-198.

Sachidanandam R, Weissman D, Schmidt SC, Kakol JM, Stein LD, Marth G, Sherry S, Mullikin JC, Mortimore BJ, Willey DL, Hunt SE, Cole CG, Coggill PC, Rice CM, Ning Z, Rogers J, Bentley DR, Kwok PY, Mardis ER, Yeh RT, Schultz B, Cook L, Davenport R, Dante M, Fulton L, Hillier L, Waterston RH, McPherson JD, Gilman B, Schaffner S, Van Etten WJ, Reich D, Higgins J, Daly MJ, Blumenstiel B, Baldwin J, Stange-Thomann N, Zody MC, Linton L, Lander ES, Altshuler D, International SNP Map Working Group. A map of human genome sequence variation containing 1.42 million single nucleotide polymorphisms. Nature. 2001; 409(6822):928-933.

Shafqat S, Hedley-Whyte ET, Henson JW. Age-dependent rate of anaplastic transformation in low-grade astrocytoma. Neurology. 1999 10;52(4):867-869.

Shahbazi M, Pravica V, Nasreen N, Fakhoury H, Fryer AA, Strange RC, Hutchinson PE, Osborne JE, Lear JT, Smith AG, Hutchinson IV. Association 
between functional polymorphism in EGF gene and malignant melanoma. Lancet. 2002; 359(9304):397-401.

Shintani S, Matsuo K, Crohin CC, McBride J, Tsuji T, Donoff RB, Posner M, Todd R, Wong DT. Intragenic Mutation Analysis of the Human Epidermal Growth Factor Receptor (EGFR) Gene in Malignant Human Oral Keratinocytes. Cancer Res. 1999; 59(16):4142-4147.

Smith JS, Tachibana I, Passe SM, Huntley BK, Borell TJ, Iturria N, O'Fallon JR, Schaefer PL, Scheithauer BW, James CD, Buckner JC, Jenkins RB. PTEN mutation, EGFR amplification, and outcome in patients with anaplastic astrocytoma and glioblastoma multiforme. J Natl Cancer Inst. 2001; 93(16):1246-1256.

Splinder KLG, Nielsen JN, Linderbjerg J, Brandslund I, Jakobsen A. Prediction of response to chemoradiation in rectal cancer by a gene polymorphism in the epidermal growth factor receptor promoter region. Int $\mathrm{J}$. Radiation Oncology Biol. Phys. 2006; 66 (2): 500-504.

Sugawa N, Ekstrand AJ, James CD, Collins VP. Identical splicing of aberrant epidermal growth factor receptor transcripts from amplified rearranged genes in human glioblastoma. Proc Natl Acad Sci U S A. 1990; 87(21):8602-8606.

Surawicz TS, McCarthy BJ, Kupelian V, Jukich PJ, Bruner JM, Davis FG. Descriptive epidemiology of primary brain and CNS tumors: results from the Central Brain Tumor Registry of the United States, 1990-1994. Neuro Oncol. 1999; 1(1):14-25.

Talapatra S, Thompson CB. Growth factor signaling in cell survival: implications for cancer treatment. J Pharmacol Exp Ther. 2001; 298: 873878. 
Tanabe KK, Lemoine A, Finkelstein DM, Kawasaki H, Fujii T, Chung RT, Lauwers GY, Kulu Y, Muzikansky A, Kuruppu D, Lanuti M, Goodwin JM, Azoulay D, Fuchs BC. Epidermal growth factor gene functional polymorphism and the risk of hepatocellular carcinamo in patients with cirrhosis. Jama. 2008; 299(1): 53-60.

Vauleon E, Auger N, Benouaich-Amiel A, Laigle-Donadey F, Kaloahi G, Lejeune J, Delattre JY, Thillet J, Sanson M. The 61 A/G EGF polymorphism is functional but is neither a prognostic marker nor a risk factor for glioblastoma. Cancer Genetics and Cytogenetics. 2007; 172: 33-37

Venook AP. Epidermal growth factor receptor-targeted treatment for advanced colorectal carcinoma. Cancer. 2005; 103(12):2435-2446.

Von Deimling A, Louis DN, Wiestler OD. Molecular pathways in the formation of gliomas. Glia. 1995; 15(3):328-338.

Ware ML, Berger MS, Binder DK. Molecular biology of glioma tumorigenesis. Histol Histopathol. 2003; 18(1):207-216.

Watanabe K, Sato K, Biernat W, Tachibana O, von Ammon K, Ogata N, Yonekawa $\mathrm{Y}$, Kleihues $\mathrm{P}$, Ohgaki $\mathrm{H}$. Incidence and timing of p53 mutations during astrocytoma progression in patients with multiple biopsies. Clin Cancer Res. 1997; 3(4):523-530.

Wong AJ, Ruppert JM, Bigner SH, Grzeschik CH, Humphrey PA, Bigner DS, Vogelstein B. Structural alterations of the epidermal growth factor receptor gene in human gliomas. Proc Natl Acad Sci U S A. 1992; 89(7):2965-2869.

Woodburn JR. The epidemal growth factor receptor and its inibitions in cancer therapy. Pharmacol Ther. 1999; 82: 241-250. 
Xu J, Thompson KL, Shephard LB, Hudson LG, Gill GN. T3 receptor suppression of Sp1-dependent transcription from the epidermal growth factor receptor promoter via overlapping DNA-binding sites. J Biol Chem. 1993; 268(21):16065-16073. 